Portland State University

PDXScholar

Summer 8-12-2015

\title{
School Reform and Coaching: Identifying Structures for Successful Implementation of a Data Informed Decision-Making Program
}

Kristan D. Parman

Portland State University

Follow this and additional works at: https://pdxscholar.library.pdx.edu/open_access_etds

Part of the Educational Leadership Commons, Educational Methods Commons, and the Teacher Education and Professional Development Commons

Let us know how access to this document benefits you.

\section{Recommended Citation}

Parman, Kristan D., "School Reform and Coaching: Identifying Structures for Successful Implementation of a Data Informed Decision-Making Program" (2015). Dissertations and Theses. Paper 2487.

https://doi.org/10.15760/etd.2484

This Dissertation is brought to you for free and open access. It has been accepted for inclusion in Dissertations and Theses by an authorized administrator of PDXScholar. Please contact us if we can make this document more accessible: pdxscholar@pdx.edu. 
School Reform and Coaching: Identifying Structures for Successful Implementation of a Data Informed Decision-Making Program

by

Kristan D. Parman

A dissertation submitted in partial fulfillment of the requirements for the degree of

\title{
Doctor of Education
}

in

Educational Leadership: Curriculum and Instruction

\author{
Dissertation Committee: \\ Micki M. Caskey, Chair \\ Amy Petti \\ Moti Hara \\ Priya Kapoor
}

Portland State University

2015 
(C) 2015 Kristan D. Parman 


\title{
SCHOOL REFORM AND COACHING
}

\begin{abstract}
During the past 50 years, the landscape of education shifted from a rank order model to a system where all students are expected to achieve at a minimum level. This led to reforms in the way schools operate and teachers teach. One change to teaching is the use of data to inform instructional practices and student groupings. The need for teachers to increase their data use and change their instruction has prompted the need for professional development practices to be more effective. Coaching has been shown to be an effective professional development strategy to help teachers transfer new skills into their practice. This mixed-methods study examined one urban school district's two-year attempt to implement a data informed decision-making model of instruction in 20 schools through the use of instructional coaches. The study used two data sets - archival literacy benchmark scores and coach surveys - to identify a purposive selection of interview participants. The interviews were conducted to determine what structures and factors increased the implementation of the data informed decision-making initiative. Findings indicate professional development and leadership structures were needed for successful implementation of the data initiative. Results of this study showed the factors of trust, focus, coach-principal relationship, and assessment literacy contributed to the coaches' ability to implement the data initiative successfully.
\end{abstract}


SCHOOL REFORM AND COACHING

Dedication

To those we have failed. I often wonder what could have been different. 


\section{SCHOOL REFORM AND COACHING}

\section{Acknowledgements}

I would like to thank Micki M. Caskey, the chairperson of my committee, for her unwavering belief in my ability to do this. Six years ago, I asked you how to order my master's degree diploma, and a year later I was enrolled in the doctoral program. Thank you, Micki, for your willingness to meet over the weekend, read and edit countless drafts, and continually guide and support me in this process.

I also want to express my gratitude to my committee members: Amy Petti, Moti Hara, and Priya Kapoor. Each of you has enriched this process for me, and I am very grateful. Dr. Petti, thank you for being my mentor, your insights and experience in my field have been invaluable. Dr. Hara, thank you for teaching me statistics and meeting me, sometimes very late in the evening, to talk about quantitative methods and what methods would be best for my data set. Dr. Kapoor, thank you for your feedback. You bring a different lens to my work, and I appreciate the insights and questions you have posed.

Thank you, Danelle Stevens, your writing seminar kicked me into gear last year, and I realized I could get this done. Paulina Gutierrez Zepeda, thank you for being my writing buddy and cheerleader. Clair Pople, thank you for Monday night writing and camping with laptops and piles of books. Thank you to my cohort members for the writing retreats and writing evenings (though we did not get much done).

Finally, thank you to my family. Emmett and Griffin, thanks for playing basketball outside my office window, and being patient (especially about the laundry). 


\section{SCHOOL REFORM AND COACHING}

Amy Whitney, I probably could have done this without you, but it was more interesting, meaningful, and fun doing it together. Thank you for taking this journey with me. 


\section{SCHOOL REFORM AND COACHING}

\section{Table of Contents}

Abstract

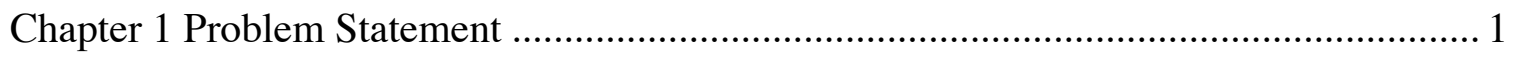

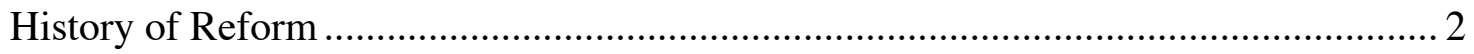

Data Informed Decision-Making ...................................................................... 5

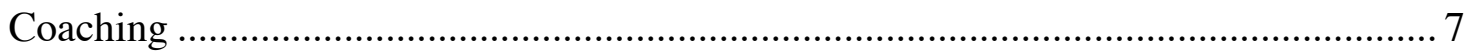

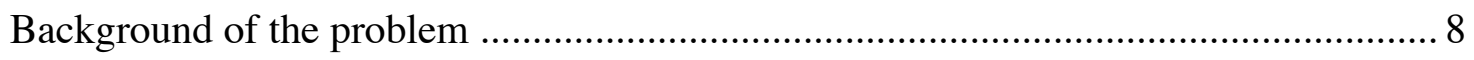

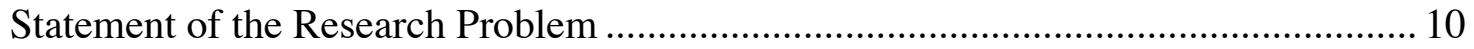

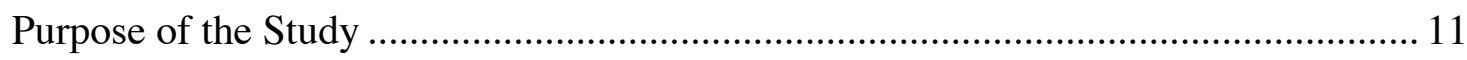

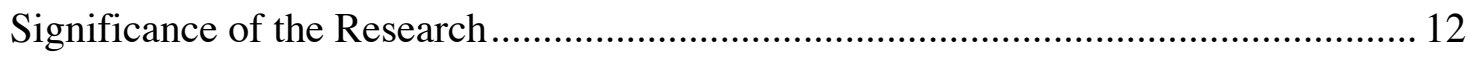

Research Methodology and Research Questions ............................................... 13

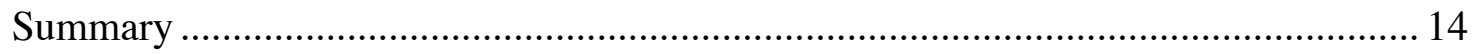

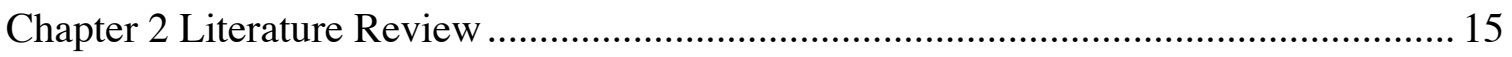

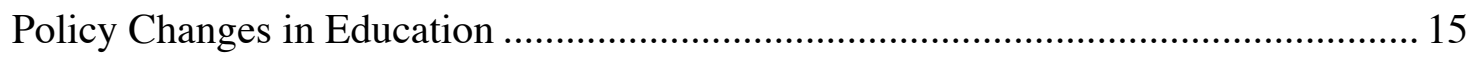

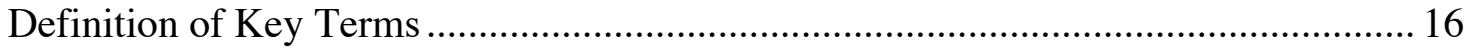

Theoretical Framework .................................................................................. 16

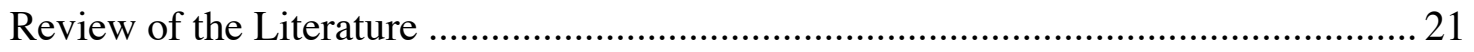




\section{SCHOOL REFORM AND COACHING}

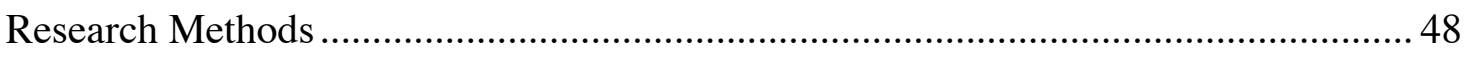

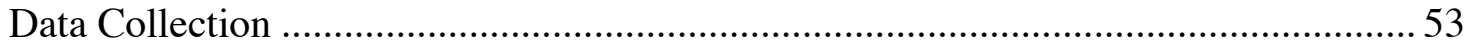

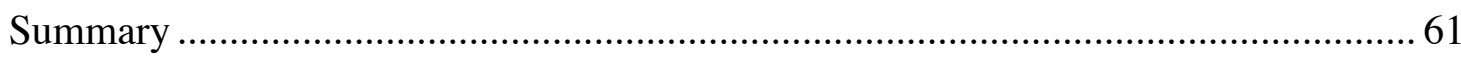

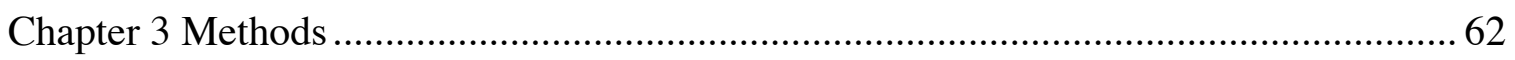

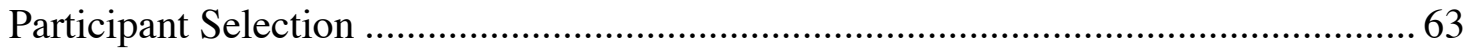

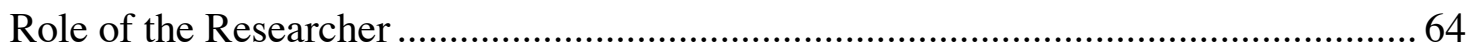

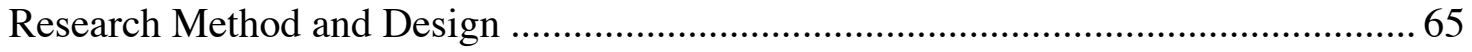

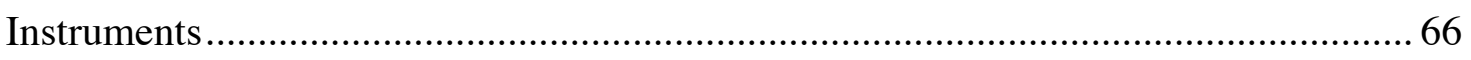

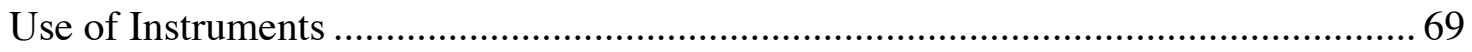

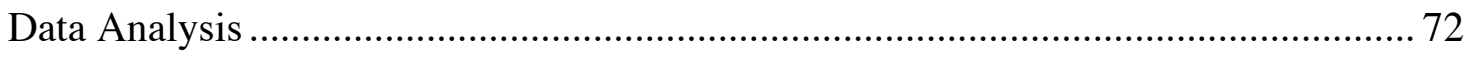

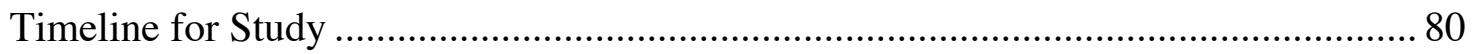

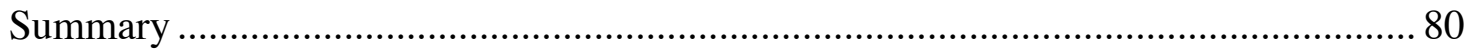

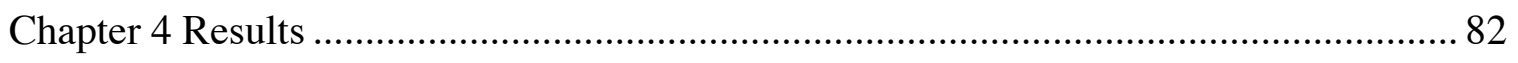

Literacy Benchmarking Data Results .......................................................................... 82

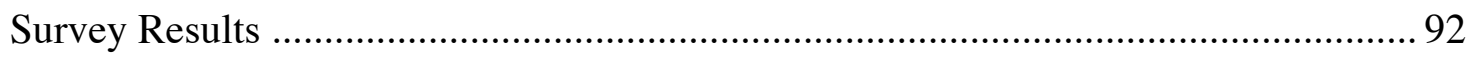

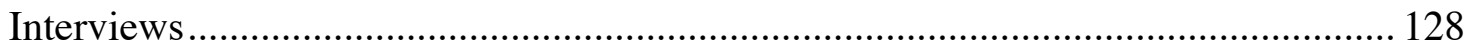

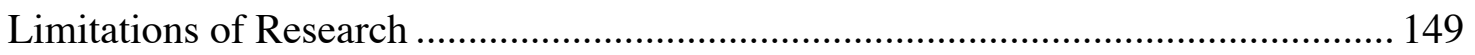

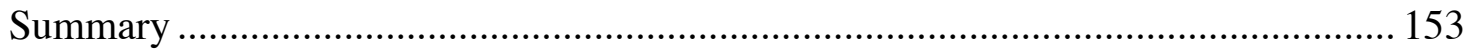

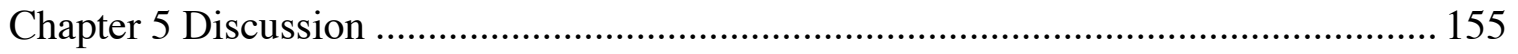

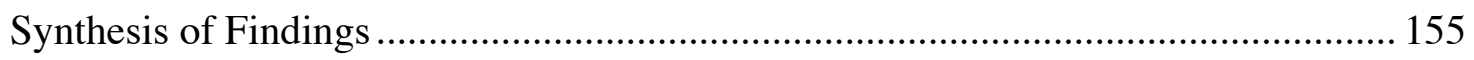

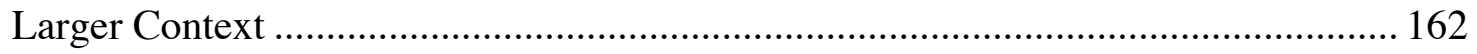

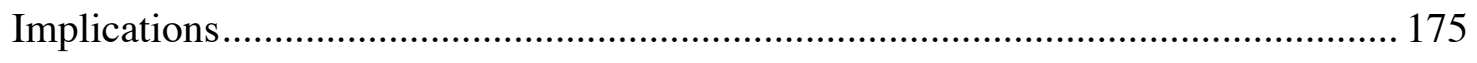




\section{SCHOOL REFORM AND COACHING}

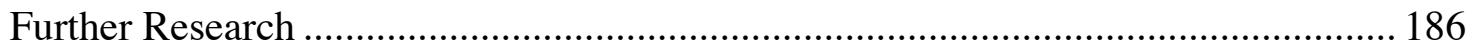

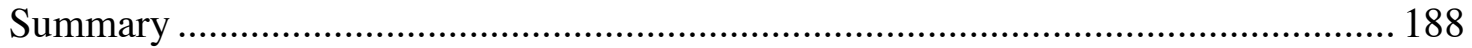

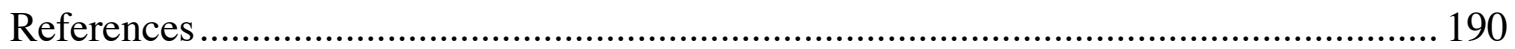

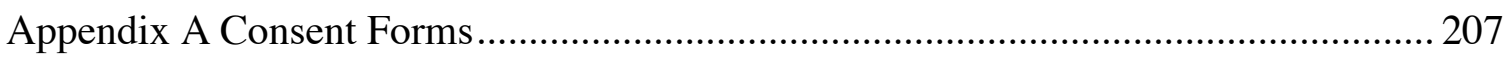

Appendix B Coach Survey …………………........................................................... 211

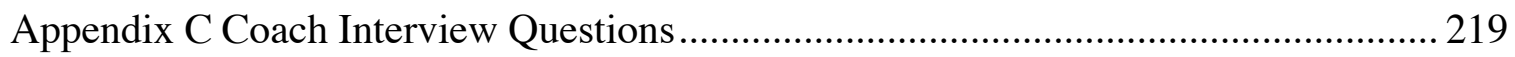

Appendix D Principal Interview Questions .......................................................... 220 


\section{SCHOOL REFORM AND COACHING}

\section{List of Tables}

Table 1. Sample of Literacy Benchmarking Scores 67

Table 2. Horizontal versus Vertical Data Formatting 68

Table 3. Pearson $\chi^{2}$ tests being used to identify schools with statistically 75 significant increases in literacy benchmark scores

Table 4. Decision Rules for Placement of Schools into Changes in Benchmarking Score Categories

Table 5. Research Questions and Data Used 83

Table 6. Descriptive Statistics Fall 2011 to Spring 2013

Table 7. Pearson $\chi^{2}$ Test Fall 2011 to Spring 2013

Table 8. Descriptive Statistics Elkton, Hazel Hill, and Willakenzie schools $\quad 88$

Table 9. Pearson $\chi^{2}$ Tests Fall 2011 to Spring 2012 and Fall 2012 to Spring $\quad 89$ 2013

Table 10. Descriptive Statistics Elkton, Owl Creek, and Willakenzie 90

Table 11. Grade Level Pearson $\chi^{2}$ Test Fall 2011to Spring 2013

Table 12. Years of Experience Teaching Before Coaching 94

Table 13. Coach's Area of Teacher Licensure/Authorization 95

Table 14. Coach's Current Employment 96

Table 15. Years of Use of the Data Wise Process for School Improvement 96 Before 2011-2012

Table 16. Administrator Longevity 97

Table 17. Continued Implementation of Literacy Benchmarking and Data 97 Team Meetings

Table 18. Job Responsibilities of Coaches 99 


\section{SCHOOL REFORM AND COACHING}

Table 19. Dependent t-test of coach experience of change of teacher use of professional practices that lead to increases in student literacy scores between 2011-2012 and 2012-2013

Table 20. Administrator Support and Coach's Sense of Success

Table 21. Coach sense of success and coach perception of principal's understanding of the data informed decision-making process

Table 22. Coach Experience of Structures to Support the Data Informed Decision-Making Process Comparing Year 1 (2011-2012) and Year 2 (2012-2013)

Table 23. Principal Participation in District Offered Coach-Principal Professional Development

Table 24. Selected Responses of Survey Questions for Elkton and Willakenzie Schools

Table 25. Frequency of Coach Participation in District Led Professional Development

Table 26. Selected Responses of Survey Questions for Hazel Hill and Owl 
SCHOOL REFORM AND COACHING

\section{List of Figures}

$\begin{array}{ll}\text { Figure 1. Systems Thinking } & 19\end{array}$

Figure 2. Data Wise Cycle of Inquiry 48 


\section{SCHOOL REFORM AND COACHING}

\section{Chapter 1}

\section{Problem Statement}

At the beginning of each school year, teachers and administrators come back to the building ready and excited to meet the new students and start the year. For teachers in low performing schools (as identified by the federal government), they are often met with a new initiative that promises to increase achievement for all students. Teachers begin working on incorporating the new initiative, staff meetings are spent training and revisiting the key components, and administrators are confident that this initiative is going to work. However, the initiative often does not produce the results everyone expects. Students' scores do not increase. Teachers buy-in wanes, and the staff lunch room is filled with conversations about the new initiative being a waste of time, corporations making money off of the school district, strategies being contrary to the initiative used the year before, and so on. Administrators and teachers are frustrated that the initiative is not working, so everyone decides to abandon the initiative and try something new next year. In many urban areas around the country, the schools that have experienced the most significant amounts of changes like these are in low-income, high minority areas (Farmer-Hinton, 2002). Unfortunately, this scenario is played out in many schools across the United States that are in the process of responding to reforms mandated by the federal government.

Many school reform efforts could be implemented in ways to increase student achievement. The purpose of this study is to determine what organizational structures are needed for a coach to successfully implement a data informed decision-making initiative. 


\section{SCHOOL REFORM AND COACHING}

In this chapter, the research is situated in the historical context of school reform in the United States and the complexity of schools as organizations. Addressing the use of data to inform instruction as a mechanism to lead to increased student achievement is included, and coaching as an effective professional development practice is discussed. The statement of the research problem, purpose of the study, significance of the research, and research methodology and questions are also presented in this chapter.

\section{History of Reform}

For most of the history of the United States, education has been the responsibility of the state and local governments. Historically, the federal government played a minimal role in education policy in the United States (U.S. Department of Education, 2012). The way schools received funding supported this structure of educational responsibility. In 2011-12, the majority of funding for elementary and secondary schools (about 87.7\%) came from sources other than the federal government (U.S. Department of Education, 2012). Until the late 1950s, the federal influence on education came from Supreme Court decisions such as Brown v. Topeka Board of Education (Berman, Greenwood, McLaughlin \& Pincus, 1975). The National Defense Education Act (NDEA) of 1958 and the Elementary and Secondary Education Act (ESEA) of 1965 were the first major policies that defined a new federal role in U.S. education (Berman et al., 1975). The NDEA was a reaction to Sputnik, while the ESEA was a response to the civil rights and anti-poverty movements of the 1960s (Berman et al., 1975).

Congress passed the ESEA to provide a better education and encourage higher education for children of color and the poor (McLaughlin, 1974). With mandates from 


\section{SCHOOL REFORM AND COACHING}

the federal government came financial resources for specific programs, such as Title I of the ESEA, which earmarked funds for students of low socio-economic status (McLaughlin, 1974). The passage of the ESEA led to a shift of thinking in education. The idea that students of poverty and students of color could achieve in school, and that education would help these students rise up from poverty to the middle class (McLaughlin, 1974) was a shift from the rank-order model of education, which was prevalent in the U.S. education system for decades (Elmore, 2004; Stiggins, 2005). The premise that all students could achieve was refined through different inceptions of the ESEA, specifically Goals 2000, No Child Left Behind (NCLB), and Race to the Top. During the 1980s and 1990s, a shift to a standards-based system of education occurred in states across the U.S. (Ravitch, 2010). This change was attempted at the national level when congress passed Goals 2000: Educate America Act to continue the federal government's support of equitable educational opportunities for all students. The legislation called for the adoption of voluntary national standards (United States Congress, 1994). All of these changes to the ESEA slowly increased the role the federal government played in education.

The re-authorization of the ESEA in 2002, known as The No Child Left Behind Act (NCLB), caused another shift in the federal government's role in education (Supovitz, 2009). President George W. Bush signed NCLB into law in January 2002. The law included a number of high-stakes accountability measures all determined by the summative exam each state administers to third through twelfth graders. Schools, districts, and states were expected to disaggregate this data by race, socioeconomic status, 


\section{SCHOOL REFORM AND COACHING}

and special program participation (ESL and special education). NCLB also held these states, districts, and schools accountable for the improvement of all students, but specifically students in the sub-categories mentioned previously (Kerr, Marsh, Ikemoto, Darilek, \& Barney, 2006). The federal government used accountability-focused testing systems to determine the effectiveness of the instruction in each state, district, and school. As federal policy shifted away from a rank-order model of education, the need for a change in the teaching profession emerged. Teachers would need professional development to help them make this policy paradigm shift a reality in classrooms (Porter, Garet, Desimone, Yoon, \& Birman, 2000).

These shifting policies focused on the new expectation that all students could learn and the increased use of high stakes accountability testing; these policies also revealed the disconnect between how schools function and the expected student outcomes. This disconnect requires a shift in how educators view instruction and professional development (Neufeld \& Roper, 2003). One shift that research has shown increases in student achievement is using data to inform instruction (Datnow, Park, Wohlstetter, 2007; Feldman \& Tung, 2001; Kerr et al., 2006; Knapp, Copland, \& Swinnerton, 2007; Lachat \& Smith, 2009; Marsh, Pane, \& Hamilton, 2006 ; Mason, 2002; Park, Daly, \& Guerra, 2012).

In the rank order model of education, teachers continued to teach, those students that kept up would continue to learn, and those that did not would fall farther behind (Deshler, 2007). With federal mandates that all students learn, teachers may need to change their instruction to ensure that all students meet the minimum proficiencies set 


\section{SCHOOL REFORM AND COACHING}

forth by the state and/or federal governments. Typically, schools respond to students not making adequate growth with technical changes: (a) master schedule re-configuration; (b) release time for teachers to be coaches; (c) increased use of technology; (d) teacher materials/resources; and/or (e) professional development (Deshler, 2007; Elmore, 2004). These changes lead to some progress, but school reform also requires non-technical changes, which Elmore (2004) called adaptive changes - shifts in the teaching and/or organization that lead to prolonged increases in student achievement. Elmore (2009) argued that three adaptive changes could improve student learning and performance: (a) increase the knowledge and skills of teachers; (b) change the content; and (c) change the relationship between the teacher, the student, and the content. Elmore (2009) noted that teachers receive little support in making shifts toward a standards based model of education. For example, school districts ask teachers to use data to inform their instruction to improve teacher effectiveness and increase student achievement, but schools rely on professional development practices that do not provide the support necessary to implement these changes successfully (Cornett \& Knight, 2009).

\section{Data Informed Decision-Making}

With the increase of accountability demands, many school districts started analyzing data to increase instructional effectiveness and student achievement (Kerr et al., 2006). This shift is known as data informed decision-making and it refers to teachers, administrators, and district leaders collecting and analyzing different data sets to guide decision-making to improve student and school-wide outcomes (Marsh et al., 2006). Understanding how students make progress through school, how they fall behind, and 


\section{SCHOOL REFORM AND COACHING}

how school leaders and teachers can shift practices will help more students be successful. To do this it is imperative to have an understanding of how data informed decisionmaking supports the school system to ensure students are receiving the support and interventions when they need it, and not after it is too late (Swan \& Mazur, 2011) .

Research shows the promise data use has to improve instruction has not been realized to its fullest potential (Herman \& Gribbons, 2001; Ingram, Louise, \& Schroeder, 2004; Jimerson \& McGhee, 2013; Jimerson \& Wayman, 2012; Murray, 2013). The reasons for the lack of improvement when using data are varied, but one reason cited was lack of effective and/or sustained professional development (Herman \& Gribbons, 2001; Murray, 2013; Park et al., 2012) to help teachers and school/district leaders understand how to use the data to inform their practice, not just as an accountability measure. There are multiple data sets educators can use to continually improve their instruction (Bernhardt, 2004), but often teachers and leaders do not know what data to use and/or how to use it to improve the work being done in schools (Daly, 2012).

School district leaders across the country are asking teachers to use data to inform their instruction to improve teacher effectiveness and increase student achievement (Daly, 2004; Marsh et al., 2006), but schools rely on professional development practices that do not provide the support necessary to implement these changes successfully (Cornett \& Knight, 2009). The problem is changing teacher practices is not easy. To ensure the implementation of changes in instruction, teachers need meaningful professional development to integrate new strategies into their practice. Coaching is one way teachers sustain and institutionalize changes in their own practice over time 


\section{SCHOOL REFORM AND COACHING}

(Burkins, 2007; Cornett \& Knight, 2009; Joyce \& Showers, 1981, 2002; Toll, 2009). While professional development and coaching are technical changes, they lead teachers and administrators toward making the adaptive changes needed to help all students reach their potential. The intersection between technical and adaptive changes is the topic of this research, specifically, coaching.

\section{Coaching}

Often, people in education use the terms mentor and coach interchangeably. Coach implies there is a destination. For athletics it is winning games and championships, and for teachers a coach carries teachers toward more effective instructional practices. The term coach originates from Hungary. Kocsi is a carriage of Kocs, a Hungarian village where the carriages were first made in the $15^{\text {th }}$ century. The term is seen in various forms in most European languages and it became the meaning of a large carriage of any kind. Later (c. 1830) the term was used to mean instructor or trainer and was slang at Oxford for a tutor who "carries" a student through exams. The first time that the term coach was used in reference to athletics was in 1861 (Harper, 2001). From its origin, a coach carries people from one point to their destination. A coach is different than a mentor, which has its roots in Greek and means "wise advisor" (Harper, 2001). A mentor might be wise and knowledgeable, but mentorship focuses on what the mentee needs/wants to learn/discover on their journey. A mentor does not act as the person who moves the work forward (Lipton, Wellman, \& Humbard, 2003). For the purposes of this research, the term coach refers to any teacher who is not in the classroom and whose main job responsibility is to assist teachers in improving their instruction with the 


\section{SCHOOL REFORM AND COACHING}

outcome of increasing student achievement. Coaching is the interaction between the coach and teacher that leads to changes in instructional practices.

\section{Background of the problem}

Fundamentally changing the way that schools operate to address the need to teach all students a set of standards and ensure students achieve at the highest levels possible independent of their race and/or social class is a high priority in the U.S. (United States Congress, 1994). NCLB in 2002 and now Race to the Top are both federal policies that mandate these priorities. School reform is a documented need in the U.S. school system (Elmore, 2004; Fullan, 2008a; Hargreaves \& Fullan, 2012; Reeves, 2003; Senge, 1990). As schools and districts look to models of reform a number of hurdles exist to transforming the theory of a reform into actions resulting in increased student achievement (Fullan, 2008a; Muhammad, 2009; Senge, 1990). Teachers need meaningful, ongoing professional development to increase their knowledge and prompt changes in teacher and learning (Elmore, 2009). One technical change that can address the transformational learning needed for adults to change the relationship between teachers, students, and the content is coaching. Coaching provides intensive, differentiated support for teachers (Knight, 2006). Coaches help teachers implement research-based instructional practices in the classroom (Cornett \& Knight, 2009; Joyce \& Showers, 1981). Coaches frequently observe and/or model lessons, facilitate professional development, and collect and/or analyze data around the components of high-leverage instructional practices. Coaches have a firm understanding of research-based instruction and can explain these practices to teachers (Knight, 2006). 


\section{SCHOOL REFORM AND COACHING}

Schools are complex social organizations (Frank, Zhao, \& Borman, 2004) that rely on both formal and informal power and communication structures to operate (Muhammad, 2009). Because schools are complex social organizations, it is important to note that an innovation will only be successfully implemented if it fits with the values and beliefs of the individuals in the organization and/or in the values of the organization as a whole (Rogers, 1962). Finding ways to spread initiatives throughout the organization has been a challenge for educators (Elmore, 2004; Fullan, 2008b; Fullan \& Knight, 2011; Rogers, 1962). Research has shown traditional professional development models (trainings, seminars, and unconnected weekly professional development) do not lead to lasting implementation of new teaching strategies or initiatives (Cornett \& Knight, 2009; Joyce \& Showers, 1981; 2002) Coaching can be one way for initiatives to be diffused throughout a school and/or district (Cornett \& Knight, 2009; Joyce \& Showers, 1981; Marsh, McCombs, \& Martorell, 2009).

The use of coaches has increased in public education in the past decade (Bean, Draper, Hall, Vandermolen, \& Zigmond, 2010). Coaching has been widely used as a method to increase student achievement based on the belief that teacher collaboration with coaches will lead to instructional change resulting in increased student achievement (Ippolito, 2010). Research shows organizational change in schools is not selfimplementing (Cuban, 1990), and the changes do not "penetrate predictably or frequently into the 'instructional core' of the classroom" (Borman \& Feger, 2006, p. 1). Coaching, as a professional development model, can help teachers implement new initiatives and programs to ensure they penetrate the instructional core. 


\section{SCHOOL REFORM AND COACHING}

\section{Statement of the Research Problem}

Joyce and Showers (1981) provided early quantitative research supporting the claim that coaching increased the rate of transfer of a new skill learned by a teacher into her/his teaching repertoire. Specifically, teachers who were coached after a training transferred the information from the training into their teaching practices (mean transfer scores were 14.80 for coached and 10.67 for uncoached, $\mathrm{p}<0.05)$. Cornett and Knight (2009) supported Joyce and Showers early work with another quantitative study supporting the use of coaching to increase teacher transfer and the effectiveness of professional development. Knowing that coaches can provide teachers with the quality and supportive professional development needed to increase teacher effectiveness, schools and districts have used coaches as a technical change that many hope will bring about the adaptive changes in instruction that will lead to sustained increases in student achievement (Marsh et al., 2009). Unfortunately, many coaches spend their time on activities that do not lead to the adaptive change schools and districts are hoping for (Killion, 2009). To date, there has not been any research that links coaching to increases in student achievement. However, there is research that supports the use of coaches to increase teacher effectiveness (Bean et al., 2010; Cornett \& Knight, 2009; Joyce \& Showers, 1981; Ippolito, 2009, 2010; Marsh et al., 2009). Teacher effectiveness has been identified as one of the most important school-based factors in increasing student achievement (Sanders \& Rivers, 1996; Wenglinky, 2000). Toll (2009) claimed, "research on the effectiveness of...coaching may depend on an examination of coaching's effect on teachers, not students" (pp. 62-63). Coaching has been documented 


\section{SCHOOL REFORM AND COACHING}

to increase teacher transfer of new initiatives (Joyce \& Showers, 1981), but coaches are being used in districts around the country, and the results expected are not necessarily being seen (Knight, 2009; Marsh et al., 2009).

The role of coaches is constantly evolving, but research shows that there are specific aspects of coaching that will increase a coach's effectiveness with teachers (L'Allier, Elish-Piper, \& Bean, 2010; Ippolito, 2009; Woodruff, 2009). Knowing that increased coaching effectiveness can lead to increases in teachers' use of high leverage instructional practices, one wonders whether the increase in the use of high leverage instructional practices can lead to increases in student achievement. Toll (2009) argued that the direct client of the coach is the teacher, so it would be extremely difficult to link student achievement to the activities of a coach. However, when comparing teacher implementation of a new practice and the interactions those teachers had with different coaches, one could argue that coaching effectiveness can be linked to teacher's implementation of high leverage strategies which can lead to increases in student achievement. The problem is the limited research available to help district and school leaders determine the structures and supports needed for a coach to effectively increase the knowledge and skill of teachers in their school.

\section{Purpose of the Study}

The purpose of this study was to determine what organizational structures are needed for a coach to successfully implement a data informed decision-making initiative. An existing data source, student literacy benchmarking data, was examined to determine the schools where the data informed decision-making initiative was being used 


\section{SCHOOL REFORM AND COACHING}

effectively. A survey of coaches was also completed. This data was used for the purposive selection of two principals and three coaches who were interviewed to determine what structures and supports were in place to support coaches, administrators, and teachers in implementing the data informed decision-making initiative.

\section{Significance of the Research}

Understanding what needs to be in place for coaching to be effective can lead to more thoughtful implementation of coaching programs. Coaches can play a number of roles in a building (Killion, 2009), so knowing what needs to be in place for coaches to be successful could help districts and schools determine the best use of resources to ensure coaching programs are effective at reaching the goals that are intended. As school funding is a constant concern, the need to implement effective technical changes is critical to ensure that adaptive changes can occur in schools. As federal, state, and local resources go toward coaching programs and data collection methods (benchmarking and progress monitoring tools) it is important to determine how coaches increase the effective use of data to lead to better outcomes for students (Marsh et al., 2009). If coaching works, what does effective coaching look like, and how can school and district leaders design structures and supports to ensure coaches will be successful? Understanding the organizational infrastructure that needs to be in place before a coach can be highly effective will help schools and districts use their human and financial capital more effectively. Also, identifying the high leverage practices a coach employs when working to diffuse a new innovation to teachers across a school or district will help district leaders 


\section{SCHOOL REFORM AND COACHING}

develop meaningful professional development, supports, and accountability measures for coaches.

\section{Research Methodology and Research Questions}

This study used a mixed method approach (Krathwohl, 2009; Morgan, 2012) to answer the following questions:

1. Which urban schools showed increases in students' literacy benchmarking scores?

2. What did the coach perceive as the significant structures that led to the implementation of the data informed decision-making model?

3. What did the principal perceive as the significant structures that led to the implementation of the data informed decision-making model?

4. What factors within the structure of the organization supported the coach in implementing the data informed decision-making model?

The core method of research was a sequential mixed method using primarily qualitative data with preliminary quantitative contribution. The research design used was quant $\rightarrow$ QUAL (Morgan, 2012). Fourth to eighth grade reading benchmarking data from 20 schools was analyzed using Pearson $\chi^{2}$ tests focused on the school year, school, and grade. This analysis allowed for a purposive sampling of buildings where increases in school-wide, school-year, or grade-level data were seen. A survey was administered to all coaches. The principal and coach in the buildings identified were interviewed using a semi-structured life world interview structure (Kvale, 2007). The interviews and surveys were analyzed to determine the commonalities among coaches, principals, and/or building dynamics that might help coaches in other buildings increase their effectiveness. 


\section{SCHOOL REFORM AND COACHING}

\section{Summary}

Schools have shifted from a rank-order model of education to places where all students are expected to learn a predetermined set of skills. Though the philosophy and policies of education have changed, some teacher practices remain that limit teachers' ability to meet the needs of all students. Many initiatives have been introduced through school reform efforts. Most of these have been technical changes that hoped to create adaptive and lasting changes. Professional development on these initiatives has also remained stagnant. Coaching is a technical change that can help teachers transfer their newly learned skills into their repertoire of teaching practices. The use of data informed decision-making is one initiative that can change teacher practices for the better. The use of coaches as professional development for this initiative can help teachers learn how to use data to inform their instruction, and how to ensure all students are learning to the highest levels possible. Research is needed to determine how to effectively use coaches to help teachers and school leaders effectively implement a new teaching practice, specifically a data informed decision-making initiative. 


\section{SCHOOL REFORM AND COACHING}

\section{Chapter 2}

\section{Literature Review}

The purpose of this study was to determine what organizational structures are needed for a coach to successfully implement a data informed decision-making initiative. The research was situated in the theoretical framework of organizational change. A literature review of systems thinking, technical and adaptive change, adaptive leadership, coaching, and data informed decision-making is included in this chapter. Initiatives used by the coaching program in the district being studied are also reviewed, specifically Response to Intervention (RtI) and the Data Wise cycle of inquiry process. This research aimed to support the idea that data informed decision-making with coaching can lead to adaptive changes if the leaders of the building understand how change happens and use that information when introducing and maintaining new initiatives and/or policies.

\section{Policy Changes in Education}

A number of policy changes in education occurred in the last half century. One of the changes, No Child Left Behind, led to a dramatic increase in the use of high stakes testing in the United States. This focus on high-stakes, accountability-based testing can be seen as a systemic reform to education (Supovitz, 2009). The shift toward testing has led to other organizational changes in the education system. When viewing the education system through a lens of organizational change theory (Senge, 1990), one can acknowledge that changes in one part of the system (increased use of high stakes testing) leads to unintended consequences in other parts of the system (the use of multiple, and often competing, initiatives) (Fullan, 2009; Knight, 2009; Reeves, 2006; Senge, 1990; 


\section{SCHOOL REFORM AND COACHING}

Supovitz, 2009). Understanding organizational change is important in education because a theory of change helps schools and districts understand how change happens and gives all the members of the organization a way to talk about reforms to lead to deeper understanding and more thoughtful implementation (Evans, Thornton, \& Usinger, 2012).

\section{Definition of Key Terms}

While examining organizational change theory, it will be important to define a few key terms in the organizational change literature. Learning organizations are collective entitites that focus on the characteristics needed for the organization to learn. Organizational learning focuses on how learning is developed within an organization. To differentiate these two terms, learning organizations are the type of organization, and organizational learning is how the learning happens (Yeo, 2005). Continuous

Improvement postulated that small, incremental changes at every level of the organization will lead to substantial improvement over time (Deming, 1982). Diffusion of innovation is the process by which changes in an organization are communicated and implemented through certain channels over a period of time (Rogers, 1962).

\section{Theoretical Framework}

Organizational change theory is the theoretical framework that serves as a lens for this research. This is because principals and district leaders often implement new programs without a theory of change as an anchor (Evans et al., 2012). Recent research suggested district leaders in large, urban districts relied more on individual change efforts, instead of system-wide strategies focused by a common framework. This individualized change approach hindered the development of a shared vision by district 


\section{SCHOOL REFORM AND COACHING}

leaders and led to little organizational growth (Evans, Thornton, \& Usinger, 2010). Fullan (2008a, 2008b, 2009), a prolific writer and successful school change practitioner repeatedly argued that schools, districts, and policymakers need to understand and implement a theory of change to be successful in school reform efforts.

The first step in understanding change theory is for educators to begin thinking about the system of education, not the individuals providing the services (Streeter, 1994). Educators need to deal with root causes instead of consequences from those problems. Deming (1962) argued when a problem exists in an organization it is the system $85 \%$ of the time, and an individual $15 \%$ of the time. Focusing more on the system and less on individuals will require a paradigm shift in many schools and districts. These shifts have been seen in certain schools with some success (Schmoker \& Wilson, 1993). Depending on the theory of change, the conversation focuses on finding leverage points to move the work forward (Senge, 1990), and/or on determining a component of the system that needs to be improved (Deming, 1982). Understanding the history of change theory will help in understanding how change theory can be applied to schools and districts.

Change theory. Many school leaders attempt to enact changes without a theoretical understanding of organizational change. Evans et al. (2012) argued if district leaders' understand change theory they could provide an opportunity for the school district to design meaningful improvements. Change theory comes from the business sector and many of the changes that have been implemented in schools mirror the changes made in private sector businesses (Evans et al., 2012). In the 1960s and 1970s, businesses shifted from a mechanistic view of organizations to an organic view (Yeo, 


\section{SCHOOL REFORM AND COACHING}

2005). The organic view emphasized trust, interdependence, and shared responsibility. Argyris and Schön (1978) were some of the first theorists to bring the belief that the organization can learn to prominence. It was Senge's (1990) work that propelled organizational learning to the widespread use in business and education that are seen today (Yeo, 2005).

Understanding organizational change theory is important for principals and district leaders. Creating a common vision of how change occurs also helps coaches and teachers. Without a theory of change, the aforementioned initiative fatigue will continue and schools will get the results they have always gotten (Darling-Hammond \& Friedlaender, 2008; Fullan, 2008a; Knight, 2009; Reeves, 2006; Senge, 1990). Change can only occur in education if teachers improve their practices in the classroom. Knowing this adds a level of complexity to change within schools. The change leaders-principals, district leaders, and consultants - are not the people doing the work with students. In the industrial age mindset of businesses, change leaders implemented changes and told workers to change how they worked (Senge, 1990). Schools are often run using the industrial age mindset, but teachers spend much of the day working autonomously (Senge, 1990). This makes changing how teachers deliver instruction more complex than how workers work in a factory because there is no daily, direct oversight (Senge, 1990). Therefore, focusing on how teachers teach, and building teachers' capacity focused on instructional improvements should lead to improvements in student learning. Shifting to a learning organization should generate a paradigm shift from the mechanistic to the 


\section{SCHOOL REFORM AND COACHING}

organic model of organizational structure. The organic model leads to organizational learning and long term change in how schools function (Senge, 1990).

Learning organization. Argyris and Schön's (1978) theory of organizational learning stated that there is a close link between organizational and individual learning. However, if an individual is learning that does not mean the organization is learning. For organizational learning to occur, members of the organization must use strategies to integrate individual and organizational learning into skills and knowledge that will affect the organization (Evans et al., 2012). Senge (1990) coined the term learning organization to describe an organization that focuses on learning and has processes in place to ensure high quality knowledge is being acquired. There are five disciplines in Senge's learning organization. The first four are: personal mastery, mental models, shared vision, and team learning. The final component-systems thinking-permeates all aspects of the learning organization (see Figure 1). All five components work together and help to create a culture where learning is normalized (Evans et al., 2012).

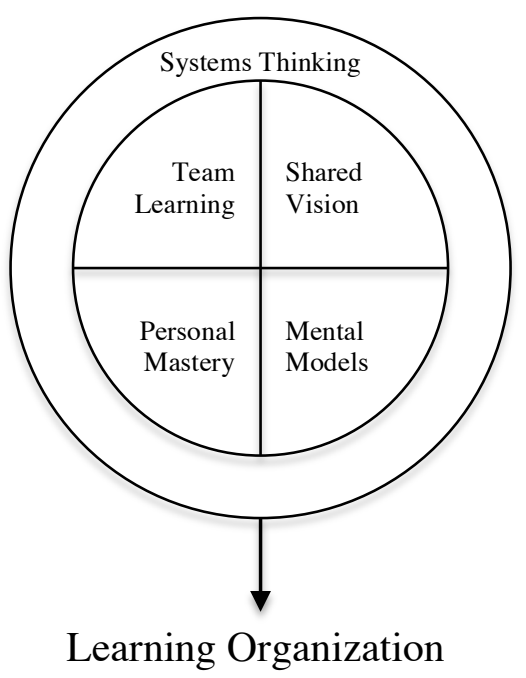




\section{SCHOOL REFORM AND COACHING}

Figure 1. System thinking surrounds the other four disciplines to create a learning organization (Senge, 1990).

While reviewing the literature on learning organizations, there was a dearth of quantitative studies focused on linking learning organization interventions to individual or organizational improvements (Kiedrowski, 2006). Even without research to support the effectiveness of the learning organization, in 1997 the Harvard Business Review identified Senge's (1990) work as one of the seminal management books of the past 75 years (Smith, 2001). Kiedrowski (2006) provided a quantitative study of the implementation of Senge's learning organization intervention at a bank. In the study, Kiedrowski compared three sets of employee satisfaction surveys of employees at a bank department receiving the learning organization intervention, approximately 1,500 employees, and the employees in all other departments within the same bank without the intervention, approximately 100,000 employees. He found employees in the sample had a statistically significant increase in attitude toward learning organizations and their job satisfaction. Kiedrowski's study revealed that when comparing this increase to the control group, the shift in attitude was not statistically significant between the two groups.

Systems thinking. Systems thinking is the ability to see situations from a holistic perspective. Systems thinking requires individuals to look at problems and goals as components of a larger structure that affects each problem and goal within an organization (Senge, 1990). An unbelievable number of decisions are made in schools 


\section{SCHOOL REFORM AND COACHING}

every day; most of those decisions are made quickly, finding the most immediate solution. “...(T)here's a very real chance some of these quick fixes will do more harm than good in the long run. Moreover, reacting to each event immediately and solving problems as they come up helps develop a kind of 'attention-deficit culture' in the school system" (Senge, 1990, p. 77). A shift to systems thinking requires schools to have a paradigm shift in problem solving. Instead of the linear cause and effect problem solving prevalent in schools, systems thinking pushes school personnel to use a circular problem solving model that can lead to higher levels of performance because the system is functioning properly (Streeter, 1994).

\section{Review of the Literature}

Change in schools need multiple elements occurring at the same time to lead to the adaptive changes reform efforts are hoping to see (Fullan, 2009). Schools regularly implement new initiatives aimed at increasing student achievement. These initiatives, technical solutions, often do not lead to increases in student achievement because many initiatives are technical changes, or solutions, to adaptive challenges (Deshler, 2007; Elmore, 2004; Heifetz \& Laurie, 1997). True reform in schools - producing sustained student achievement gains - requires changes in how teachers teach and students learn (Deshler, 2007; Elmore, 2004; Fullan, 2009; Reeves, 2003). Adaptive changes can only be sustained if all stakeholders own the solutions to these challenges (Heifetz \& Laurie, 1997). Technical changes can lead to adaptive changes when school and district leaders focus on using adaptive leadership practices (Heifetz \& Laurie, 1997) and situate the technical change within a theory of organizational change (Deming, 1982; Evans et al., 


\section{SCHOOL REFORM AND COACHING}

2012; Senge, 1990). When teachers, coaches, and principals all feel they are a part of the adaptive changes, they have the ability to implement an initiative and decrease initiative fatigue (Reeves, 2006), perpetually starting new initiatives to attempt to accomplish adaptive changes in teaching and learning. The review of the literature examines the technical versus adaptive solutions, adaptive leadership, initiative fatigue, coaching, and data informed decision-making. The literature review also includes two initiatives the district being studied attempted to implement, Response to Intervention (RtI) and the Data Wise cycle of inquiry, during the course of the coaching program.

Technical versus adaptive. Schools are complex organizations that have many challenges (Supovitz, 2009). These challenges can be delineated into technical and adaptive challenges. Technical challenges are well defined and anyone with expertise and organizational resources could solve them (Heifetz \& Laurie, 1997). Technical challenges are consistent with current values and norms of the organization (Waters, Marzano, \& McNulty, 2003). Master schedule creation, identifying new curriculum to use, using data to inform practices, and instructional coaching models can be solutions to technical challenges. Adaptive challenges are not well defined, so the solutions are not known in advance (Heifetz \& Laurie, 1997). Interestingly, one person can perceive a challenge as technical, but another person can perceive the same challenge as adaptive (Waters et al., 2003). School leaders understanding of different ways to address technical or adaptive challenges can help create and sustain an environment that embraces the adaptive changes needed to increase student achievement. Adaptive challenges involve a number of different stakeholders who each have a different interpretation of the issues at 


\section{SCHOOL REFORM AND COACHING}

hand (Heifetz \& Laurie, 1997). Heifetz and Linsky (2002) argued adaptive challenges can only be addressed using adaptive leadership. Adaptive leadership operates on the premise that leadership is more of a process than an individual person's set of skills. Adaptive leadership addresses the problems where a gap exists between people's values/beliefs and the current reality they face. According to Heifetz and Linsky, adaptive leadership involves all stakeholders in working to solve the problems and create solutions. This type of leadership can lead to positive change that is non-threatening to those working to make the change. "If a leader fails to recognize that the organization is being confronted by adaptive problems, and applies instead a more technical solution, successful change will be compromised" (Randall \& Coackley, 2007, p. 328). Unfortunately, many school reforms and initiatives are designed to address adaptive challenges, but are implemented without adaptive leadership, so only the technical challenges are addressed and change does not occur (Cuban, 1990; Elmore, 2004; Fullan, 2008b; Reeves, 2003; Supovitz, 2009).

Using experience with managers from around the world, Heifetz and Laurie (1997) offered six principles for leading adaptive work: "getting on the balcony"; identifying adaptive challenges; regulating distress; maintaining disciplined attention; giving the work back to the people; and protecting voices of leadership from below. All six of these components lead to increasing collaborative work of all members of an organization. For these principles to work, leaders need to first break their behavior patterns and resist finding solutions. Instead, leaders should focus on problem solving and hearing multiple perspectives from all stake holders. Second, leaders must learn to 


\section{SCHOOL REFORM AND COACHING}

ask hard questions instead of giving people answers. Instead of protecting people from the reality, "...leaders should allow them (workers) to feel the pinch of reality to stimulate them to adapt" (Heifetz \& Laurie, 2002, p. 125). In schools, leaders can work to find the balance between offering solutions for technical changes and asking hard questions to address adaptive challenges that need solutions co-created by all stakeholders.

Very few studies have been conducted to measure the use of adaptive leadership as a process to address the demands placed on schools to change the outcomes for students. Randall and Coakley (2007) conducted two case studies of the use of adaptive leadership practices in higher education change initiatives. The first case study examined a leader attempting to use technical changes and top-down leadership to address an adaptive challenge. The university being studied had recently relocated from an urban setting to a more suburban area. The President of the college was replaced, and the new President approached the multiple problems facing the institution using a top-down approach and only consulting the Vice President when making decisions. The President focused on long-term planning even though many were worried the University would not be able to open their doors the coming term. The Board voted to remove the President and replaced him with the current Vice President. The new President worked to involve faculty in recruitment of students to increase the student body, but the faculty felt so marginalized by the initial changes they did not assist the effort as much as the President was expecting. The faculty felt the fiscal problems of the institution were the problem of the Board and the President, and the school was foreclosed on in the coming term. 


\section{SCHOOL REFORM AND COACHING}

The second case study observed a leader that identified the challenges as adaptive and provided the time and space for stakeholders to come together to solve the complex problems collectively. A newly appointed department chair noticed declining enrollment in an historically successful master's program. The department chair met with full-time and part-time faculty and students to try and determine the reason for the decreasing enrollment. The department chair spent three months interviewing stakeholders and found that the decline had been occurring for much longer than originally thought because there had been attempts at improving the program and these provided some short-term, technical, fixes that occasionally increased enrollment for a short period of time. The department chair realized through the conversations that a change in curriculum would not lead to lasting changes. Instead, a change to the core behaviors and culture of the department were needed. Randall and Coackley (2007) found the leader in the second case study successfully addressed the complex challenges the institution faced, while the institution in the first case study did not and subsequently closed its doors indefinitely.

A meta-analysis of the leadership literature (Waters et al., 2003) suggested educational leaders who find a balance between technical and adaptive leadership practices could effectively improve student achievement. The meta-analysis looked at 70 studies (including dissertations) that met the specified criteria: quantitative student achievement data from standardized or norm-referenced tests; student achievement data as the dependent variable; and teacher perceptions of leadership as the independent variable. On average, the effect size between leadership and student achievement was 


\section{SCHOOL REFORM AND COACHING}

0.25. The findings ranged from an effect size for leadership and achievement of 0.50 to -0.02. Waters et al. determined two primary variables accounted for the wide range of the findings: (a) the focus of change and (b) the leader's understanding of the magnitude of change. Magnitude of change is the understanding that some change has greater implications than others. Waters et al. classified the magnitude of change as first order or second order change, which equates to Heifetz and Laurie's (1997) technical (first order) and adaptive (second order) challenges.

If school leaders implement adaptive leadership practices to increase student achievement, what conditions must be in place to ensure the adaptive work can take place? Daly and Chrispeels (2008) examined this question, and determined trust is an important prerequisite for adaptive changes to occur in schools. An original survey was used to collect data from district and building leaders and teachers. The survey sample was purposive because only individuals from four districts undergoing adaptive changes were surveyed. A strong, positive correlation existed between trust and leadership dimensions (correlations ranged from 0.75 to 0.89 ).

Research supporting the idea trust is a precursor to adaptive leadership and adaptive change can help education leaders consider aspects of trust and efficacy when looking at how to implement adaptive leadership practices in schools. Some researchers have argued the leadership literature, in education, has some significant gaps. In education, much of the research on school change and leadership focuses on schools in need of reforms and/or in crisis based on standardized or norm-referenced test results (Southworth, 2002). Southworth argued the focus on leadership of poorly performing 


\section{SCHOOL REFORM AND COACHING}

schools, the lack of regard for the variety of the school (size, location, demographics) and/or leader (the gender, locus of leadership within the school, changes over time), and the use of leadership "taxonomies" (lists of what leadership entails) has led to an overly prescriptive and simplified view of leadership in education. Southworth contended that instead of focusing on leaders, research should be more focused on instructional leadership. Research should not work to offer lists of how to be an instructional leader. Instead, research should describe what it looks like to be an instructional leader. Though instructional leadership is important, schools are complex organizations that require leaders who can be both technical leaders (running the day to day components of the building) and adaptive leaders, pushing individuals and the organization to shift their mental models and paradigms about teaching and learning to lead to increases in student achievement. The most important aspect of school leadership is determining whether a problem is technical or adaptive, and how one goes about addressing the challenge in the appropriate way (Heifetz \& Laurie, 1997; Randall \& Coakley, 2007).

Understanding technical and adaptive change is important when considering the implementation of new initiatives for three reasons. First, many initiatives fail to deliver the results people expect (Elmore, 2004; Fullan, 2008a; Reeves, 2003). The first question leaders should be asking is whether the initiative is being used to address technical or adaptive challenges (Heifetz \& Laurie, 1997). Once that is determined, a leader can proceed accordingly. Second, understanding how change occurs in schools will help decrease initiative fatigue because leaders will work with stakeholders to find solutions to the adaptive challenges instead of just abandoning the initiative because "it did not 


\section{SCHOOL REFORM AND COACHING}

work." Finally, understanding adaptive leadership and change requires all stakeholders to be part of the solution may help to empower teachers and coaches when offering solutions to the adaptive challenges in schools. This can lead to increases in student achievement found through the meta-analysis conducted by Waters et al. (2003). Understanding adaptive leadership and leadership structures is important in schools if change is going to be successful. The need for leadership to focus on a specific reform effort is documented in the research (Reeves, 2003; Schmoker \& Wilson, 1993, 1995). One research-based practice showing increases in student achievement is the use of data to inform instructional decisions.

Data informed decision-making. In recent years many technical changes have been implemented in schools to address the federal government's policies dictating a need for increased student achievement on standardized tests (No Child Left Behind [NCLB], 2002). One of these changes is data informed decision-making. Data informed decision-making is a technical change in schools that hopes to lead to adaptive changes in how students learn and teachers teach. Proponents of data informed decision-making argue that it can lead to lasting changes in student achievement and teacher practices (Kerr et al., 2006). Data informed decision-making is a process by which school personnel look at data from multiple sources to make decisions that lead to improvements in the school and/or student achievement. Data informed decision-making can be a tool to identify inequities in practice and structure. The process includes: looking at different types of data from multiple sources; engaging in data analysis to determine strengths and weaknesses; developing a plan to address challenges; and repeating this process in a 


\section{SCHOOL REFORM AND COACHING}

cyclical and systemic way to ensure flexibility and ongoing inquiry (Feldman \& Tung, 2001). Data informed decision-making includes all teachers looking at, and thinking about, data.

To use data effectively, data should be aligned, valid and reliable, and sensitive to differences (Heritage \& Yeagley, 2005). Alignment of data ensures the assessments being considered are aligned to the standards the assessment proports to address (Porter, 2002; Webb, 1997). Validity and reliability refer to the accuracy of the data. Validity is the accuracy of the assessment to measure what it is suppose to measure (Krathwohl, 2009). Reliability is the consistency of the assessment or measurement (Krathwohl, 2009). Data should also be sensitive to differences in race, class, language ability, gender, ability, etc. For example, when looking at assessment scores of English language learners, it is important for the teacher or administrator to understand the test measures the students' knowledge of both the content and their English. Knowing information like this is an example of how data informs decisions, but does not drive decisions. Educators must be aware of the students they are discussing when making data informed decisions (Shen \& Cooley, 2008).

Effective data use in school depends on the educators ability to align valid and reliable data while also considering differences in individual students. It also depends on several factors being in place within the organization: strong leadership, up front planning for data collection and use, and strong human capacity for data-driven inquiry (Kerr et al., 2006; Mason, 2002). Each of these factors are important, but teachers' capacity for data-driven inquiry is reliant on the ability of the school leader to create a 


\section{SCHOOL REFORM AND COACHING}

culture and space for data informed decision-making to take place. "...(D)ata use lives and dies in the principal's office..." (Wayman, Cho, \& Johnston, 2007, p. 55). Without strong leadership from the principal, data informed decision-making will be difficult for teachers to implement.

Many professions use data to assess progress and make decisions about next steps. Data has been used in education to determine the quality of instruction since the 1900s (Shen et al., 2012). Classroom teachers were the primary users of student data. Teachers have routinely assessed and reported student progress through grades (Jimerson \& McGhee, 2013). A huge shift in thinking about data collection occurred late in the $20^{\text {th }}$ century, and schools, districts, and states started using data to ensure all students were learning. This shift in data use started in earnest after the publication of A Nation at Risk in 1983 (Murray, 2013) and continues today. The use of data shifted from improving instruction to using data as a high stakes accountability measure mandated by state and federal governments (Jimerson \& McGhee, 2013). Educators have more access to data than ever before, but the access to data has not translated into school improvement (Shen \& Cooley, 2008). Policy makers and education leaders increased their expectations that principals and teachers use research and data to focus on increasing student achievement (Coburn \& Talbert, 2006; Heritage \& Yeagley, 2005), but the use of data focuses mainly on accountability and meeting requirements and not on improving teaching and learning (Murray, 2013).

Data use terminology in schools. Three different terms are used when looking at data use in schools: (a) data driven decision-making; (b) data based decision-making; and 


\section{SCHOOL REFORM AND COACHING}

(c) data informed decision-making. The terms highlight an evolution of thinking about data use in education (Shen et al.2012). Though the terms seem interchangeable, having a common language and understanding of the role of data in decision-making is important. Are the decisions driven by, based upon, or informed by the data? Data is a tool in decision-making. Many authors argue data should inform decisions, not drive them (Knapp, Swinnerton, Copland, \& Monpas-Huber, 2006; Murray, 2013; Shen \& Cooley, 2008; Shen et al., 2012). Murray (2013) explained the sentiment well:

Data can serve as an important element in effective decision-making but decisions should not be totally based on or driven by data. Education is a human enterprise involving children and data fail to give educators all the information they need to help children learn. (p. 171)

Data is used by teachers and principals when making instructional decisions. Even though different research studies use each of these terms, for ease of the reader, and in acknowledgement that the terms have evolved from data driven to data informed, the term data informed decision-making will be used for all of the discussion about data use by school personnel that focuses on improving teaching and learning.

Types of data. When discussing data informed decision-making, it is important to understand the different types of data that can be collected, analyzed, and used to inform decisions in schools. Many prinicpals and district officials only use student achievement data from high stakes, accountability driven state tests (Shen \& Cooley, 2008). There is a misunderstanding among educators that data informed decision-making equates to how to increase test scores, instead of how to use multiple pieces of data to determine how to 


\section{SCHOOL REFORM AND COACHING}

best meet each child's learning needs (Jimerson \& McGhee, 2013). Shen and Cooley argued school personnel need to better understand the variety of data sources to better identify the root causes of inequalities in learning outcomes.

Bernhardt (2004) argued there are four types of data teachers and admistrators can consider: demographic; student learning; perception; and school process. Demographic data provide descriptive information about the school and/or students. Demographi data can include: race/ethnicity, gender, grade-level, socio-economic status, enrollement, attendance, drop-out rate, etc. Student learning data describes the outcomes of our education system. Large scale achievement tests, benchmarking assessments, formative assessments, and grades would all be considered examples of student learning data. Perception data helps school personnel understand what students, parents, teachers, and others think about the school and/or learning environment. Perception data can be collected through questionairres, surveys, interviews, focus groups, and observations. Perception data is important because people's beliefs and perceptions dictate their actions (Bernhardt, 2004). Finally, school process data describes what teachers are doing to get the results they are getting. School process includes programs, instructional strategies, and classroom practices. School process data is the hardest for teachers to provide. Teachers often say they just do what they do intuitively and/or they are too busy to document and reflect on their teaching process. Teachers and school administrators need to get better at collecting and analyzing school process data if people in schools want to be able to document what is and is not working for their students (Bernhardt, 2004). 


\section{SCHOOL REFORM AND COACHING}

Bernhardt (2004) believed the only way to create a vivid picture of what is happening in schools is by looking at the intersections of two or more measures. For example, looking at student performance on an assessment would be a single measure. However, one could look at how students who attend school everyday scored in comparison with students who do not. Looking at both demographic and student learning data gives the teacher and/or administrator a clearer picture of what is going on. The principal could look at the same attendance and test score data, but also consider students in a special reading program's score compared to those not in the program. Now, three types of data-demographic, student learning, school process - are being considered, and the data becomes even clearer. Finally, these data points could also be used with a student efficacy survey that students completed earlier in the year. This would show how student attendance, sense of efficacy, and program participation contributed to the test score. One can see that the more intersectionality teachers and administrators can get, the more vivid a picture of the process of learning and problems within the system they will have, which in turn, may lead to solutions that address the root causes of the data discrepencies (Shen \& Cooley, 2008).

Helping teachers to collect, analyze, and act based on the data is an important step in the data informed decision-making process (Boudett $\&$ Steele, 2007). One promising approach to helping teachers use data to inform their practice is the use of instructional coaches (Marsh et al., 2009). Understanding the role of the coach and the research that supports coaching as an effective professional development model is the focus of the next section. 


\section{SCHOOL REFORM AND COACHING}

Coaching. As businesses have shifted to post-industrial age practices, change leaders have realized that their workforce is comprised of knowledge workers (Davenport, 2005). Therefore the ways that change occurs and the instruments of motivation have shifted in successful businesses that employ knowledge workers (Davenport, 2005). Teachers have always been knowledge workers, yet they are treated as industrial age workers (Senge, 1990). The need to give teachers some choice and voice in the change occuring is important because the only way change will occur in the classroom is if teachers transform their thinking about their students, the curriculum, and/or their teaching practices (Elmore, 2004; Knight, 2006). Coaching can be a conduit between the change leaders and the practices in the classroom (Fullan \& Knight, 2011). Working with teachers and regularly discussing curriculum and instruction, observing and modeling teaching practices, and ensuring the new initiatives are being implemented in classrooms situates coaches in a unique and powerful position within the organization and as a leader of change (Fullan \& Knight, 2011).

The practices of coaches - goal setting, observations, feedback, and collaborative conferencing - have been used in education for many years, but the combination of these skills and labelling of them as "coaching" did not occur until the early 1980s (Brown, Stroh, Fouts, \& Baker, 2005). Joyce and Showers (1981) were the first to suggest and research the notion that coaching is one important element in effective professional development. Much of the research on coaching in education is focused on peer coaching (Gersten, Morvant, \& Brengelman, 1995; Hasbrouck, 1997; Kohler, Crilley, Shearer, 1997). Peer coaching is teachers, still in the classroom, coaching each other, 


\section{SCHOOL REFORM AND COACHING}

sometimes referred to as reciprocal peer coaching. This study focuses on expert coaching where a person with more expertise is responsible for facilitating the coaching process (Brown et al., 2005).

Empirical research. A dearth of empirical research exists on coaching effectiveness in schools (Cornett \& Knight, 2009; Driscoll, 2008; Kretlow \& Bartholomew, 2010). The seminal study showing coaching increased teacher transfer of new information into their teaching practices through coaching was conducted by surveying and observing middle school language arts and social studies teachers (Showers, 1982). The study was conducted using a control group of uncoached teachers and an experimental group of coached teachers. The study was performed in three phases: sample selection and baseline testing; professional development and dividing into coached and uncoached groups; and coaching and transfer. The study considered both teacher knowledge and skills and students' performance on common assignments completed by students in all classrooms being studied. Multiple regressions were used to determine the contribution of coaching on the transfer of training to practices in the classroom (coached $\bar{x}=11.67, \mathrm{SD}=4.21 ;$ uncoached $\bar{x}=5.75, \mathrm{SD}=4.23$ ). The multiple regression analysis showed that coaching correlated 0.60 with transfer and not being coached correlated $0.06\left(\mathrm{R}^{2}=0.37\right.$, df 2,14; $\left.\mathrm{F}=4.19, \mathrm{p}<0.05\right)$.

Another empirical study conducted by Cornett and Knight (2009) looked at the implementation of new teaching practices by 82 teachers in Topeka, Kansas. The teachers were given professional development around the new practices, and then instructional coaches worked with the teachers to assist with implementation. Of the 82 teachers, 70 


\section{SCHOOL REFORM AND COACHING}

(85\%) implemented the new teacher practices. There was no control group for the study, so Knight used data from Joyce and Showers (1981) study that reported professional development without coaching resulted in a 15\% implementation rate. Cornett and Knight argued future research should focus on the following four questions: (1) What support systems should be in place for coaching to flourish? (2) What are best practices for coaches? (3) On which teaching practices should coaches focus? (4) What impact does coaching have on student achievement?

Coaching and data informed decision-making. Marsh et al. (2009) studied the relationship between coaching practices and teacher's use of data to change their instruction. They used a purposive selection of middle schools from large districts in Florida where coaches had a range of experience and approaches. After selecting the districts, Marsh et al. selected 180 schools randomly and had 113 schools agree to participate. In each school, principals, coaches, and ten teachers, five reading and five social studies, were surveyed. The research showed teachers who had more interactions with the coach (i.e. looking at data together at least once a month) felt the coach influenced changes in their instruction. The findings also indicated a positive relationship between teacher reports of coaches reviewing assessment data and student reading and math achievement. This relationship was not proven to be a causal relationship, but the findings are some of the first to start connecting the implementation of coaching programs to increases in student achievement. Marsh et al.'s study also revealed the importance of the coach was twofold. First, coaches need to help teachers interpret the data. Second, the coaches need to be able to help teachers determine 


\section{SCHOOL REFORM AND COACHING}

instructional strategies to address the data. Marsh et al. argued that taking action is more complex than just analyzing the data. Without coach support, it would be very difficult for teachers to analyze the data, determine plans to address student needs, and collect more data to determine if the changes made a difference. Coaches can bridge the assessment literacy, instructional strategies, and daily practices for teachers to successfully implement a data informed decision-making initiative. Finally, the study showed coaches with more experience, three or more years, were more likely to spend significant time analyzing data with teachers. This study showed the importance of coach experience as an indicator of the coach's ability to complete the tasks asked of them by the school and district leaders.

Responsive and directive. Ippolito (2010) examined the need for coaches to balance between responsive and directive interactions with teachers. Coaching requires complex interactions between teachers and coaches, and these relationships are sometimes difficult to establish (Ippolito, 2010). Ippolito suggested there are two distinct ways a coach can situate him/herself in relationship to the teacher-responsive or directive. Responsive implies the teacher is directing the interaction and the coach is responding to the teachers' needs (Dozier, 2006). In directive interactions, the coach is the expert and asserts her/himself as such to the teacher by telling the teacher what to do (Deussen, Robinson, \& Autio, 2007). A survey was distributed to 78 literacy coaches, supporting grades $\mathrm{K}$ through 12 , in a school district. 57 returned the surveys, and 24 were chosen to participate to ensure variety of what grade level(s) coaches were supporting, socioeconomic factors of the schools, and other variables the researchers 


\section{SCHOOL REFORM AND COACHING}

attempted to control. These 24 were asked to participate in grade level focus groups and then follow-up interviews. Of the 24 asked to participate, 15 agreed. The researchers found all coaches, no matter the grade level they focused on, struggled with the tension between helping teachers and pushing the work forward.

The major findings of Ippolito's (2010) study were that (a) coaches often shifted between responsive and directive; (b) protocols helped balance responsive and directive interactions; and (c) shared leadership helped to align school goals. First, coaches often shifted between responsive and directive coaching within a single coaching session. It was previously assumed that coaches participated in one-on-one coaching that tended to be more responsive, and group-coaching (or professional development) sessions tended to be more directive (Killion, 2008; Ippolito, 2009; Moran, 2007). Second, protocols in coaching sessions helped to balance responsive and directive interactions. A protocol is any agreed upon sets of discussion or observation rules that helped to guide the work of the coach and/or the conversations with the teacher(s). Finally, shared leadership roles helped to align teacher, coach, and principal goals. Distributive or facilitated leadership has been discussed in educational leadership literature (Spillane, Halverson, \& Diamond, 2001). Shared leadership roles have also recently been discussed in relation to how it supports coaching work (Burkins, 2007; Kral, 2007; Toll, 2009). However, little research exists on how coaches, teachers, and principals share leadership roles with one another. In discussing the areas for further research, Ippolito suggested a number of organizational factors that may support coaches in finding the balance between responsive and directive interactions. These included the number of teachers assigned to a coach, amount of 


\section{SCHOOL REFORM AND COACHING}

available planning time, degree of collegiality among teachers, degree teachers feel accountable to one another, and the trust teachers have in the school leadership.

Coach as change agent. The notion of a coach as a change leader is one of the many expectations and job descriptions of coaches (Deussen et al., 2007; Fullan \& Knight, 2011; Killion, 2009; L'Allier et al., 2010). The varied and fragmented nature of coaching is in part because the term coach is a very broad term loosely defined as any teacher leader based at the school site and working to help teachers change practices to ensure all students are successful and achieving at the highest possible level (Brown et al., 2005; Deussen et al., 2007; Killion, 2009). Coaches can provide professional development to individuals and teams, facilitate learning, provide feedback and support to teachers, and help to trouble-shoot implementation of new strategies (Borman \& Feger, 2006; Deussen et al., 2007; Joyce \& Showers, 2002; Killion, 2008; Toll, 2005; Veenman \& Denessen, 2001; Walpole \& Blamey, 2008). With all of these roles, it can be challenging for coaches to ensure their time is not fragmented (Killion, 2009). When a coach's work is too expansive, there is potential the coach's impact could be diluted (Killion, 2009; L'Allier et al., 2010; Marsh et al., 2009). Coaches need clear job descriptions, performance standards, and goals. The clearer these job descriptions and goals are, the easier it will be for coaches to prioritize requests for their time (Marsh et al., 2009).

One of the ways that coaches can focus and prioritize is by working closely with the principal of the school. Historically, the principal has been the manager of the school building (Cuban, 1988). Changes in education policy have shifted the principal's role 


\section{SCHOOL REFORM AND COACHING}

from building manager to instructional leader, and most literature on instructional leadership focuses on the role of the principal (Hallinger, 2005). Teacher leaders and coaches are also leaders of change within buildings. These roles are relatively new in education, so there is little research or examination of teacher leaders or coaches as change agents in education reform (York-Barr \& Duke, 2004). Principals, teachers, and coaches are expected to work together, and their roles and responsibilities can be interconnected (Spillane et al., 2001), yet the research does not reflect this reality. Instead, there are separate bodies of research, often in different academic journals that examine the role of the teacher leader, the coach, and the principal (Neumerski, 2012). Neumerski argued these studies should be considered together and not separately. First, it is difficult to apply findings from one topic of research to another. Second, the knowledge researchers create by keeping these topics separate might actually alter the type of questions asked in research. Finally, focusing on who the instructional leader is, keeps the focus on the people and not on how leaders bring about change. "What is missing is an integrated literature that centers on how various instructional leaders lead, regardless of position, title, or combination of leaders" (Neumerski, 2012, p. 312). Principals, coaches, and other instructional leaders work together to create change in schools. The research on how this process occurs should include all of the individuals helping to create the change, instead of focusing on only one aspect of the complex interactions that create change in schools.

Coaching and diffusion of innovation. In his seminal work on diffusion of innovation, Rogers (1962) argued the first people to participate in a new innovation are 


\section{SCHOOL REFORM AND COACHING}

the innovators (about $2.5 \%$ of the population) and the early adopters (about $13.5 \%$ of the population). The early majority (34\% of the population) is the next group of people to participate. Finally, the late majority (34\%) and the laggards (16\%) will eventually participate in the new innovation once the saturation level of over $50 \%$ of the population has started using the new innovation. The diffusion of innovation in education can take three to five years for an initiative to be implemented (Reeves, 2006). Coaching can increase teachers' ability to transfer of new skills learned into their teaching. Rogers stated the innovation is diffused through specific channels over time among the participants in a social system. So, coaches can be a used as a channel to diffuse a new innovation (i.e., initiative) in a school setting.

Initiatives. While change occurs in schools at rapid rates, most of these change initiatives fail (Cuban, 2013; Fullan, 2008a; Knight, 2006; Spillane, 2010; Tyack \& Cuban, 1995). Researchers offer ideas about why these initiatives fail including: (a) leaders and teachers did not understand the theoretical basis for the change (Evans et al., 2012; Spillane, 2010); (b) the changes being made are not directly impacting the instruction in the classrooms (Cuban, 2013; Deschler, 2004; Elmore, 2009); (c) teachers and administrators do not have adequate support to make the changes the district, state, and/or federal government are requiring (Hargreaves \& Fullan, 2012; Senge, 1990); (d) too many changes occur at the same time with little thought about how those changes interact with each other (Fullan, 2008b; Knight, 2009); and, (e) the changes are not necessarily the right changes (Fullan, 2008b; Reeves, 2003; Schmoker, 2006). Often, these changes occuring in education are devoid of a theoretical underpinning (Evans et 


\section{SCHOOL REFORM AND COACHING}

al., 2012). Understanding how initiatives are, or are not, implemented in schools can help leaders make decisions about how and when to bring in new initiatives.

The district being studied has a number of different initiatives being implemented in individual schools across the district. The coaches in this study were hired and trained to assist teachers and school leaders to implement two initiatives, Response to Intervention and the Data Wise cycle of inquiry. The literature about these initiatives will be examined to gain an understanding of what the coaches in this study were asked to assist teachers in implementing over the course of the two year project.

Response to Intervention. One research-based practice that has been used in some school districts is Response to Intervention (RtI). RtI is a multi-tiered system to give students instruction at the appropriate level. RtI can be a three to six tiers with each tier increasing the intervention intensity. Though RtI does not look the same across districts, there are some central tenants that all RtI systems adhere to: (a) high quality instruction; (b) universal screening; (c) continuous progress monitoring; (d) researchbased interventions; (e) progress monitoring during interventions; and (f) fidelity to the program (Bradley, Danielson, \& Doolittle, 2005).

RtI is rooted in special education eligibility practices for students with learning disabilities. The Individuals with Disabilities Education Act (IDEA) specifically outlines the eligibility criteria for students with learning disabilities, but does not specify eligibility criteria for any other disability (Bradley et al., 2005). In the past, learning disabilities were identified using the IQ-achievement discrepancy model. The reauthorization of IDEA in 2004 allowed practitioners the option of using RtI to determine 


\section{SCHOOL REFORM AND COACHING}

eligibility of learning disabled students for special education programs (Fuchs \& Fuchs, 2006). RtI programs vary, but all programs have the following data informed decision making and progress-monitoring cycle. First, students need to be administered a benchmark assessment at the beginning of the year. The assessment gives teachers and administrators base-line data and helps to determine which students should be identified as at-risk and in need of interventions in the subject tested (usually reading and/or math). Then, identified students receive an intervention and are progress monitored-reassessed to determine if students are learning the skills needed-every six to eight weeks. As the school year progresses, students are benchmarked again, allowing students to shift into and out of interventions based on the new data (Fuchs \& Fuchs, 2006). The data informed decision making of RtI is one way that schools and districts can change the practices of teachers. RtI operates on the assumption that all teachers have a responsibility to provide quality, explicit instruction to all students, and that teachers provide early intervention to ensure all students continue to perform at the highest levels possible (Farstrup, 2008).

easyCBM. The RtI benchmarking tool used by the district being studied was easyCBM (Easy Curriculum Based Measurement) a research-based curriculum measurement developed at the University of Oregon. Researchers at the University of Oregon have completed over twenty technical research reports each year since 2004 to support the validity and reliability of the benchmark tool. The research focused on internal consistency of the benchmarking tool (Guerreiro, Alonzo, \& Tindal, 2014; Wray, Alonzo, \& Tindal, 2013), development and scaling of easyCBM to the new Common 


\section{SCHOOL REFORM AND COACHING}

Core State Standards (CCSS) (Alonzo, Park, \& Tindale, 2014a; Alonzo, Park, \& Tindale, 2014b; Guerreiro et al., 2014), and determining the validity and reliability of the measure (Alonzo, Park, \& Tindale, 2014c; Irvin, Alonzo, Lai, Park, \& Tindale, 2012).

Data informed decision-making. Researchers have identified characteristics of strong leadership focused on data informed decision-making. First, school leaders were knowledgeable and committed to data use. These leaders built a strong vision for data use in their schools (Feldman \& Tung, 2001; Herman \& Gribbons, 2001; Lachat \& Smith, 2009; Mason, 2002). The principal could also show strong data leadership by being the initial data inquiry leader, but then creating distributed leadership focused on data use (Copland, 2003; Wayman \& Stringfield, 2006). Strong data leaders also worked to address low staff buy-in to using data. Ingram, Louis, and Schroeder (2004) looked at longitudinal data from nine high schools who used continuous improvement practicies. They found some teachers' held mental models that did not align with continuous improvement. Additionally, some teachers resisted using testing and other data to identify areas for improvement. Teachers also discounted assessment data because they have their own metrics to use. Ingram et al.'s study also revealed that teachers in high poverty schools feel more dienfranchised by data use than teachers in higher socioeconomic areas. This could be because teachers in high poverty schools have seen the over use of high stakes accountability reforms like NCLB which have significantly reformed high poverty schools in the last decade. Some researchers pointed to the unintended linking of data informed decision-making with federal accountability measures like NCLB (Jimerson \& McGhee, 2013; Mason, 2002; Murray, 2013; Shen \& 


\section{SCHOOL REFORM AND COACHING}

Cooley, 2008; Shen et al., 2012). This linkage had some unintended consequences such as teachers in high poverty schools feeling disenfranchised by data use. Finally, strong administrators ensured data use was nonthreatening and seen as a positive tool for change (Lachat, 2001; Wayman \& Stringfield, 2006).

Schools rarely use data effectively to inform school improvement because educators' data use lacks depth. Teachers and administrators often lack the skills and/or knowledge to use data to improve teaching and learning (Coburn \& Talbert, 2006; Cosner, 2011). The function and role of data in school improvement is poorly defined. School leaders are confused about what data to use and when and how to use the data they have (Murray, 2013). Even though the use of data has shifted through the increase of high-stakes accountability measures, many teachers embrace the idea of using data. However, they have feelings of mistrust towards formal "data use" (Early \& Fullan, 2003; Jimerson \& Wayman, 2012). The new emphasis on data necessitates new systems, knowledge, and skills for educators to use data effectively (Kerr et al., 2006). A common understanding of data and its uses is critical if data use is intended to lead to school improvement (Wayman \& Stringfield, 2006).

The interest in data informed decision-making is increasing in the field of education (Marsh et al., 2009). One approach to help guide educators through all of the data is the use of on-site coaches. These master teachers can offer ongoing instructional and data support to teachers and administrators with the focus of improving instruction and teacher's use of data. The use of coaches in literacy initiatives is common. Reading First and Striving Readers have encouraged the use of coaches to transfer training 


\section{SCHOOL REFORM AND COACHING}

knowledge into practice. There is a dearth of research focused on how coaches can support the data informed decision-making process (Marsh et al., 2009).

Data Wise. The school district identified for this study used the Data Wise process of inquiry to create change in student outcomes. Data Wise is an eight-step process that helps building leaders determine what could be done to improve student achievement based on the data available (Boudett, City, \& Murnane, 2005). The Data Wise process is broken into three categories: prepare, inquire, and act. Prepare focuses on creating a structure for looking at and understanding data. To prepare for a cycle of inquiry, two steps need to occur: (a) organize for collaborative work, and (b) build assessment literacy (Boudett et al., 2005). Organize for collaborative work includes creating and guiding a data team-a group of teacher leaders and administrators that meet regularly to inventory, analyze, triangulate, and organize data to decide on next steps for the staff. Organizing for collaborative work also includes creating and supporting productive meetings using protocols and group norms. Build assessment literacy is step two in the Data Wise process. Building assessment literacy focuses on ensuring that teachers and administrators have the knowledge of assessment practices and data usage to accurately decide how best to increase student achievement. Inquire focuses on collecting the knowledge needed to decide how to increase student learning. There are three steps in the inquiry process: (a) create data overview; (b) dig into student data; and (c) examine instruction. Create data overview focuses on creating an easy way for staff to access the important data. The creation of the data overview focuses on "telling a story" about the students and/or school using multiple data points (Kaufman, 2012). When there is too 


\section{SCHOOL REFORM AND COACHING}

much data for a staff of teachers to make decisions, the data team can use the data to create a story that will empower teachers to take action (Kaufman, 2012). Dig into student data helps teachers and administrators to look closely at specific data sets to determine the knowledge and skills students need to achieve at grade level expectations. At this step, teachers identify the learner-centered problem (LCP)—a data focused problem identified by the teachers. The final category, Act focuses on what needs to be done to improve instruction and assessing whether the changes made have led to increases in student learning. Act also has three steps: (a) develop an action plan; (b) plan to assess progress; (c) act and assess. Develop an action plan involves creating a formal action plan addressing the Problem of Practice (PoP) - the specific way that teachers' practices contribute to the learner centered problem (LCP). Plan to assess progress is the step that allows teachers the opportunity to explicitly explain how they will collect data to assess the progress of their students on the LCP. Finally, step eight, acting and assessing allow teachers and administrators an opportunity to determine if the actions and data are showing improvements.

If there are improvements, then teachers can continue to do the work, possibly making the changes on a larger scale. If the data shows that the strategy chosen does not lead to increases in student achievement, then the inquiry process starts over again. The Data Wise improvement process is a continuous cycle. The Data Wise improvement process graphic (see Figure 2) shows how these steps are cyclical-the last step of act leads back to inquiry and/or preparation. 


\section{SCHOOL REFORM AND COACHING}

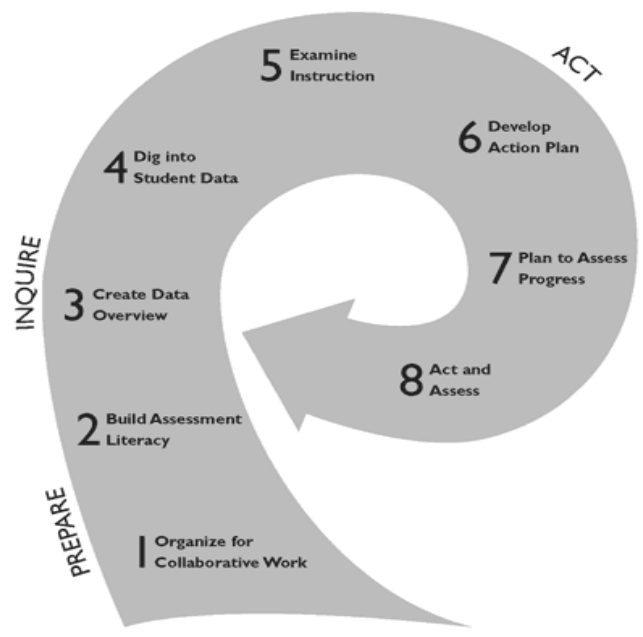

Figure 2: The Data Wise cycle of improvement is cyclical and teachers move from inquired to act and back to inquire (from Boudett et al., 2005).

\section{Research Methods}

Inquiry of the research questions will be conducted using a mixed methods research design. Mixed methods is a combination of qualitative and quantitative data collection and analysis (Creswell, 2013) in either concurrent or sequential phases of the study (Morgan, 2012). Mixed methods should lead to more complete understanding of the complexity of the study (Morgan, 2012). Using qualitative and quantitative research methods may give a more complete picture of the breadth and scope of the issues. This section will discus the strengths and limitations of qualitative, quantitative, and mixed methods designs as well as the knowledge paradigms that support each approach.

Qualitative methods. Qualitative research is a way for researchers to immerse themselves in the everyday life and/or setting being studied (Creswell, 2013). The researchers can develop complete pictures of the issues being studied and are conducting the research in the natural setting. Because qualitative research is rooted in the lived 


\section{SCHOOL REFORM AND COACHING}

experience of individuals, it is difficult to make generalizations based on this research. The strength of qualitative research is the descriptions and themes identified in a specific context and location (Creswell, 2013). The theoretical underpinnings of qualitative research are varied. Some qualitative research is conducted to generate a theory, as in grounded theory research. Other studies use theory as a broad explanation for behavior and attitudes. Most qualitative research uses theory as a lens or perspective in which to situate the topic being studied. The lens/theory informs the research questions, the data collected and analyzed, and the next steps for further research (Creswell, 2013).

Quantitative methods. Quantitative research is a more definitive approach to research that relies on classification and statistical analysis to explain the study and findings (Creswell, 2013). Quantitative research is rooted in the post-positivist paradigm. Post-positivism is the belief that causes determine effects or outcomes. The postpositivist paradigm has dominated traditional forms of research and is often referred to as the scientific method. Quantitative research is focused on testing or verifying hypotheses and measures information numerically (Creswell, 2013). Quantitative research designs can be experimental-determining if a specific treatment influences an outcome-or true experiments. It can also be quasi-experimental which is a less rigorous experiment that uses numeric data to find patterns and/or support a theory (Creswell, 2013). The strengths of quantitative research are: the generalizability of the data analysis; the unbiased approach to collecting and analyzing data; and the high standards of validity and reliability within the post-positivist paradigm (Creswell, 2013). 


\section{SCHOOL REFORM AND COACHING}

Mixed methods. As mentioned, qualitative and quantitative research have different strengths. Mixed methods combines quantitative and qualitative methods. Mixed methods uses each method's strengths (Creswell, 2013), and also provides serious challenges when designing and executing mixed methods research (Morgan, 2012). Research projects that use multiple methods are not necessarily preferable to single method research. The choice depends on what question the researchers are asking and what information the researchers are using to support their findings. Currently, there is little consensus exists on how to bring together quantitative and qualitative research methods (Morgan, 2012). Knowing the strengths and limitations of mixed methods, and the different ways both methods can be used is important when working to determine the most effective way to use qualitative and quantitative research to answer questions and collect data in mixed methods research. To understand the strengths and limitations of mixed methods, an understanding of the philosophical underpinnings can be helpful.

Pragmatism. Mixed methods is rooted in pragmatism (Creswell, 2013; Morgan, 2012). All research is rooted in a research paradigm. Kuhn's (1962) seminal work on paradigms focused on the work of natural science research and defined research paradigms as a belief system that allows a community of researchers to agree on the most appropriate questions to ask and the methods to answer those questions. Social science did not have the same paradigms that Kuhn posited are essential for a community of researchers to agree upon (Guba \& Lincoln, 1994). Smaller groups of researchers within a discipline created shared paradigms focused on the philosophy of knowledge (e.g., realism or constructivism), but those paradigms were not the overarching research 


\section{SCHOOL REFORM AND COACHING}

paradigms Kuhn described. Guba and Lincoln (1994) developed this form of knowledge for the social sciences based on ontology, epistemology, and methodology. Guba and Lincoln argued that research should begin with a set of beliefs about reality, which frame the questions asked and the methods used to collect the data. Many social scientists use this understanding of paradigms to conduct research. Unlike other philosophical worldviews, pragmatism focuses on the nature of experiences instead of the nature of reality (Morgan, 2012).

Pragmatism is the belief that all human action cannot be separated from past experiences or the situations/contexts in which the experience occurs (Morgan, 2012). Actions are linked to consequences and are dependent on a worldview that is a socially shared set of beliefs. As an individual repeatedly takes actions in similar situations, $\mathrm{s} / \mathrm{he}$ experiences the consequences of those actions and learns the likely outcomes. This process produces warranted beliefs, learning the likely outcomes of an action from previously experienced situations that are similar. Actions in different situations produce different consequences. For example, a two year old throwing a tantrum in public will have different consequences than an eight year old throwing a similar tantrum in public. One, in our culture, is a more socially acceptable action than the other. Finally, pragmatists believe it is impossible to experience the exact experience twice because every action cannot be separated from the situation. Because every action is connected to the situation, pragmatists believe you can only act based on the warranted beliefs of the likely consequences of an action. Because meaning of actions change when the consequences and/or situation change, pragmatists' beliefs are continually changing. 


\section{SCHOOL REFORM AND COACHING}

These beliefs are interrelated and not isolated products of experiences. Pragmatism is a worldview that shapes all actions based on warranted beliefs. Essentially, pragmatists focus on determining what difference would it make to act in one way rather than another.

Pragmatism was first detailed by William James in the early 1900s, and the work was built upon by Charles Peirce, John Dewey, and George Herbert Mead (Morgan, 2012). Pragmatism in education originated with the work of John Dewey. Dewey (1910) theorized that education needed to apply a scientific approach to the work of teaching. Teachers experience the consequences of their actions and develop warranted beliefs about what will work in their classroom. Teachers can change their actions based on the outcomes of their students and their practices.

Pragmatism, as a research paradigm, was not included in most social science research paradigm discussions until recently (Creswell, 2013). Morgan speculated a possible reason for this lack of discussion was because of the lack of a metaphysical basis for the pragmatic paradigm. Kuhn (1962) used multiple meanings to the word paradigm, but the construct he referred to the most was the idea that a paradigm is a human construct that is reshaped as a community of researchers uses it. Under this definition, all paradigms -including pragmatism - fit Kuhn's definition (Morgan, 2007).

I situated my study in the pragmatic paradigm for three reasons. First, the work of coaches is pragmatic. Coaches should constantly be changing their practice to fit the needs of the school and the teachers they work with (Killion, 2009; Knight, 2009). Second, data informed decision-making is also pragmatic. Using data to determine where 


\section{SCHOOL REFORM AND COACHING}

a student is, where they are going, and creating plans to help them close that gap (Chappuis, 2009) is an example of the type of actions Dewey (1910) argued were effective for educators to change their practice. Finally, the research itself is pragmatic. I intend to find patterns of actions taken that produce increased student outcomes in schools. I hope to create some warranted beliefs about what is needed in schools for coaches to effectively implement a data informed decision-making program. These findings could be used to help districts, principals, and coaches determine the structures that are necessary before using coaching as a way to support the implementation of a new initiative.

\section{Data Collection}

The data in this study was collected in three ways: an archival data set of literacy benchmark results from the 2011-2012 and 2012-2013 school years; a survey of all the coaches; and interviews of principals and coaches. To ensure the validity and reliability of the data being collected through, archival data sets, surveys, and interviews; a brief review of the literature was completed.

Archival Data Set. An archival data set is quantitative data that has already been collected by another source (Creswell, 2013). The use of archival data, or preliminary quantitative data, is common in mixed methods research (Morgan, 2012). A weakness of qualitative data collection is the reliance on detailed data from relatively few participants (Morgan, 2012). The qualitative study is only as good as the data sources (participants) that are being studied. The use of an archival, quantitative data set allows the researcher the ability to search through a larger number of potential data sources to find the 


\section{SCHOOL REFORM AND COACHING}

individuals and/or sites that can provide the data that best answers the qualitative questions being posed (Morgan, 2012). This selection of specific individuals and/or sites is known as purposive selection. Purposive Selection in qualitative research means the researcher is looking for a specific type of individual or site to supply the information one is looking for. Quantitative methods are one way to locate data sources that match a researcher's purpose (Morgan, 2012).

Surveys. Surveys provide quantitative descriptions of trends, attitudes, or opinions of a sample of the population in an attempt to generalize the findings to the larger population (Creswell, 2013). Surveys can be used to gather qualitative data, but the construction of the survey and the analysis of the data is more complex than using an archival data set (Krathwohl, 2013). The construction of a survey tool is vital to ensuring the survey measures what it intends to measure. "Every survey involves a number of decisions that have the potential to enhance or detract from accuracy (or precision) of survey estimates" (Fowler, 2014, p. 6). The decisions that need to be made encompass the total survey design, a set of decisions made to optimize resources when constructing a survey tool (Fowler, 2014). The total survey design includes the decisions made about sampling, data collection, and question design. Fowler argued these three components are interrelated, and the survey tool will be no better than the most error prone aspect of the design. For example, if the questions are not clear and easy for people to understand, changing the sample size will most likely not impact the outcome of the study because the error in the design is in the questions, not the sample size. 


\section{SCHOOL REFORM AND COACHING}

Sampling. Many decisions need to be made when considering the sample for the survey. Considering who has the chance to be selected to participate in the survey, sample frame, as well as how those people will be chosen to participate, sample design, are both important decisions to make before the survey is administered (Fowler, 2014). The sample size and acceptable rate of response should be decided on to ensure there is enough data from a large enough sample to make some generalizations from the survey (Fowler, 2014).

Data collection. When determining how the data will be collected, decisions are often based on time and money factors (Fowler, 2014). When considering time, the survey creator should think about how much time the instrument takes to administer and how much time the researcher has to collect the data from the survey. Money must be a factor as well. Deciding if respondents will be paid for their time, and whether or not to train and pay research assistants to administer the survey tool both impact the total survey design. Finally, the data collection method must be determined. Specifically, is the data collected in person, over the telephone, using paper and pencil, or on the Internet or computer? Deciding how the data will be collected will also impact the time and money needed to administer the survey (Fowler, 2014).

Question design. A good question maximizes the relationship between the answers and what the researcher is trying to measure (Fowler, 2014). To create a good question, survey designers need to know the type of data they want to collect. Surveys can collect four types of data: nominal; ordinal; interval; and ratio (Fowler, 2014). Each type of data being collected lends itself to types of questions asked in the survey. 


\section{SCHOOL REFORM AND COACHING}

Surveys are composed of open and closed questions. Closed questions give the participants a list of acceptable answers (Fowler, 2014). Closed questions allow the researchers to conduct quantitative analysis of the participant's responses. The strength

of closed questions are: they are more reliable; it is easier to interpret the data; it narrows the choices so the data is analytically interesting; and checking a box is easier than keying in an open-ended answer (Fowler, 2014). Open questions allow participants the freedom to provide their opinions. There strengths of open-ended questions are: the ability to see unanticipated answers; the real views of the respondents; the desire of respondents to answer in their own words; and the ability to ask a question when the list of possible answers would be too long (Fowler, 2014).

Researchers work to maximize the question reliability and consistency on a survey tool. Ensuring all the questions mean the same thing to all respondents increases reliability and ensures all participants are asked the same questions making the survey more consistent (Fowler, 2014). Designers of survey instruments are constantly weighing the tension between providing complete definitions and keeping questions clear and simple (Fowler, 2014). There are multiple reasons why the accuracy of a survey tool can be compromised: participants do not understand the question; participants genuinely do not know the answers; participants cannot recall the answers even though they know it; and/or the participants do not want to report the answers in the context.

To increase the validity of a survey instrument, Fowler (2014) explained ways to increase factual reporting by addressing each of the ways survey tools are compromised. First, surveys should include definitions of key terms to ensure respondents understand 


\section{SCHOOL REFORM AND COACHING}

the questions being asked. Open-ended questions can help ensure respondents understand the question because it allows respondents to answer in their own words (Fowler, 2014). The next issues with factual reporting can be addressed with similar considerations when constructing the survey. Sometimes respondents do not know the answer and/or they cannot recall the answer, though they know it. Often, if respondents are asked questions they do not know the answer to or cannot remember the answer, they will guess and/or estimate instead of thinking more deeply to be as accurate as possible. Asking respondents less detailed questions and providing estimations as answer choices can help respondents answer questions they may or may not know the answer to (Fowler, 2014). Finally, there are some questions that respondents do not feel comfortable reporting the answer in an interview survey context. Ensuring interviewers minimize judgment and remind respondents that the answers they provide are confidential and anonymous can help to increase a respondent's willingness to answer sensitive questions. Survey creators can also consider collecting the data through methods that allow respondents to self-administer the survey, paper-pencil or computer-based (Fowler, 2014). Surveys can collect information from a larger number of participants, allowing the researcher the ability to make generalizations from the findings. If a researcher wants get a deeper understanding of issues affecting a complex organization like a school, then they could benefit from conducting interviews (Krathwohl, 2013).

Interviews. Conversations are how people interact, so interviews are an important and useful way to collect information about people and their lived experiences. Interviews are conversations that have a structure and purpose that is constructed by the 


\section{SCHOOL REFORM AND COACHING}

interviewer. Interviews are professional interactions and the purpose is for the interviewer to ask questions and be a careful listener to obtain thoroughly tested knowledge of the interviewee's lived experience (Kvale, 2007). Interviewers can collect this knowledge in different ways. Kvale explained the difference using two metaphors for the interviewer, a miner and a traveller.

A researcher who believes interviewers are like miners believes the knowledge is buried and the interviewer must uncover it (Kvale, 2007). Interviewer as miner conducts the interview and later analyzes the information. The knowledge is in the person's experience, it is up to the interviewer to find the information within the conversation. This method of interviewing is aligned with a positivist or empiricist world-view. Interviewer as a traveller wanders through a conversation and collects stories and experiences along the way (Kvale, 2007). The traveller takes this information and unfolds it through the traveller's interpretation. This style of interviewing allows the interviewer to interview and analyze simultaneously. This type of interviewing is a semistructured life-world interview (Kvale, 2007).

Semi-structured life-world interviews. The semi-structured life-world interview is a method of interviewing that allows the interviewer the opportunity to obtain description of the lived experience of the interviewee and then interpret the meaning of the described phenomena (Kvale, 2007). The semi-structured life-world interview focuses on central themes of the subject's lived world. The interviewer focuses on both the factual experience and the meaning levels of the conversation. The interviewer attempts to interpret meaning, i.e. read between the lines, and then send those interpretations back to 


\section{SCHOOL REFORM AND COACHING}

the interviewee to get feedback. This interaction is qualitative, and there is not an attempt to quantify or add numeric value to this process. The process is also descriptive and specific. The interviewer asks questions that focus the interviewee on specific situation and tries to keep the interviewee from making broad generalizations in order to create meaning on a concrete level (Kvale, 2007). The interview is focused on specific themes, it is not strictly structured, but it is also not non-directive. This method of interviewing acknowledges that the interview is an interpersonal situation. The interviewer and the interviewee reciprocally influence each other and therefore the meaning constructed during the interview.

In the semi-structured life-world interview, interviewers needs to hold an important balance between qualified naïveté and sensitivity to the subject matter (Kvale, 2007). The interviewer should have qualified naïveté, a willingness to be open to new

phenomena. The interviewer should not attempt to have ready-made schema or interpretations before the interview. Conversely, the interviewer needs to have enough knowledge of the subject matter to ensure they are sensitive to the nuances being discussed (Kvale, 2007). This balance is important because sometimes the interviewee will provide contradictory statements. It is the job of the interviewer to determine if that ambiguity is because of a failure of communication or an actual inconsistency, ambivalence, and/or contradiction in their world-view (Kvale, 2007). Balancing qualified naïveté and sensitivity to the subject matter will enable the interviewer the ability to ask more questions to ensure the ambiguities are being addressed. 


\section{SCHOOL REFORM AND COACHING}

Finally, the semi-structured life-world interview allows the interviewee to change aspects of her/his themes. The interviewee might, through the process of the interview, make new meaning. The interview, itself, can provide a structure of reflection for the interviewee. Both the interviewer and the interviewee can walk away from the experience with new meanings about the events being discussed (Kvale, 2007). This interview experience can be very positive because it can help the interviewee learn more about their life experiences. It is sometimes difficult to end the interview because the interviewee wants to continue talking about, and learning from, the life experiences being discussed (Kvale, 2007).

Interviews have become a common research method in the past few decades in the health and education fields and, if done right, can lead to substantial new knowledge in those fields (Kvale. 2007). The interview is a one-way dialogue dictated by the interviewer and the scientific research being conducted. Kvale, explained that the research interview is somewhere between the philosophical dialogue of Socrates and a therapeutic interview. A philosophical dialogue seeks the true knowledge through argumentative, unrelenting questioning (Kvale, 2007). The therapeutic interview provides the interviewee the opportunity to change through emotional, personal interaction (Kvale, 2007). The research interview is less oppositional than the philosophical dialogue. The interviewee is an informant or partner and the interviewer is not arguing her/his own thinking. Instead, the research interviewer works to pose questions to gain understanding of the other's world-view. In a therapeutic interview the focus is on personal change. In a research interview the focus is on knowledge 


\section{SCHOOL REFORM AND COACHING}

production. Because there is not a standard methodology for interviews, one consideration when constructing an interview is the ethical issues that surround interviewing as a research method (Kvale, 2007).

Ethical issues. The interview is a social relationship between the interviewer and the interviewee. The interviewer should create a space that is safe to talk about private matters, but also ensure the interviewee is comfortable having the information shared be public later. According to Kvale (2007), the most important ethical issue with interviews is balancing the interviewer's concern for pursuing interesting knowledge with the ethical respect for the integrity of the interview subject. Considering this balance throughout the process ensures the interview will be a positive experience for both the researcher and the interviewee.

\section{Summary}

This chapter explored the theoretical framework of organizational change, specifically systems thinking. The literature review included a review of research on organizational change, instructional coaching, and data informed decision-making. The chapter also provided a brief review of the specific reform initiatives used in the district being studied. Finally, a review of the research methodology discussed the pragmatic paradigm, and the data collection methods of surveys and interviews. The next chapter describes and explains the research methodology for the study. 


\section{SCHOOL REFORM AND COACHING}

\section{Chapter 3}

\section{Methods}

The purpose of this study was to determine what organizational structures are needed for a coach to implement a data informed decision-making initiative successfully. Data Wise (Boudett \& Steele, 2007) is the data informed decision-making format used by teachers and coaches to analyze the easyCBM literacy benchmarking data of the students, grades 4 to 8 . The district identified schools in need of increasing literacy and math scores and placed coaches in each of those buildings. Coaches were trained in the Data Wise process of data informed decision-making and used the easyCBM literacy benchmarking tool. Coaches led data team meetings with the literacy teachers in their building. Coaches were used to increase the application of data informed decisionmaking in 20 schools across a large, urban school district. The research questions that framed my study were:

1. Which urban schools showed increases in students' literacy benchmarking scores?

2. What did the coach perceive as the significant structures that led to the implementation of the data informed decision-making model?

3. What did the principal perceive as the significant structures that led to the implementation of the data informed decision-making model?

4. What factors within the structure of the organization supported the coach in implementing the data informed decision-making model? 


\section{SCHOOL REFORM AND COACHING}

\section{Participant Selection}

The Columbia School District (pseudonym) hired 18 coaches to serve 19 schools during the 2011-2012 and 2012-13 school years. The district initially had 19 schools prioritized to have coaches working to increase teachers' use of data to improve literacy instruction. At the end of the first year of the initiative, one school of the 19 closed. That coach was moved with the students and teachers from the closed building, to another school. Therefore, the data analyzed was from the 20 schools where coaches were placed by the district during the two years of the initiative. These 18 coaches participated in bimonthly professional development for the duration of the project. During phase I of the study, archival, literacy benchmark data from the 20 schools in Columbia School District was analyzed. All fourth to eighth grade student literacy benchmark scores in the 20 schools were analyzed for statistically significant improvements over a one or two-year period. Any educator who served as a coach during the two-years of the initiative was asked to complete a survey about their experience, the school, and their opinions about the project. Participant selection for the qualitative interviews was completed based on the analysis of the benchmark data and the survey results from the coaches. This purposive participant selection process was used in the study to ensure the qualitative data collected and analyzed is from schools where increases in student benchmark scores were observed, and the coach in the building had an understanding of the processes that helped teachers and students increase scores over the two year period. 


\section{SCHOOL REFORM AND COACHING}

\section{Role of the Researcher}

As the researcher, it is important to note that I was a coach in the district being studied. Though I was not a participant researcher, I did participate in the work being studied, and I am familiar with the people who will be interviewed. I spent two years working with all of the coaches, and I have taught with some coaches over the past 13 years I worked in the Columbia School District. My experience in the district hopefully allowed the participants to be more comfortable because there is already a level of familiarity and trust between the participants and me, the researcher (Krathwohl, 2009). Knowing the participants as well as I do, I worked to ensure my biases and prior experiences are kept separate from the research; however I also know that bias is inevitable (Krathwohl, 2009). My bias was, and is, very pragmatic in nature. I am interested, as a researcher and an instructional leader, in learning from this research to inform my practice and, hopefully, the work of others.

I worked to reduce my bias in a number of ways. First, I used the archival data set to select the locations that I would study further. Using statistics to analyze the literacy benchmarking scores ensured that I was not selecting locations where I knew the coach and/or principal. Second, I removed the names from the coach surveys (This will be discussed more in the use of instruments section). I did this to ensure I was reading the surveys only for the content of what the participant included, and not what I thought about the individual coach that was responding. I know that I have preconceptions about the people that I worked with for two years, and I wanted to ensure the information in this research was their thoughts and beliefs of the work, and not my beliefs about them and/or 


\section{SCHOOL REFORM AND COACHING}

their work. Finally, I included member checking in the interviewing methods. Again, I worked to ensure the findings represent the perceived structures from the coaches and principals, and not my preconceived notions based on prior experiences.

\section{Research Method and Design}

The research method for this study was a sequential, mixed methods design (Morgan, 2012). Creswell (2013) described a mixed methods approach as pragmatic because researchers using this approach are concerned with solutions to problems. Researchers using mixed methods believe that there is relevance in the results of different types of research-based on different research paradigms (Morgan, 2012). Different research methods can be used to gain more meaning from the research compared to a single method of data collection (Morgan, 2012). A number of typologies in mixed methods research explain the motivation for using mixed methods. These typologies have focused more on the theories about how to combine the methods instead of the reason the methods are being combined (Morgan, 2012). Morgan argued for the use of a set of purpose driven typologies. The typologies are more appropriate for mixed methods research because the typologies are pragmatic and designed to solve a problem.

The study used a preliminary quantitative input in a core qualitative project (quan $\rightarrow$ QUAL) (Morgan, 2012). This method was employed because the quantitative data was used for the purposive selection of data sources leading to the core qualitative study. The use of quan $\rightarrow$ QUAL is the most common use of preliminary quantitative input research design (Morgan, 2012). Preliminary quantitative methods allowed me the 


\section{SCHOOL REFORM AND COACHING}

ability to examine a large number of potential data sources, and find the most appropriate sites for the in-depth qualitative analysis (Morgan, 2012).

\section{Instruments}

In this study, I used three different data collection methods. Because schools are complex organizations with multiple challenges (Suppovitz, 2009), I believed the array of data being collected would provide a more complete picture of the schools where successful implementation of the data informed decision-making process occured. Using quantitative data from the literacy benchmarking data set and the coach survey provided enough information to ensure the principals and coaches chosen to be interviewed would provide the most complete picture of their success in implementing the data informed decision-making initiative.

Literacy benchmarking data. The initial question, which urban schools showed increases in students' literacy benchmarking scores, was answered using the literacy benchmarking data from the Columbia School District. The data is archival data from the 20 schools being studied. The data set consists of all fourth to eighth grade student literacy benchmark scores from a two year period: 2011-2013. The benchmarking tool used was easyCBM, a norm-referenced assessment that scores students on their oral reading fluency, vocabulary, and comprehension. Benchmarking was completed every fall, winter, and spring. Each student's score is compared to other students in the state being studied, and the student's score is calculated in two ways - percentile ranking compared to other students and risk level for not reading at grade level benchmarks. Each student has four scores for each benchmark period - fall, winter, and spring (see 


\section{SCHOOL REFORM AND COACHING}

Table 1). Three scores - reading fluency, vocabulary, and comprehension - have two values, risk rating (high, medium, and low) and percentile ranking. The fourth score is the student's overall risk rating: high, the student is significantly at risk of not meeting grade level reading expectations; some, the student has some gaps that should be filled to meet grade level reading expectations; and low, the student has grade level reading skills and should maintain those skills with solid instruction at grade level.

Table 1

Sample of Literacy Benchmark Scores for one benchmarking period

\begin{tabular}{|c|c|c|c|c|c|c|c|c|c|}
\hline \multirow[b]{2}{*}{ Proxy ID } & \multirow[b]{2}{*}{ School } & \multirow[b]{2}{*}{ Grade } & \multicolumn{2}{|c|}{ Fall PRF } & \multicolumn{2}{|c|}{ Fall Voc } & \multicolumn{2}{|c|}{ Fall MCRC } & \multirow[b]{2}{*}{ Fall Risk } \\
\hline & & & score & $\%$ tile & score & \%tile & score & $\%$ tile & \\
\hline 58483920 & Hazel Hill & 6 & 128 & 35 & 18 & 78 & 12 & 37 & Some \\
\hline 48382910 & Hazel Hill & 6 & 57 & 4 & 6 & 12 & 3 & 17 & High \\
\hline 83829183 & Hazel Hill & 6 & 175 & 85 & 19 & 93 & 19 & 98 & Low \\
\hline 33847462 & Hazel Hill & 6 & 98 & 30 & 19 & 93 & 13 & 42 & Some \\
\hline
\end{tabular}

PRF: Passage Reading Fluency; Voc: Vocabulary; MCRC: Multiple Choice Reading Comprehension; \%tile: Percentile Ranking

Vertical v. horizontal data set. The district data analyst created a vertical data set to be analyzed. This means that each student's score for each benchmarking period was represented in a different row (see Table 2). This data format allowed for analysis of the expected and observed frequencies of categorical data (risk level and benchmarking period). To analyze the change in an individual student score over the two year period, the data would need to be manipulated and reformatted to create a horizontal data set. A horizontal data set would allow me to analyze individual student scores over time using dependent $t$-tests (Field, 2009). Because the purpose of this research was not focused on individual student data, the data was not reformatted into a horizontal data set. 


\section{SCHOOL REFORM AND COACHING}

Table 2

Horizontal versus Vertical Data Formatting

\begin{tabular}{|c|c|c|c|c|}
\hline Proxy ID & School & $\begin{array}{c}\text { Benchmark } \\
\text { Period }\end{array}$ & Grade & Risk \\
\hline 58483920 & $\begin{array}{c}\text { Hazel } \\
\text { Hill }\end{array}$ & $\begin{array}{c}\text { Fall } \\
2011\end{array}$ & 6 & Some \\
\hline 58483920 & $\begin{array}{c}\text { Hazel } \\
\text { Hill }\end{array}$ & $\begin{array}{c}\text { Winter } \\
2012\end{array}$ & 6 & Low \\
\hline 58483920 & $\begin{array}{c}\text { Hazel } \\
\text { Hill }\end{array}$ & $\begin{array}{c}\text { Spring } \\
2012\end{array}$ & 6 & Some \\
\hline 48382910 & $\begin{array}{c}\text { Hazel } \\
\text { Hill }\end{array}$ & $\begin{array}{c}\text { Winter } \\
2012\end{array}$ & 6 & High \\
\hline 48382910 & $\begin{array}{c}\text { Hazel } \\
\text { Hill }\end{array}$ & $\begin{array}{c}\text { Spring } \\
2012\end{array}$ & 6 & High \\
\hline 48382910 & $\begin{array}{c}\text { Hazel } \\
\text { Hill }\end{array}$ & $\begin{array}{c}\text { Fall } \\
2012\end{array}$ & 7 & Some \\
\hline 48382910 & $\begin{array}{c}\text { Hazel } \\
\text { Hill }\end{array}$ & $\begin{array}{c}\text { Winter } \\
2013\end{array}$ & 7 & Low \\
\hline 48382910 & $\begin{array}{c}\text { Hazel } \\
\text { Hill }\end{array}$ & $\begin{array}{c}\text { Spring } \\
2013\end{array}$ & 7 & Low \\
\hline 33847462 & $\begin{array}{c}\text { Hazel } \\
\text { Hill }\end{array}$ & $\begin{array}{c}\text { Fall } \\
2011\end{array}$ & 6 & Some \\
\hline
\end{tabular}

\begin{tabular}{|c|c|c|c|c|c|c|c|c|c|c|c|c|c|}
\hline \begin{tabular}{l}
$\theta$ \\
\multirow{\widehat{x}}{0}{} \\
$\vdots$
\end{tabular} & $\begin{array}{l}\overline{8} \\
\frac{0}{5} \\
\text { ns }\end{array}$ & 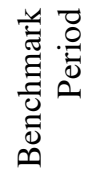 & $\begin{array}{l}\frac{8}{\pi} \\
\tilde{U}\end{array}$ & $\frac{y}{a x}$ & 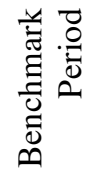 & $\begin{array}{l}\frac{\mathscr{T}}{\pi} \\
\tilde{U}\end{array}$ & $\frac{u}{a}$ & 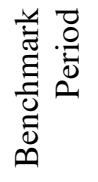 & 宽 & $\frac{4}{a}$ & 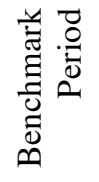 & $\frac{\tilde{E}}{\tilde{E}}$ & $\frac{\ddot{n}}{a}$ \\
\hline 58483920 & $\begin{array}{c}\text { Hazel } \\
\text { Hill }\end{array}$ & $\begin{array}{c}\text { Fall } \\
2011 \\
\end{array}$ & 6 & Some & $\begin{array}{c}\text { Winter } \\
2012 \\
\end{array}$ & 6 & Low & $\begin{array}{c}\text { Spring } \\
2012 \\
\end{array}$ & 6 & Some & & & \\
\hline 48382910 & $\begin{array}{l}\text { Hazel } \\
\text { Hill }\end{array}$ & $\begin{array}{c}\text { Winter } \\
2012\end{array}$ & 6 & High & $\begin{array}{l}\text { Spring } \\
2012 \\
\end{array}$ & 6 & High & $\begin{array}{c}\text { Fall } \\
2012\end{array}$ & 7 & Some & $\begin{array}{c}\text { Spring } \\
2012 \\
\end{array}$ & 7 & Low \\
\hline 33847462 & $\begin{array}{c}\text { Hazel } \\
\text { Hill }\end{array}$ & $\begin{array}{c}\text { Fall } \\
2011\end{array}$ & 6 & Some & & & & & & & & & \\
\hline
\end{tabular}

Survey. A survey was administered electronically to all the coaches. I developed the survey tool to collect demographic information about the coaches as a group, and ask questions regarding the role of the coach and the implementation of the data informed decision-making process (see Appendix A). The survey included four sections school 


\section{SCHOOL REFORM AND COACHING}

climate, structures, job responsibilities, and demographics. The quantitative data from the benchmarking tool was used in conjunction with the results from the survey to identify a purposive selection of participants for the interview portion of the research.

Interviews. Two schools were identified using the literacy benchmarking data and the coach survey. The principal and coach at each school were asked to participate in individual interviews detailing the work that was done in the school during the 2011-13 school years (see Appendices B and C). I conducted the interviews in a convenient and comfortable location for each interviewee, and the interview was audio recorded to ensure transcription accuracy. I transcribed and coded the interviews to identify categories and themes to understand how the structures that were in place led to increases in teacher use of data informed decision-making in their instruction. Each interviewee reviewed the interview findings to assure the findings were an accurate representation of his or her thoughts and feelings.

\section{Use of Instruments}

Literacy benchmarking data. The archived database was acquired from the school district being studied. The district created a database with proxy IDs and scores, but no student names attached. This ensured the study was in compliance with Family Educational Rights and Privacy Act (FERPA) (U.S. Department of Education, 1974). This large data source $(12,338$ records $)$ of fourth to eighth graders in 20 schools was used for statistical analysis of the literacy benchmark scores.

During the first year of the initiative, the district attempted to measure the growth of students based on literacy benchmarking scores in individual grades and schools. The 


\section{SCHOOL REFORM AND COACHING}

people analyzing the data only looked at percentage change in the different categories. These descriptive statistics were interesting and led to dialogue about how different schools were getting gains. However, the $N$ for the grade level analysis was, in some schools, very low. For example, one school had 17 students in the seventh grade. The percent change of students from fall to spring was compared to another school that had 148 seventh graders. The use of statistics to analyze the data will allow for a more accurate interpretation of significant differences in the number of students in each of the risk categories. The analysis in my research matched the data analysis completed by the district in the first year of the project, and will hopefully enrich the conversation about what schools were getting gains and how those gains were obtained. Comparing the schools this way may not give an accurate representation of which schools are making progress and which are not. Using statistics is one way to determine what schools had significant increases in student benchmark scores.

While there were more than 3,000 students in the data set, the student data from different schools and in specific grade levels is much smaller. Descriptive statistics were run for each school and grade level. Collecting and analyzing data allowed me to gather more data than can be observed and/or summarized in a calculation (Krathwohl, 2009). The use of statistics ensured the cursory look at the data was not the way decisions were made. Statistics ensured the validity of the statement of increases or decreases in scores was accurate and significant (Krathwohl, 2009). Internal integrity issues will be accounted for by using multiple chi-squared tests to determine if the significant change is across a one or two year period, the entire school, or just a grade level. 


\section{SCHOOL REFORM AND COACHING}

Survey. The survey design was cross-sectional and self-reported (Creswell, 2013). The survey data was collected at one point in time. The surveys were sent electronically (with an agreement attached) to all of the teachers who were coaches during the two-year project. There were 20 schools with a total of 18 coaches, but 23 different people filled those 18 positions through the duration of the initiative because some coaches left their position before the end of the initiative. The survey was sent to all teachers who served as coaches during the 2011-12 and/or 2012-13 school years. I used Qualtrics, an online survey tool, to collect the survey information from participants. I selected Qualtrics because of the ease of accessibility and the time needed for the participants to complete the survey. The survey was confidential but not anonymous because it was being used to identify which school sites would be studied further. To ensure as much anonymity as possible, I created unique numbers for each survey participant. As surveys were completed, I printed the survey and wrote the unique identifier at the top. All surveys were read without participant or school identification to ensure I was as unbiased as possible. Survey information was linked to individuals for purposes of seeing who returned the survey and where each coach was located. The survey was used to collect baseline information about each coach and school and to determine which coaches and principals were the most appropriate to study in-depth through the interview process.

Interviews. Once the purposive sampling was completed, individuals that were identified to be interviewed were contacted via email to set up a time to meet. Interviews were done individually, each coach and principal answering questions on their own. 


\section{SCHOOL REFORM AND COACHING}

Interviews were the method of data collection because the complexity of the school setting and organizational change make it difficult to use survey or other mass collection methods to adequately collect enough information for me to find meaningful patterns and/or trends (Creswell, 2013). The in-depth and focused interviews were used to explore information that would help other schools with coaches and data informed decision making programs better understand what successful programs have done in the past. Interviews were semi-structured interviews to allow me to understand the process each individual felt was important in the implementation of the data informed decisionmaking project (Krathwohl, 2009). The format was a semi-structured life world interview (Kvale, 2007) allowing for some open ended questions in the beginning of the interview, and structuring the final questions based on what information the interviewee shares throughout the process (see Appendices C and D). I conducted a member check after the interview was transcribed, coded, and analyzed. Member checking allowed the interviewee the opportunity to read the findings from his or her interview to ensure the data collected was an accurate representation of the person's experience (Krathwohl, 2009). Finally, I included reflections from each interview and analytic memos during coding to document the judgments, consistency, and possible bias in the interview and/or my interpretations (Krathwohl, 2009).

\section{Data Analysis}

The data was analyzed in two phases. The first phase included statistical analysis of the archived literacy benchmark scores and quantitative analysis of the coach survey results. This analysis was used for the purposive selection of the two school sites where 


\section{SCHOOL REFORM AND COACHING}

the principal and coach were interviewed. The second phase involved coding of the open ended questions from the survey and coding the interviews with the principals and coaches.

Literacy benchmarking data. The literacy benchmarking tool used was easyCBM. Students have three, short assessments in each benchmarking period: passage reading fluency (reading aloud to someone who is tracking words read and accuracy for one minute), vocabulary (20 multiple choice questions about word meaning), and comprehension (reading a passage and answering 20 multiple choice questions about the reading). These three scores are compiled, and the student is given a risk rating (low, some, or high) for the benchmarking period. Pearson $\chi^{2}$ tests were used to analyze the benchmark data. Pearson $\chi^{2}$ tests were used because two pieces of categorical data were being compared (risk level is high, medium, or low and benchmark period is fall, winter, spring). Because only categorical variables were being used, the frequency of each category occurring was measured instead of a measure of central tendency (Field, 2009). The Pearson $\chi^{2}$ test compared the frequencies observed in certain categories to the frequencies expected by chance (Field, 2009). Statistical analysis often relies on the assumption that the data is continuous and normally distributed. A normal distribution of data could not be assumed in this analysis because the data is categorical, not continuous. Two assumptions can be made when using the Pearson $\chi^{2}$ test (Field, 2009). One assumption is the independence of the data. Each student has only one score for each benchmarking period fall, winter, and spring each school year. The other assumption made is that no expected frequency is below five. Descriptive statistics were run and the 


\section{SCHOOL REFORM AND COACHING}

analysis included consideration of the expected frequency value, especially in smaller schools with grade levels that have small numbers of students. Field (2009) suggested the use of the Fisher Exact Test for expected frequencies below five for any category. An important assumption of the Fisher Exact Test is there are only four categories of data (a two-by-two contingency table). The contingency tables used were not two category by two category tables. To use the Fisher exact test, the data can only be two categories (e.g. male/female gender categories compared to a yes/no answer on a survey would be a two by two contingency table). Therefore, the Fisher Exact Test was not used. If it was determined that the expected frequency was below five, this was noted in the data.

Pearson $\chi^{2}$ tests were run for each school each year and over multiple years (see

Table 3). The data being analyzed was for fourth to eighth grade students. Some schools in the district are traditional elementary schools (K-5) and middle schools (6-8). Other schools are K-8s, so the data being compiled for each school depended on the structure and the students served. Fourth to eighth grade students were included because many students in these grades struggle with the advanced literacy skills needed to read in the content areas (Kamil et al, 2008). Because of this, each grade level was analyzed to determine if there is statistical significance in the reading benchmarking scores in any particular grade. The grade-level analysis provided more information to ensure the purposive selection of a school and coach was as effective as possible. 


\section{SCHOOL REFORM AND COACHING}

Table 3

Pearson $\chi^{2}$ tests being used to identify schools with statistically significant increases in literacy benchmark scores

\begin{tabular}{|c|c|c|c|c|}
\hline & 2011-2012 & 2012-2013 & \multicolumn{2}{|c|}{$2011-2013$} \\
\hline School Structure & Whole School & Whole School & Whole School & Grade Specific \\
\hline $\begin{array}{c}\text { Elementary School } \\
\left(4^{\text {th }} \text { and } 5^{\text {th }} \text { grade }\right)\end{array}$ & $\begin{array}{l}\text { Fall to Spring } \\
\text { benchmark } \\
\text { scores }\end{array}$ & $\begin{array}{l}\text { Fall to Spring } \\
\text { benchmark } \\
\text { scores }\end{array}$ & $\begin{array}{l}\text { Fall to Spring } \\
\text { benchmark } \\
\text { scores }\end{array}$ & $\begin{array}{c}4^{\text {th }} \text { and } 5^{\text {th }} \text { grade } \\
\text { fall to spring } \\
\text { benchmark } \\
\text { scores }\end{array}$ \\
\hline $\begin{array}{c}\text { K-8 School } \\
\left(4^{\text {th }} \text { to } 8^{\text {th }} \text { grade }\right)\end{array}$ & $\begin{array}{l}\text { Fall to Spring } \\
\text { benchmark } \\
\text { scores }\end{array}$ & $\begin{array}{l}\text { Fall to Spring } \\
\text { benchmark } \\
\text { scores }\end{array}$ & $\begin{array}{l}\text { Fall to Spring } \\
\text { benchmark } \\
\text { scores }\end{array}$ & $\begin{array}{l}4^{\text {th }} \text { to } 8^{\text {th }} \text { grade } \\
\text { fall to spring } \\
\text { benchmark }\end{array}$ \\
\hline $\begin{array}{l}\text { Middle School } \\
\left(6^{\text {th }} \text { to } 8^{\text {th }} \text { grade }\right)\end{array}$ & $\begin{array}{l}\text { Fall to Spring } \\
\text { benchmark } \\
\text { scores }\end{array}$ & $\begin{array}{c}\text { Fall to Spring } \\
\text { benchmark } \\
\text { scores }\end{array}$ & $\begin{array}{l}\text { Fall to Spring } \\
\text { benchmark } \\
\text { scores }\end{array}$ & $\begin{array}{l}6^{\text {th }} \text { to } 8^{\text {th }} \text { grade } \\
\text { fall to spring } \\
\text { benchmark } \\
\text { scores }\end{array}$ \\
\hline
\end{tabular}

Survey. The survey collected from the coaches contributed to the purposive selection of interviewees, and it also increased my understanding of the schools that were going to have personnel interviewed. This allowed me to ask more thorough interview questions because the survey results provided some data to begin the conversation (Morgan, 2012). The survey was analyzed using semi-statistical quantitative analysis and qualitative coding. The survey responses helped to answer two of the research questions: (a) what did the coach perceive as the significant structures that led to the implementation of the data informed decision-making model?; (b) What factors within the structure of the organization supported the coach in implementing the data informed decision-making model?

Quantitative analysis. Each survey was linked to the school and school years the person served as a coach. This information was used to create different groups of survey 


\section{SCHOOL REFORM AND COACHING}

results (see Table 4). The results were divided into three categories: schools with (a) increases in benchmark score (b) no change in benchmark scores and (c) decreases in benchmark scores. I developed decision rules for determining whether a school's benchmark scores were increasing, decreasing, or not changing (see Table 4). Increasing benchmark scores means the percentage of students in the low risk category was increasing from fall to spring, and the percentage of students in the high risk category was decreasing from fall to spring.

Decreasing benchmark scores signifies the percentage of low risk students is decreasing and/or the percentage of high risk students were increasing from fall to spring. No change in benchmark scores means there was no change in percentage of low and high risk students from fall to spring, or there was some change in percentage for either low risk or high risk, but not both. These three groups were determined for three different time periods: year one (2011-12), year two (2012-13), and fall of year one (2011) to spring of year two (2013). Survey questions using a Likert scale were analyzed by comparing different measurements of central tendencies (mean, median, mode, and range) to find patterns or trends in answers to these questions based on the literacy outcomes of the different schools over the three periods of time. Because the number of survey participants was small $(N=18)$, statistics were not used to determine any differences. The mean, mode, range and standard deviation of Likert questions was observed to determine if any generalizations could come from the data. Some Likert scale questions focused on the work of the coaches in year one compared to year two were analyzed using a dependent $t$-test to determine if any statistical significance was 


\section{SCHOOL REFORM AND COACHING}

observed between perceived changes between years one and two. Closed questions that had categorical answers were not analyzed statistically. Those answers were observed in

relation to the respondent groups mentioned previously. The surveys were also separated based on the question "Do you feel your work as a coach was a success?" Participants could select 'yes', 'not sure', or 'no'. The answer to this question was used to compare the answers to other questions in the survey using cross-tabulations. I looked for patterns in the categories compared to the feeling of success coaches had during the duration of the initiative.

Coding. The open-ended questions were grouped based on the literacy benchmarking data. I identified three groups based on the decision rules in Table 4: schools with increases in benchmarking scores, schools with no change in benchmarking scores, and schools with decreases in benchmarking scores. The open-ended questions on the survey were coded. First cycle coding used descriptive coding methods (Saldaña, 2009) to look for overarching patterns and trends in the answers to the survey questions. Second cycle coding was used to find larger patterns and trends in answers to the survey questions to lead to some claims about the experiences of the coaches (Saldaña, 2009). The experiences were compared between the three groups to determine what factors contributed to the implementation of the data informed decision-making initiative. 


\section{SCHOOL REFORM AND COACHING}

\section{Table 4}

Decision Rules for Placement of Schools into Changes in Benchmarking Score Categories

\begin{tabular}{|c|c|c|c|c|}
\hline Category & Decision Rules & \multicolumn{3}{|c|}{ Example } \\
\hline \multirow{9}{*}{$\begin{array}{l}\text { Increases in } \\
\text { Literacy } \\
\text { Benchmark } \\
\text { Scores }\end{array}$} & \multirow{2}{*}{$\begin{array}{l}\text { Increases in Low Risk percentage is } \\
\text { greater than } 2 \%\end{array}$} & & Fall & Spring \\
\hline & & Low & $45.3 \%$ & $52.1 \%$ \\
\hline & \multirow{2}{*}{$\begin{array}{l}\text { Decreases in High Risk percentage is } \\
\text { greater than } 2 \%\end{array}$} & High & $25.9 \%$ & $23.1 \%$ \\
\hline & & \multicolumn{3}{|c|}{ Both changes are $>2 \%$} \\
\hline & \multirow{5}{*}{$\begin{array}{l}\text { OR } \\
\text { Either an increase in low risk or decrease } \\
\text { in high risk is greater than } 5 \% \text { and the } \\
\text { other change is less than } 2 \% \text { but still } \\
\text { showing an increase }\end{array}$} & & & \\
\hline & & & Fall & Spring \\
\hline & & Low & $37.8 \%$ & $38.2 \%$ \\
\hline & & High & $45.6 \%$ & $35.4 \%$ \\
\hline & & \multicolumn{3}{|c|}{ Low risk not $>2 \%$ and High Risk $>5 \%$} \\
\hline \multirow{12}{*}{$\begin{array}{l}\text { No Change } \\
\text { in Literacy } \\
\text { Benchmark } \\
\text { Scores }\end{array}$} & & & Fall & Spring \\
\hline & \multirow{3}{*}{$\begin{array}{l}\text { Increase in Low Risk percentage is not } \\
\text { greater and } 2 \% \\
\text { Decrease in High Risk percentage is not } \\
\text { greater than } 2 \%\end{array}$} & Low & $45.3 \%$ & $45.6 \%$ \\
\hline & & High & $25.9 \%$ & $25.0 \%$ \\
\hline & & \multicolumn{3}{|c|}{ Both changes are $<2 \%$} \\
\hline & \multirow{4}{*}{$\begin{array}{l}\text { OR } \\
\text { Increase in Low Risk or decrease in } \\
\text { Risk is less than } 2 \% \text { but the other } \\
\text { percentage change is less than } 5 \% \\
\text { OR }\end{array}$} & & Fall & Spring \\
\hline & & Low & $37.8 \%$ & $38.2 \%$ \\
\hline & & High & $45.6 \%$ & $41.8 \%$ \\
\hline & & \multicolumn{3}{|c|}{ Low is $<2 \%$ and High is not $>5 \%$} \\
\hline & \multirow{4}{*}{$\begin{array}{l}\text { Either an increase in low risk or decrease } \\
\text { in high risk is greater than } 5 \% \text { and the } \\
\text { other change is either an increase in high } \\
\text { risk or a decrease in low risk percentages } \\
\text { not greater than } 2 \%\end{array}$} & & Fall & Spring \\
\hline & & Low & $56.2 \%$ & $55.4 \%$ \\
\hline & & High & $35.2 \%$ & $26.7 \%$ \\
\hline & & \multicolumn{3}{|c|}{ Low is decreasing but $<2 \%$ and High $>5 \%$} \\
\hline \multirow{8}{*}{$\begin{array}{l}\text { Decrease in } \\
\text { Literacy } \\
\text { Benchmark } \\
\text { Scores }\end{array}$} & \multirow{4}{*}{$\begin{array}{l}\text { Decrease in Low Risk percentage is more } \\
\text { than } 2 \% \\
\text { Increase in High Risk percentage is more } \\
\text { than } 2 \% \\
\text { OR }\end{array}$} & & Fall & Spring \\
\hline & & Low & $45.3 \%$ & $40.6 \%$ \\
\hline & & High & $25.9 \%$ & $33.2 \%$ \\
\hline & & \multicolumn{3}{|c|}{ Both changes are $<2 \%$} \\
\hline & \multirow{4}{*}{$\begin{array}{l}\text { Either an increase in low risk or decrease } \\
\text { in high risk is greater than } 5 \% \text { and the } \\
\text { other change is either an increase in high } \\
\text { risk or a decrease in low risk percentages } \\
\text { and is greater than } 2 \%\end{array}$} & & Fall & Spring \\
\hline & & Low & $37.8 \%$ & $43.9 \%$ \\
\hline & & High & $45.6 \%$ & $55.2 \%$ \\
\hline & & \multicolumn{3}{|c|}{$\begin{array}{l}\text { Low is increasing }>5 \% \text { but High is also } \\
\text { increasing }>5 \%\end{array}$} \\
\hline
\end{tabular}

Interviews. The interviews were recorded and transcribed. First cycle coding involved multiple coding methods. First, I collected attribute coding during the 


\section{SCHOOL REFORM AND COACHING}

interview. This coding gave some information about each participant including demographic information and setting of the interview. After transcription, structural coding was completed on all of the interviews. The codes used for structural coding were "supports," "structures," and "implementation." These codes relate directly back to my research questions, so they were used to ensure there was enough information on each of the broad topics being researched. Then, I completed an analytic memo to synthesize my thinking about each of the interviews. Next, I coded the interview data using descriptive coding methods. Topics were included in the margins and analytic memos were completed after each interview was coded. After the descriptive coding, I examined the coach and principal interviews for each school together. I re-read and coded those interviews as a group and completed another analytic memo. Finally, I read the coach interviews and completed an analytic memo, and then I read the principal interviews and completed another analytic memo. In between first and second cycle coding, I created wordles (wordless.net) of each interviewee's codes. I then combine the coach codes and the principal codes to create a wordle for the coaches and another for the principals.

During second cycle coding, I looked for patterns and trends within the first cycle coding. Descriptive coding was used to develop major categories of ideas from the interviews. These major categories were compared with each other and consolidated to find the themes and then identify the key assertions from the data (Saldaña, 2009). These key assertions were used to make some generalizable predictions of what supports are needed for the successful implementation of a coaching program working to improve teachers' data informed decision-making in the classroom. 


\section{SCHOOL REFORM AND COACHING}

The first cycle coding of the surveys occurred before the interviews were completed and coded. The second cycle of coding of the surveys was completed after the interview coding was completed. The process of coding the interviews and surveys in this way allowed me to see how the findings from the interviews of coaches and principals in buildings with statistically significant increases in student literacy benchmark data compared to the findings from other schools with increases and contrast those findings with the schools where no change was seen in literacy benchmark scores. This iterative process confirmed the findings and coding from the interviews matched the findings and coding in the survey. This process also allowed me to make more definitive statements about what structures and factors were needed for coaches because the survey data provided some insight into structures and factors that were lacking in some of the schools were coaches attempted to implement the initiative.

\section{Timeline for Study}

This study was completed during the 2014-15 school year. Phase I data was obtained, collected, and analyzed by the end of February 2015. Interviews were completed in March and interview data was also analyzed in March 2015. Because the coach project was completed at the end of the 2012-13 school year, it was imperative to complete this study as quickly as possible to ensure individuals' memory of events were as accurate as possible.

\section{Summary}

This study used a sequential mixed-methods approach to determine the structures and supports needed to successfully implement a coaching program focused on 


\section{SCHOOL REFORM AND COACHING}

increasing teachers' use of data informed decision-making in their instruction. The methods of data collection were an archival data set, a survey of the coaches, and one-onone interviews with coaches and principals in schools that were purposively selected based on benchmark data and survey results. The quantitative data from the benchmarking tool was analyzed using multiple Pearson $\chi^{2}$ tests. The surveys were analyzed using demographic data analysis (quantitative) and descriptive coding for the open-ended survey questions. Finally, the individual interviews were analyzed using descriptive coding. The validity, reliability, and researcher bias were considered during each phase of the data collection and analysis. 


\section{SCHOOL REFORM AND COACHING}

\section{Chapter 4}

\section{Results}

The purpose of this study was to determine what organizational structures were needed for a coach to implement a data informed decision-making initiative successfully. Three data sets were used to determine what organizational structures were needed: literacy benchmarking data, survey of coaches, and interviews of coaches and principals. The literacy benchmarking data and the survey of coaches led to a purposive selection of the coaches and principals to be interviewed. The research questions were: (a) which urban schools showed increases in students' literacy benchmarking scores; (b) what did the coach perceive as the significant structures that led to the implementation of the data informed decision-making model; (c) what did the principal perceive as the significant structures that led to the implementation of the data informed decision-making model; and (d) what factors within the structure of the organization supported the coach in implementing the data informed decision-making model. Each of the research questions was answered using data from one or more sets of data (see Table 5). The results of the data analysis, interpretations of findings, and limitations of the study will be discussed in this chapter.

\section{Literacy Benchmarking Data Results}

In the Columbia School District, 20 schools were allocated district funding for a coach during the two years of the project. The primary job responsibility of the coach was to help teachers complete a cycle of data inquiry, using multiple data points, including literacy benchmark data to create action plans focused on students with specific 


\section{SCHOOL REFORM AND COACHING}

skill needs. This included working with teachers to complete literacy benchmarking assessments from Kindergarten to grade eight. Coaches then worked with teachers to use Response to Intervention (RtI) to tier students into interventions. Finally, coaches ran data team meetings with grade level teacher groups to look at all of the data, identify a sub-set of students, and create action plans to help those students increase their literacy skills. The literacy benchmarking tool used for grades four to eight was easyCBM.

Table 5

\section{Research questions and data used}

\begin{tabular}{ll}
\hline Research Question & Data Used \\
\hline 1. $\begin{array}{l}\text { Which urban schools showed increases in students' literacy } \\
\text { benchmarking scores? }\end{array}$ & $\begin{array}{l}\text { easyCBM literacy benchmark } \\
\text { data gr. 4-8 for all schools }\end{array}$ \\
$\begin{array}{l}\text { 2. } \begin{array}{l}\text { What did the coach perceive as the significant structures that } \\
\text { led to the implementation of the data informed decision- } \\
\text { making model? }\end{array} \\
\text { survey and coach interviews }\end{array}$ \\
$\begin{array}{l}\text { 3. What did the principal perceive as the significant structures } \\
\text { that led to the implementation of the data informed decision- } \\
\text { making model? }\end{array}$ & principal interviews \\
$\begin{array}{l}\text { What factors within the structure of the organization } \\
\text { supported the coach in implementing the data informed } \\
\text { decision-making model }\end{array}$ & $\begin{array}{l}\text { survey and coach/principal } \\
\text { interviews }\end{array}$ \\
\hline
\end{tabular}

The easyCBM literacy benchmarking occurred three times a year-fall, winter, and spring. These scores were recorded for each student. Each score was recorded for each student in a different row in the data file obtained from the district. There were 12,338 separate benchmarking scores. One student could, potentially, have six separate rows of data. The statistical analysis used to determine which schools had statistically significant gains was the Pearson $\chi^{2}$ test. The Pearson $\chi^{2}$ test does not consider an individual student's score across the two-year period. The statistical analysis does 


\section{SCHOOL REFORM AND COACHING}

assume that each student has no more than one score for each of the benchmarking periods. This assumption is accurate in this data set.

Fall 2011 to spring 2013. The first data set that was examined was the change in literacy benchmark scores over the two-year period of the project. Descriptive statistics were used to determine which schools had increases in literacy benchmark scores over the two-year period (see Table 6). After the descriptive statistics were examined, a Pearson $\chi^{2}$ test was completed to determine which schools had statistically significant increases in student benchmark scores. Each benchmarking period has three separate scores to consider-low, some, or high risk. Increased literacy benchmark scores was twofold: (a) an increased percentage of students in the low risk category from fall to spring and (b) a decreased percentage of students in the high risk category from fall to spring. Using the decision rules outlined earlier (see Table 5), nine schools (Amity, Chehalem Mountain, Hazel Hill, Naches, Owl Creek, Red Hill, Snipes Mountain, Umpqua Valley, and Wahluke) had increases in literacy benchmark scores; eight schools (Applegate, Carlton, Chelan, Goose Ridge, Meridian, Red Mountain, Ribbon Ridge, and Rogue) had no change in scores; and three schools (Elkton, Walla Walla, and Willakenzie) had decreases in literacy benchmark scores. Understanding which schools had increases in literacy benchmark scores was helpful in creating a purposive selection of coaches and principals to be interviewed, but I also wanted to determine if any of the schools had statistically significant increases in benchmark risk ratings over the two year period. 


\section{SCHOOL REFORM AND COACHING}

\section{Table 6}

Descriptive Statistics Fall 2011 to Spring 2013

\begin{tabular}{|c|c|c|c|c|}
\hline School & Risk Rating & Fall & Spring & Change \\
\hline \multirow{2}{*}{ Amity* } & High & $31.6 \%$ & $28.6 \%$ & $-3.00 \%$ \\
\hline & Low & $36.8 \%$ & $41.1 \%$ & $4.30 \%$ \\
\hline \multirow{2}{*}{ Applegate** } & High & $33.7 \%$ & $34.6 \%$ & $0.90 \%$ \\
\hline & Low & $34.0 \%$ & $35.1 \%$ & $1.10 \%$ \\
\hline \multirow{2}{*}{ Carlton** } & High & $23.8 \%$ & $22.2 \%$ & $-1.60 \%$ \\
\hline & Low & $42.1 \%$ & $44.4 \%$ & $2.30 \%$ \\
\hline Chehalem & High & $43.4 \%$ & $38.4 \%$ & $-5.00 \%$ \\
\hline Mountain* & Low & $28.3 \%$ & $29.1 \%$ & $0.80 \%$ \\
\hline \multirow{2}{*}{ Chelan** } & High & $49.2 \%$ & $50.4 \%$ & $1.20 \%$ \\
\hline & Low & $17.5 \%$ & $17.9 \%$ & $0.40 \%$ \\
\hline \multirow{2}{*}{ Elkton*** } & High & $31.5 \%$ & $31.1 \%$ & $-0.40 \%$ \\
\hline & Low & $37.4 \%$ & $29.5 \%$ & $-7.90 \%$ \\
\hline \multirow{2}{*}{ Goose Ridge** } & High & $41.5 \%$ & $36.8 \%$ & $-4.70 \%$ \\
\hline & Low & $27.0 \%$ & $28.3 \%$ & $1.30 \%$ \\
\hline \multirow{2}{*}{ Hazel Hill* } & High & $32.1 \%$ & $25.2 \%$ & $-6.90 \%$ \\
\hline & Low & $35.4 \%$ & $47.6 \%$ & $12.20 \%$ \\
\hline \multirow{2}{*}{ Meridian** } & High & $40.7 \%$ & $40.3 \%$ & $-0.40 \%$ \\
\hline & Low & $27.9 \%$ & $29.8 \%$ & $1.90 \%$ \\
\hline \multirow{2}{*}{ Naches* } & High & $36.1 \%$ & $32.7 \%$ & $-3.40 \%$ \\
\hline & Low & $34.3 \%$ & $40.0 \%$ & $5.70 \%$ \\
\hline \multirow{2}{*}{ Owl Creek* } & High & $34.2 \%$ & $28.5 \%$ & $-5.70 \%$ \\
\hline & Low & $36.5 \%$ & $41.8 \%$ & $5.30 \%$ \\
\hline \multirow{2}{*}{ Red Hill* } & High & $29.2 \%$ & $25.5 \%$ & $-3.70 \%$ \\
\hline & Low & $40.5 \%$ & $43.9 \%$ & $3.40 \%$ \\
\hline \multirow{2}{*}{ Red Mountain** } & High & $30.3 \%$ & $31.7 \%$ & $1.40 \%$ \\
\hline & Low & $35.8 \%$ & $36.6 \%$ & $0.80 \%$ \\
\hline \multirow{2}{*}{ Ribbon Ridge** } & High & $32.3 \%$ & $30.3 \%$ & $-2.00 \%$ \\
\hline & Low & $43.3 \%$ & $42.8 \%$ & $-0.50 \%$ \\
\hline \multirow{2}{*}{$\operatorname{Rogue}^{* *}$} & High & $32.3 \%$ & $34.1 \%$ & $1.80 \%$ \\
\hline & Low & $35.4 \%$ & $32.9 \%$ & $-2.50 \%$ \\
\hline \multirow{2}{*}{ Snipes Mountain* } & High & $27.4 \%$ & $24.6 \%$ & $-2.80 \%$ \\
\hline & Low & $38.5 \%$ & $41.2 \%$ & $2.70 \%$ \\
\hline \multirow{2}{*}{ Umpqua Valley* } & High & $40.1 \%$ & $33.8 \%$ & $-6.30 \%$ \\
\hline & Low & $20.3 \%$ & $24.7 \%$ & $4.40 \%$ \\
\hline \multirow{2}{*}{ Wahluke* } & High & $32.6 \%$ & $26.5 \%$ & $-6.10 \%$ \\
\hline & Low & $38.4 \%$ & $41.4 \%$ & $3.00 \%$ \\
\hline \multirow{2}{*}{ Walla Walla*** } & High & $27.6 \%$ & $34.4 \%$ & $6.80 \%$ \\
\hline & Low & $33.3 \%$ & $33.3 \%$ & $0.00 \%$ \\
\hline \multirow{2}{*}{ Willakenzie**** } & High & $17.7 \%$ & $24.3 \%$ & $6.60 \%$ \\
\hline & Low & $59.7 \%$ & $51.2 \%$ & $-8.50 \%$ \\
\hline
\end{tabular}




\section{SCHOOL REFORM AND COACHING}

\section{Table 7}

Pearson $\chi^{2}$ Test Fall 2011 to Spring 2013

\begin{tabular}{lccl}
\hline School & value & df & p-value \\
\hline Amity & 0.686 & 2 & 0.710 \\
Applegate & 0.431 & 2 & 0.806 \\
Carlton & 0.437 & 2 & 0.804 \\
Chehalem Mountain & 0.598 & 2 & 0.742 \\
Chelan & 1.112 & 2 & 0.774 \\
Elkton & 8.067 & 2 & $0.018^{*}$ \\
Goose Ridge & 3.032 & 2 & 0.220 \\
Hazel Hill & 7.960 & 2 & $0.019^{*}$ \\
Meridian & 0.458 & 2 & 0.795 \\
Naches & 2.591 & 2 & 0.459 \\
Owl Creek & 3.083 & 2 & 0.214 \\
Red Hill & 0.825 & 2 & 0.662 \\
Red Mountain & 0.357 & 2 & 0.837 \\
Ribbon Ridge & 0.669 & 2 & 0.716 \\
Rogue & 0.216 & 2 & 0.898 \\
Snipes Mountain & 0.947 & 2 & 0.623 \\
Umpqua Valley & 2.221 & 2 & 0.329 \\
Wahluke & 2.919 & 2 & 0.232 \\
Walla Walla & 1.261 & 2 & 0.532 \\
Willakenzie & 11.773 & 2 & $0.003^{* *}$ \\
Total & 3.791 & 3 & 0.285 \\
\hline$*$ p $<0.05 * * p<01$ & & & \\
& & &
\end{tabular}

Pearson $\chi^{2}$ Test. To determine if there were any statistical differences in the change of literacy benchmark scores, Pearson $\chi^{2}$ tests were run for each school over the two-year initiative (fall 2011 to spring 2013). This analysis was completed first to determine which schools had statistically significant differences between the expected frequencies and the actual frequencies for the duration of the initiative. Three schools 


\section{SCHOOL REFORM AND COACHING}

had statistically significant differences between the fall 2011 and the spring 2013 literacy benchmarking periods: Hazel Hill, Willakenzie, and Elkton schools (see Table 7).

Looking more closely at the descriptive statistics of the three schools with statistically significant differences, I analyzed more information in an attempt to determine why the frequencies were statistically significant (see Table 8). Elkton School tested 680 students in fall 2011 and tested 315 in spring 2013. The percentage of Low Risk students in spring 2013 (29.5\%) decreased from the percentage of Low Risk in fall 2011 (37.4\%). The descriptive statistics showed that Elkton School did not have statistically significant growth in the two-year period. There could be a number of reasons for the statistically significant decline in expected frequencies including the large change in the $N$ from fall $2011(N=680)$ to spring $2013(N=315)$. Willakenzie School's descriptive statistics also showed the statistical significance measured by the Pearson $\chi^{2}$ test was not due to increases in low risk student percentages from fall $2011(59.7 \%)$ to spring 2013 (51.2\%). Again, the $N$ varied from fall $2011(N=826)$ to spring $2013(N=$ 543). Hazel Hill showed statistically significant increases in low risk students (fall $=$ $35.4 \%$; spring $=47.6 \%$ ) and decreases in high risk students (fall $2011=32.1 \%$; spring $2013=25.2 \%)$. Based on the Pearson $\chi^{2}$ test and descriptive statistics, Hazel Hill School was considered for further research.

Literacy benchmark scores by year. The second set of Pearson $\chi^{2}$ tests consist of each school's year one (fall 2011 to spring 2012) and year two (fall 2012 to spring 2013) literacy benchmark scores being analyzed separately. The same data set was used $(N=12,338)$, and the same assumptions were made from the data. In year one, only 


\section{SCHOOL REFORM AND COACHING}

Elkton School $(\mathrm{p}=0.041)$ had statistically significant differences between expected and actual frequencies using the Pearson $\chi^{2}$ test (see Table 9). Two schools, Willakenzie ( $\mathrm{p}<$ 0.00) and Owl Creek $(\mathrm{p}<0.00)$ had statistically significant differences in year two (see

Table 7). Using descriptive statistics, Elkton's 2011-2012 literacy benchmark scores did not show increases among students in the low risk category from fall of 2011 to spring of 2012 (see Table 10).

Table 8

Descriptive Statistics Elkton, Hazel Hill, and Willakenzie schools

\begin{tabular}{|c|c|c|c|c|c|}
\hline \multirow[b]{2}{*}{ School } & & \multirow[b]{2}{*}{ Risk } & & \multicolumn{2}{|c|}{ Test Window } \\
\hline & & & & Fall 2011 & Spring 2013 \\
\hline \multirow[t]{7}{*}{ Elkton } & & Low & Count & 254 & 93 \\
\hline & & & $\%$ within Test Window & $37.4 \%$ & $29.5 \%$ \\
\hline & & Some & Count & 212 & 124 \\
\hline & & & $\%$ within Test Window & $31.2 \%$ & $39.4 \%$ \\
\hline & & High & Count & 214 & 98 \\
\hline & & & $\%$ within Test Window & $31.5 \%$ & $31.1 \%$ \\
\hline & Total & & & 680 & 315 \\
\hline \multirow[t]{7}{*}{ Hazel Hill } & & Low & Count & 74 & 166 \\
\hline & & & $\%$ within Test Window & $35.4 \%$ & $47.6 \%$ \\
\hline & & Some & Count & 68 & 95 \\
\hline & & & $\%$ within Test Window & $32.5 \%$ & $27.2 \%$ \\
\hline & & High & Count & 67 & 88 \\
\hline & & & $\%$ within Test Window & $32.1 \%$ & $25.2 \%$ \\
\hline & Total & & & 209 & 349 \\
\hline \multirow[t]{7}{*}{ Willakenzie } & & Low & Count & 493 & 278 \\
\hline & & & $\%$ within Test Window & $59.7 \%$ & $51.2 \%$ \\
\hline & & Some & Count & 187 & 133 \\
\hline & & & $\%$ within Test Window & $22.6 \%$ & $24.5 \%$ \\
\hline & & High & Count & 146 & 132 \\
\hline & & & $\%$ within Test Window & $17.7 \%$ & $24.3 \%$ \\
\hline & Total & & & 826 & 543 \\
\hline
\end{tabular}

When comparing fall 2012 to spring of 2013, Willakenzie had an increase in the percentage of high risk students $($ fall $=19.7 \%$; spring $=24.8 \%)$ and a decrease in 


\section{SCHOOL REFORM AND COACHING}

percentage of low risk students $($ fall $=56.8 \%$; spring $=51.0 \%)$. At Willakenzie, the number of students who took the literacy benchmarking assessment in fall $2012(N=$ 826) was higher than the number who took it in the spring $2013(N=543)$. Further research would be needed to determine why there were statistically significant decreases in literacy benchmark scores and why there was such a large difference in the number of participants over the course of a single school year.

Table 9

Pearson $\chi^{2}$ Tests Fall 2011 to Spring 2012 and Fall 2012 to Spring 2013

\begin{tabular}{|c|c|c|c|c|}
\hline \multirow[b]{2}{*}{ School } & \multicolumn{2}{|c|}{$2011-2012$} & \multicolumn{2}{|c|}{$2012-2013$} \\
\hline & value & $\mathrm{p}$-value & value & p-value \\
\hline Amity & 0.793 & 0.673 & 0.601 & 0.741 \\
\hline Applegate & 0.548 & 0.760 & 0.399 & 0.819 \\
\hline Carlton & 0.227 & 0.893 & 0.939 & 0.625 \\
\hline Chehalem Mountain & 0.257 & 0.879 & 0.883 & 0.643 \\
\hline Chelan & 1.112 & 0.774 & - & - \\
\hline Elkton & 6.390 & $0.041 *$ & - & - \\
\hline Goose Ridge & 1.861 & 0.394 & 2.363 & 0.307 \\
\hline Hazel Hill & 5.046 & 0.080 & 1.034 & 0.596 \\
\hline Meridian & 1.636 & 0.441 & 0.861 & 0.65 \\
\hline Naches & 2.104 & 0.551 & 4.760 & 0.093 \\
\hline Owl Creek & 1.068 & 0.586 & 18.147 & $0.000 * *$ \\
\hline Red Hill & 1.699 & 0.428 & 4.215 & 0.122 \\
\hline Red Mountain & 1.109 & 0.574 & 0.729 & 0.695 \\
\hline Ribbon Ridge & 0.943 & 0.624 & 0.052 & 0.975 \\
\hline Rogue & - & - & 1.710 & 0.425 \\
\hline Snipes Mountain & 0.604 & 0.739 & 0.716 & 0.699 \\
\hline Umpqua Valley & 0.367 & 0.832 & 2.057 & 0.357 \\
\hline Wahluke & 2.569 & 0.277 & 2.319 & 0.314 \\
\hline Walla Walla & 1.261 & 0.532 & - & - \\
\hline Willakenzie & 5.306 & 0.070 & 45.804 & $0.000 * *$ \\
\hline Total & 2.996 & 0.392 & 0.901 & 0.637 \\
\hline
\end{tabular}




\section{SCHOOL REFORM AND COACHING}

Owl Creek School had decreases in the percentage of students in the high risk category (fall $2012=46.8 \%$; spring $2013=27.3 \%$ ) as well as increases in the percentage of students who were low risk (fall $2012=24.7 \%$; spring $2013=41.0 \%$ ). The percent of some risk student remained consistent $($ fall $=29.2 \%$; spring $=29.7 \%)$. The results of the Pearson $\chi^{2}$ test shows statistically significant outcomes for Owl Creek School, and the descriptive statistics showed the changes in scores to be increases in low risk students and decreases in high risk students (see Table 10). Because of the increased low risk scores and decreased high risk scores, Owl Creek was considered as a site for further research.

Table 10

Descriptive Statistics Elkton (year 1), Owl Creek (year 2), and Willakenzie (year 2) schools

\begin{tabular}{|c|c|c|c|c|c|}
\hline \multirow{2}{*}{ School } & & \multirow[b]{2}{*}{ Risk } & & \multicolumn{2}{|c|}{ Test Window } \\
\hline & & & & Fall & Spring \\
\hline \multirow{7}{*}{ Elkton } & & Low & Count & 152 & 93 \\
\hline & & & $\%$ within Test Window & $34.9 \%$ & $29.5 \%$ \\
\hline & & Some & Count & 133 & 124 \\
\hline & & & $\%$ within Test Window & $30.6 \%$ & $39.4 \%$ \\
\hline & & High & Count & 150 & 98 \\
\hline & & & $\%$ within Test Window & $34.5 \%$ & $31.1 \%$ \\
\hline & Total & & & 435 & 315 \\
\hline \multirow[t]{7}{*}{ Owl Creek } & & Low & Count & 19 & 88 \\
\hline & & & $\%$ within Test Window & $24.7 \%$ & $41.0 \%$ \\
\hline & & Some & Count & 22 & 55 \\
\hline & & & $\%$ within Test Window & $28.6 \%$ & $29.9 \%$ \\
\hline & & High & Count & 36 & 41 \\
\hline & & & $\%$ within Test Window & $46.8 \%$ & $22.3 \%$ \\
\hline & Total & & & 77 & 184 \\
\hline \multirow[t]{7}{*}{ Willakenzie } & & Low & Count & 176 & 3 \\
\hline & & & $\%$ within Test Window & $56.8 \%$ & $51.0 \%$ \\
\hline & & Some & Count & 73 & 12 \\
\hline & & & $\%$ within Test Window & $23.5 \%$ & $24.2 \%$ \\
\hline & & High & Count & 61 & 26 \\
\hline & & & $\%$ within Test Window & $19.7 \%$ & $24.8 \%$ \\
\hline & Total & & & 310 & 41 \\
\hline
\end{tabular}




\section{SCHOOL REFORM AND COACHING}

Literacy benchmark scores by grade. The final statistical analysis included grade level Pearson $\chi^{2}$ tests. Each grade level was analyzed for statistical significance during the duration of the project (2011-2013). This analysis was completed to determine if there were any other schools to consider for further research (see Table 11). The only other school that showed statistically significant difference in grade-level data was grade four at Applegate School $(\mathrm{p}<0.05)$. Looking at the descriptive statistics, Applegate's statistical significance shows increases in literacy benchmark scores. High risk student percentages stayed the same (fall $=40.5 \%$; spring $=40.6 \%$ ), but the low risk student percentage increased significantly $($ fall $=14.9 \%$; spring $=31.3 \%)$. All other grade-level significance occurred at the schools previously discussed at the school-wide level (Hazel Hill, Willakenzie, and Elkton).

Findings. Using the Pearson $\chi^{2}$ tests, the two schools with statistically significant increases in student literacy benchmark scores during data informed decision making initiative were Hazel Hill (fall 2011 to spring 2013, p = 0.018) and Owl Creek (fall 2012 to spring $2013, \mathrm{p}<0.000)$. Other schools saw statistically significant differences between expected and actual frequencies, but examination of the descriptive statistics showed the number of low risk students was not increasing. Further research would be needed to determine the sources of theses statistical differences such as variances in testing protocols, literacy instruction, and/or some other factor.

Purposive selection. Looking at the literacy benchmark data over the course of the two years of the project, I found two schools that had statistically significant increases in the literacy benchmark scores for their students in grades four through eight. Hazel 


\section{SCHOOL REFORM AND COACHING}

Hill had statistically significant increases over the two years of the project $(p=0.019)$.

Owl Creek had statistically significant increases in literacy benchmark scores in the second year $(2012-2013)$ of the project $(\mathrm{p}<0.001)$. Both of these schools had coaches who completed the survey, so survey analysis allowed me to determine if those coaches and principals would be good candidates for the interview portion of the research. I analyzed the survey results to identify patterns or trends between schools with increases in benchmark scores, statistically significant or not, and those with no changes or decreases.

\section{Survey Results}

All coaches were asked to participate in the survey (see Appendix B). At some point in the two-year initiative, there were 23 teachers who served as coaches in one or more of the 20 schools. Of the 23 coaches, 18 completed the survey, three did not complete, and one declined to participate. The survey included four sectionsdemographics, job responsibilities, school climate, and structures. In the following sections, I review the results of each of the survey sections and provide an analysis of the surveys completed by the coaches at the schools with statistical significant differences based on the Pearson $\chi^{2}$ test results. Subsequently, I report the results of the interviews, which explored the structures and supports found in schools that helped the coach implement the data informed decision-making initiative. 


\section{SCHOOL REFORM AND COACHING}

Table 11

Grade Level Pearson $\chi^{2}$ Test Fall 2011 to Spring 2013

\begin{tabular}{lccccccccccc}
\hline & \multicolumn{2}{c}{$4^{\text {th }}$ Grade } & \multicolumn{2}{c}{$5^{\text {th }}$ Grade } & \multicolumn{2}{c}{$6^{\text {th }}$ Grade } & \multicolumn{2}{c}{$7^{\text {th }}$ Grade } & \multicolumn{2}{c}{$8^{\text {th }}$ Grade } \\
School & Value & p-value & Value & p-value & Value & p-value & Value & p-value & Value & p-value \\
\hline Amity & 1.774 & 0.412 & 2.62 & 0.27 & - & - & - & - & - & - \\
Applegate & 8.71 & $0.013^{*}$ & 2.085 & 0.353 & 1.013 & 0.602 & 0.033 & 0.984 & 0.660 & 0.719 \\
Carlton & 0.361 & 0.835 & 0.561 & 0.755 & - & - & - & - & - & - \\
Chehalem Mtn & 0.717 & 0.699 & 0.074 & 0.964 & - & - & - & - & - & - \\
Chelan & 1.174 & 0.759 & 0.996 & 0.608 & - & - & - & - & - & - \\
Elkton & - & - & - & - & 1.393 & 0.498 & 10.30 & $0.006^{*}$ & 11.927 & $0.003 * *$ \\
Goose Ridge & - & - & - & - & 2.456 & 0.293 & 1.809 & 0.405 & 0.532 & 0.766 \\
Hazel Hill & 5.600 & 0.061 & 9.319 & $0.009 *$ & 4.818 & 0.090 & 6.128 & $0.047^{*}$ & 0.494 & 0.781 \\
Meridian & 0.540 & 0.764 & 4.51 & 0.105 & 0.501 & 0.778 & 0.710 & 0.701 & 2.484 & 0.289 \\
Naches & 3.987 & 0.136 & 6.915 & 0.075 & 3.64 & 0.162 & - & - & - & - \\
Owl Creek & 1.511 & 0.470 & 0.425 & 0.809 & 0.56 & 0.756 & 4.083 & 0.130 & 0.545 & 0.761 \\
Red Hill & 0.617 & 0.734 & 0.49 & 0.783 & - & - & - & - & - & - \\
Red Mountain & 1.264 & 0.531 & 0.298 & 0.862 & 1.215 & 0.545 & 2.203 & 0.332 & 2.387 & 0.303 \\
Ribbon Ridge & 0.350 & 0.840 & 0.478 & 0.787 & 0.408 & 0.816 & 0.209 & 0.901 & 0.541 & 0.763 \\
Rogue & 0.096 & 0.953 & 3.027 & 0.220 & 0.494 & 0.781 & 3.470 & 0.176 & & \\
Snipes Mtn & 0.006 & 0.997 & 0.059 & 0.971 & 0.444 & 0.801 & 2.274 & 0.321 & 1.819 & 0.403 \\
Umpqua Vly & 1.234 & 0.539 & 3.266 & 0.195 & 3.457 & 0.178 & 0.68 & 0.712 & 2.402 & 0.301 \\
Wahluke & 1.176 & 0.555 & 0.439 & 0.803 & 1.667 & 0.435 & 1.445 & 0.486 & 2.628 & 0.269 \\
Walla Walla & 0.749 & 0.688 & 2.228 & 0.328 & 0.448 & 0.799 & 2.57 & 0.277 & 3.831 & 0.147 \\
Willakenzie & - & - & - & - & 1.128 & 0.569 & 27.907 & $0.00^{*}$ & 0.423 & 0.809 \\
Total & 7.563 & $0.056 *$ & 8.543 & $0.036 *$ & 0.262 & 0.877 & 30.369 & $0.00^{*}$ & 0.026 & 0.987 \\
\hline NOTE: - indicates a grade level where data is not available because the school does not have students in those grade \\
levels. *p < 0.05 & & & & & & & & & &
\end{tabular}

Demographic information. The demographic information collected included

demographics about the coach and the school during the time of the data informed

decision-making work. The coaches also provided some information about their current position and school location. Coaches were asked about their experience before, during, and after the initiative. The information spanned the experience and structures from 


\section{SCHOOL REFORM AND COACHING}

when the coach positions were put in place, and included the coach's understanding of what is currently happening in the building where they served as a coach.

Coaches. Every coach had at least four years of teaching experience (see Table 12). Twelve of the 18 who responded to the question had 10 or more years of teaching experience. Five coaches did not have any experience teaching fourth to eighth grade, and eight coaches were new to the school where they coached. One coach reported to have zero years of experience in teaching reading. Eleven of the 18 respondents had been teaching in the building where they became the coach. Only three of those eleven served as a reading and/or instructional coach before the beginning of the initiative, and the majority (10 of the 15 respondents) were classroom teachers before taking the coach role. One teacher had 20 or more years of teaching experience in the building where s/he was the coach. All other coaches had not been in the same building for more than nine years. Of the 18 coaches who completed the survey, 12 were certified to teach elementary school, 10 had a reading endorsement, four were licensed to teach special education, six were endorsed in English as a Second Language (ESL), and eight were licensed to teach in the middle level, grades five through nine (see Table 13).

Table 12

Years of Experience Teaching Before Coaching

\begin{tabular}{lllllll}
\hline Type of experience & 0 & $1-3$ & $4-5$ & $6-9$ & $10-19$ & $20+$ \\
& years & years & years & years & years & years \\
\hline Teaching & 0 & 0 & 2 & 4 & 8 & 4 \\
Teaching reading & 1 & 1 & 4 & 4 & 6 & 2 \\
Teaching $4^{\text {th }}$ to $8^{\text {th }}$ grade & 5 & 1 & 1 & 3 & 6 & 2 \\
Teaching at the school & 8 & 3 & 4 & 2 & 0 & 1 \\
where you were the coach & & & & 2 & \\
\hline
\end{tabular}




\section{SCHOOL REFORM AND COACHING}

Table 13

\section{Coach's Area of Teaching Licensure/Endorsement}

\begin{tabular}{ll}
\hline $\begin{array}{l}\text { Area of } \\
\text { licensure/authorization }\end{array}$ & Number of Responses \\
\hline Elementary & 12 \\
Reading & 10 \\
Middle Level & 8 \\
Language Arts & 7 \\
Social Studies & 7 \\
ESL & 6 \\
Special Education & 4 \\
Early Childhood & 3 \\
Math & 2 \\
Counseling & 1 \\
Science & 1 \\
High School & 1 \\
Bilingual & 1 \\
\hline Note: Teachers could select more than one area of \\
licensure/authorization.
\end{tabular}

Most coaches that responded (13 of the 18) stated they were expected to work with more than 15 teachers on staff. Fourteen of the 18 who responded to the survey said they went to the bi-monthly coach trainings offered by the district always (6 people) or almost always ( 8 people). Of the five coaches that left before the end of the 2013 school year, three left the coach role to become administrators. Currently, eight of the coaches are administrators within the district, four returned to teaching, four remain instructional coaches, and one is retired (see Table 14). Of the 18 respondents, 11 are no longer in the building where they served as a coach.

Schools. Of the 18 respondents, six reported the teachers and administrators in the building had used the DataWise cycle of inquiry for one year prior to the data informed decision-making initiative. Five coaches responded they had never done the DataWise work, and three were unsure how many years, if at all, the DataWise cycle of 


\section{SCHOOL REFORM AND COACHING}

inquiry had been used by the school personnel (see Table 13). Four of the buildings being studied had new administrators the first year of the coach initiative. Nine buildings had administrators that were in their first three years in the building, and only five schools being studied had the same administrators for four or more years prior to the 2011-2012 school year (see Table 16). Fifteen of the participants stated the schools where they were a coach were still using literacy benchmarking; three participants were unsure. However, only seven schools are still using the data team meeting time, while four are not; seven coaches were unsure if the data team meetings were happening (see Table 17). The school data shows that the data informed decision-making initiative occurs in less than half of the buildings where literacy benchmark scores are still being collected.

Table 14

Coach's Current Employment*

\begin{tabular}{lc}
\hline Current Position & Number of Responses \\
\hline Administrator & 8 \\
Teacher & 4 \\
Instructional Coach & 4 \\
School Counselor & 1 \\
Retired & 1 \\
\hline Note: * Current Employment as of January 2015
\end{tabular}

Table 15

Years of Use of the Data Wise Process for School Improvement before 2011-2012

\begin{tabular}{lc}
\hline & Number of Schools \\
\hline None & 5 \\
1 year & 6 \\
2 years & 2 \\
3 years & 0 \\
4 years & 1 \\
Unsure & 3 \\
\hline
\end{tabular}




\section{SCHOOL REFORM AND COACHING}

Table 16

Administrator Longevity

\begin{tabular}{lc}
\hline $\begin{array}{l}\text { How many years had your principal been in the } \\
\text { building where you were a coach? }\end{array}$ & $\begin{array}{c}\text { Number of } \\
\text { Schools }\end{array}$ \\
\hline New the first year & 4 \\
1 to 3 years & 9 \\
4 to 7 years & 4 \\
8+ years & 1 \\
Unsure & 0 \\
\hline
\end{tabular}

Table 17

Continued Implementation of Literacy Benchmarking and Data Team Meetings

\begin{tabular}{lccc}
\hline & Yes & No & Not Sure \\
\hline $\begin{array}{l}\text { Is the building where you were a [coach] still collecting } \\
\text { literacy benchmarking data? }\end{array}$ & 15 & 0 & 3 \\
$\begin{array}{l}\text { Is the building where you were a [coach] still using data } \\
\text { team meetings? }\end{array}$ & 7 & 4 & 7 \\
\hline
\end{tabular}

Job responsibilities. Coaches were asked about the job responsibilities they had in their schools (see Table 18). Only one job responsibility, duty, was completed daily by almost every coach (16 of the 18 respondents). Most coaches reported looking at data on a daily basis or multiple times a week (14 of 18), but only six coaches shared data with others daily or almost daily. Many coaches appeared to have weekly or monthly responsibilities focused on providing professional development and/or working with small groups of teachers. Two coaches reported administering tests/assessments daily. In response to the question, "Do you think your work as a coach was a success," one of the coaches responded no and the other responded not sure. Conversely, the two coaches who stated they work with teachers one-on-one on a daily basis reported feeling successful as a coach. 


\section{SCHOOL REFORM AND COACHING}

School climate. School climate addressed the coach's perception of the teachers and administrators use of data to inform instructional decisions, willingness to collaborate, and teachers' ability of to reflect on their teaching. The coaches who worked for both years of the initiative were asked to complete Likert scale answers about school climate for each year (2011-2012 and 2012-2013). Their answers were compared using dependent $t$-tests to determine if there were statistically significant differences between the means in year one (2011-2012) and year two (2012-2013) of the initiative. The Likert scale for these questions was from one to four $(1=$ not at all; $2=$ less than once a week; 3 $=$ at least once a week; $4=$ daily). The mean shows the difference between the mean scores of the 2011-2012 school year and the 2012-2013 school year (see Table 19). The change in mean was negative if the year one mean was less than the year two mean. Each of the measures show a change in the mean towards more implementation of the practices identified (see Table 19). It is important to note that this data was all collected at the same point in time, which could be a limitation because each coach was selfreporting the information for both years at the same time. The data shows the coaches' perceived increases in implementation of these practices, and some of that perception could be statistically significant. 


\section{SCHOOL REFORM AND COACHING}

\section{Table 18}

\section{Job Responsibilities of Coaches}

\begin{tabular}{|c|c|c|c|c|c|c|c|}
\hline & $\begin{array}{l}\text { Rarely/ } \\
\text { Never }\end{array}$ & Quarterly & Monthly & $\begin{array}{l}2+\text { times } \\
\text { a month }\end{array}$ & Weekly & $\begin{array}{c}2+\text { times } \\
\text { a week }\end{array}$ & Daily \\
\hline $\begin{array}{l}\text { Work with teachers one-on-one } \\
\text { focused on lesson and/or } \\
\text { assessment planning }\end{array}$ & 3 & 2 & 2 & 2 & 5 & 2 & 2 \\
\hline $\begin{array}{l}\text { Work with teachers one-on-one } \\
\text { focused on instruction }\end{array}$ & 3 & 2 & 3 & 0 & 5 & 3 & 2 \\
\hline $\begin{array}{l}\text { Work with teachers one-on-one } \\
\text { focused on classroom } \\
\text { management }\end{array}$ & 5 & 1 & 2 & 1 & 5 & 2 & 2 \\
\hline $\begin{array}{l}\text { Work with groups of teachers } \\
\text { focused on lesson and/or } \\
\text { assessment planning }\end{array}$ & 1 & 2 & 8 & 1 & 5 & 0 & 1 \\
\hline $\begin{array}{l}\text { Work with groups of teachers } \\
\text { focused on instruction }\end{array}$ & 1 & 4 & 6 & 0 & 7 & 0 & 0 \\
\hline $\begin{array}{l}\text { Work with groups of teachers } \\
\text { focused on classroom } \\
\text { management }\end{array}$ & 8 & 4 & 1 & 1 & 3 & 0 & 1 \\
\hline $\begin{array}{l}\text { Plan whole staff professional } \\
\text { development }\end{array}$ & 1 & 5 & 3 & 0 & 7 & 1 & 1 \\
\hline $\begin{array}{l}\text { Deliver whole staff professional } \\
\text { development }\end{array}$ & 1 & 5 & 4 & 2 & 5 & 1 & 0 \\
\hline Meet with parents & 6 & 4 & 2 & 4 & 0 & 1 & 1 \\
\hline Administer tests/assessments & 1 & 6 & 4 & 2 & 2 & 1 & 2 \\
\hline Duty (lunch, hall, etc.) & 1 & 0 & 1 & 0 & 0 & 0 & 16 \\
\hline Look at data & 0 & 1 & 0 & 1 & 2 & 8 & 6 \\
\hline Share data with others & 0 & 1 & 1 & 4 & 6 & 5 & 1 \\
\hline
\end{tabular}




\section{SCHOOL REFORM AND COACHING}

Table 19

Dependent t-test of Coach Experience of Change of Teacher Use of Professional Practices that Lead to Increases in Student Literacy Scores Between 2011-2012 and 2012-2013

\begin{tabular}{lcccl}
\hline $\begin{array}{l}\text { In your experience as a coach, how often did teachers in your } \\
\text { building do the following? }\end{array}$ & Mean & SD & t-value & p-value \\
\hline Use best practices in reading instruction & -0.583 & 0.515 & -3.924 & $0.002^{* *}$ \\
Share ideas and resources with each other & -0.417 & 0.669 & -2.159 & 0.054 \\
Hold all students to high expectations & -0.583 & 0.669 & -3.023 & $0.012^{*}$ \\
Work collaboratively with colleagues & -0.333 & 0.651 & -1.773 & 0.104 \\
Reflect on their teaching & -0.583 & 0.515 & -3.924 & $0.002^{* *}$ \\
Support innovative ideas in instruction & -0.500 & 0.798 & -2.171 & 0.053 \\
Use data to inform their instruction & -0.500 & 0.674 & -2.569 & $0.026^{*}$ \\
Engage in the data team meeting process & -0.583 & 0.793 & -2.548 & $0.027^{*}$ \\
Use you, as a coach, to help with instruction & -0.583 & 0.900 & -2.244 & $0.046^{*}$ \\
Use you, as a coach, to help with classroom management & -0.667 & 0.985 & -2.345 & $0.039^{*}$ \\
Use you, as a coach, to help with other problems or concerns & -0.583 & 1.084 & -1.865 & 0.089 \\
\hline
\end{tabular}

$N=12 * \mathrm{p}<0.05 * * \mathrm{p}<0.01$

The practices that increased significantly through the two years of the data informed decision-making initiative were: (a) using best practices in reading instruction ( $\mathrm{p}<0.01)$; (b) holding all students to high expectations $(\mathrm{p}<0.05)$; (c) teachers reflecting on their teaching $(\mathrm{p}<0.01)$; (d) teachers using data to inform their instruction $(\mathrm{p}<0.05)$; (e) engagement in the data team meeting process $(\mathrm{p}<0.05)$; (f) using the coach to help with instruction $(\mathrm{p}<0.05)$ and classroom management $(\mathrm{p}<0.05)$. Two other practices, sharing ideas and resources with each other $(\mathrm{p}=0.054)$ and supporting innovative ideas in instruction $(\mathrm{p}=0.053)$, were not statistically significant but are worth mentioning because they were very close to the p-value of 0.05 . The other two practices, working collaboratively with colleagues $(\mathrm{p}=0.104)$ and using your coach to help with other problems $(p=0.089)$ were not statistically significant. The data set only included individuals that were coaches for both years of the initiative. Because these data are 


\section{SCHOOL REFORM AND COACHING}

perception data, further research could analyze the difference between the answers of two coaches who were in the same building during different years of the initiative.

Another question on the survey asked how supported the coach felt the principal was in helping them carry out their responsibilities. The coach was asked to rate the principal from one to ten $(1=$ not supportive and $10=$ extremely supportive $)$. The average score was $6.50(\mathrm{SD}=2.38$, range $2-10)$. There is some relationship between the support the coach felt from the principal and the success the coach felt in their work during the initiative.

Two questions that related to principal support were analyzed in relation to how successful the coach felt in their work as a coach. The first question was how supported the coach felt the principal was in helping the coach carry out her/his job responsibilities $(\bar{x}=6.50 \pm 2.38)$. The second was how well the principal understood the data informed decision-making process. Principal support is not direct support for the coach, but if the principal does not understand the data informed decision-making work, I argue it will be difficult for the principal to support the coach in moving teachers toward using data to improve their literacy instruction.

Principal's support and coach success. Coaches were asked on the survey if they felt their work as a coach was a success. Of the 18 responses, 10 said yes, four said not sure, and four said no. I examined these responses in conjunction with how supported the coach felt by the administrator. When comparing the responses, I noted a pattern (see Table 20). Coaches who said they felt successful had an average rating of principal supporting them of 7.3, which was higher than those that said they were unsure 


\section{SCHOOL REFORM AND COACHING}

of their success $(\bar{x}=6.75)$ and even higher than those that said they did not feel successful $(\bar{x}=4.25)$. This shows the average score of the administrator's support also decreased when considering how successful the coach felt they were in coaching teachers.

Table 20

Administrator Support and Coach's Sense of Success

Did you feel successful as a coach?

\begin{tabular}{ccc}
\hline Yes & Not Sure & No \\
$(N=10)$ & $(N=4)$ & $(N=4)$ \\
\hline
\end{tabular}

Mean score of the question: on a scale from one to ten, how supportive do you think the principal was in helping you carry out your responsibilities?

$\begin{array}{lll}7.3 & 6.75 \quad 4.25\end{array}$

Principal understanding and coach success. Looking again at the question of whether coaches felt successful in their work, I compared the principals' understanding and the coaches' perception of how well the principal understood the data driven decision-making work $(1=$ not at all; $2=$ somewhat; $3=$ well; $4=$ very well $)$. When asked how well their principal understood the data informed decision-making process, nine of the 18 respondents selected 'somewhat,' two 'not at all,' three 'well,' and four 'very well' (see Table 21). When comparing those two data points using cross tabulation, there is not a statistically significant difference $(\mathrm{p}=0.08)$ between expected and actual frequencies. However, the data are worth noting (see Table 21). None of the four coaches who reported their work as a coach was unsuccessful perceived their principal understood the work well or very well (two said 'not at all' and two said 'somewhat'). Expected frequencies of the values were less than five for more than one category, so the 


\section{SCHOOL REFORM AND COACHING}

Pearson $\chi^{2}$ test could be inaccurate. A Fisher exact test cannot be run because the contingency table is not two by two (Field, 2009).

Table 21

Coach Sense of Success and Coach Perception of Principal's Understanding of the Data Informed Decision-Making Process

\begin{tabular}{lcccc}
\hline How well do you think your principal & \multicolumn{4}{c}{ Do you think your work as a coach was a } \\
understood the data informed decision-making \\
process (Data Wise and RtI)? & \multicolumn{4}{c}{} \\
\cline { 2 - 5 } & Yes & No & Not Sure & Total \\
\cline { 2 - 5 } Not at all & 0 & 2 & 0 & 2 \\
Somewhat & 4 & 2 & 3 & 9 \\
Well & 3 & 0 & 0 & 3 \\
Very Well & 3 & 0 & 1 & 4 \\
Total & 10 & 4 & 4 & 18 \\
\hline
\end{tabular}

Structures. The final section of the survey contained questions pertaining to the structures in place, with administrator support, for the data informed decision-making initiative. One question on the survey asked how much the coach felt supported by the administrator in increasing the use of data to make instructional decisions (see Table 22). Each coach was asked to identify how often the administrator(s) talked about and/or performed certain tasks that would show support of the data informed decision making structures the coach was working to put in place. The questions used a Likert scale $(1=$ never; 2 = rarely; $3=$ often; $4=$ always). Coaches rated the administrator(s) for year one and year two separately. As with the teacher practices data, the coaches were asked to rate these aspects at the same time, so the rating is the coach's perception of the change occurring between those two years. The coaches rated how often the administrators in their building did the following: (a) attended data team meetings ( $\mathrm{p}=0.275$ ); (b) help complete literacy benchmarking of students $(\mathrm{p}=0.339)$; (c) support the literacy 


\section{SCHOOL REFORM AND COACHING}

benchmarking of students $(\mathrm{p}=0.586)$; use staff meetings for data teams $(\mathrm{p}=0.082)$; and

(d) use staff meeting time to discuss the importance of data team meetings $(\mathrm{p}=0.339)$.

None of the aspects had statistically significant changes from year one to year two.

Further research would be needed to determine if the coaches felt the administrative

support in these areas was adequate to move the data informed decision-making work

forward in the buildings.

Table 22

Coach Experience of Structures to Support the Data Informed Decision-Making Process Comparing Year 1 (2011-2012) and Year 2 (2012-2013)

\begin{tabular}{|c|c|c|c|}
\hline \multicolumn{4}{|c|}{ Paired Differences } \\
\hline $\begin{array}{l}\text { In your experience as a coach, how often did the principal in your } \\
\text { building do the following } \\
\text { (1=never; } 2=\text { rarely; } 3=\text { often; } 4=\text { always) }\end{array}$ & Mean & $\begin{array}{l}\text { Standard } \\
\text { Deviation }\end{array}$ & $\begin{array}{l}\text { Sig. (2- } \\
\text { tailed) }\end{array}$ \\
\hline Allotted time for data team meetings & -0.231 & 0.599 & 0.190 \\
\hline Requirement that all teachers attend data team meetings & 0 & - & - \\
\hline Time for literacy benchmarking & -0.077 & 0.227 & 0.337 \\
\hline Resources for literacy benchmarking & 0 & - & - \\
\hline Materials for literacy benchmarking & -0.154 & 0.376 & 0.165 \\
\hline Requirement that teachers complete benchmarking of their students & 0 & - & - \\
\hline
\end{tabular}

Note: - no data available. The difference between the means of year 1 and year 2 were 0 , so there is no statistical comparison.

Comparing the coach perception of teachers' changes in practices to the coach perception of changes in administrator practices, an interesting pattern emerged. Coaches saw teachers moving in statistically significant ways, but did not perceive that same movement from administrators. Further research would need to be conducted to determine if this perception was accurate by collecting the data in year one and again in year two. I know principals received little to no explanation and/or training about the work the coach would be doing and/or how to support the coach in implementing the data informed decision-making initiative. The limited professional development for coaches 


\section{SCHOOL REFORM AND COACHING}

and administrators ended after the first year, and only a small number of administrators, as reported by the coaches, attended the few trainings offered by the district (see Table 23).

Table 23

Principal participation in district offered coach-principal professional development

\begin{tabular}{lc}
\hline $\begin{array}{l}\text { Distribution of the answers to the question: How often did your } \\
\text { principal attend principal-coach sessions (two in summer and four } \\
\text { more meetings throughout 2011-12)? }\end{array}$ & Number \\
\hline Always & 0 \\
Almost every meeting & 2 \\
Half the meetings & 1 \\
Less than half & 7 \\
Never & 6 \\
\hline
\end{tabular}

\section{Literacy benchmark data and survey results}

Nine schools showed increases in literacy benchmark scores over the two-year initiative (Amity, Chehalem Mountain, Hazel Hill, Naches, Owl Creek, Red Hill, Snipes Mountain, Umpqua Valley, and Wahluke), and all coaches completed surveys except Amity and Chehalem Mountain. Eight schools had no change in literacy benchmark scores (Applegate, Carlton, Chelan, Goose Ridge, Meridian, Red Mountain, Ribbon Ridge, and Rogue). Goose Ridge and Rogue schools' coaches did not complete surveys. Finally, three schools showed decreases in literacy benchmark scores (Elkton, Walla Walla, and Willakenzie). The Walla Walla School coach did not complete the survey; Elkton and Willakenzie data will be examined more closely when comparing schools with statistically significant differences. Therefore, for this analysis, I consider only the 


\section{SCHOOL REFORM AND COACHING}

schools that saw increases in literacy benchmark scores compared to those that had no change in scores.

Some schools data was not consistent over the two years. All of those schools, except for Wahluke, had the same coach for the two years of the initiative. Wahluke had no change during the 2011-2012 school year, had increased scores during year two, and also had increased scores over the duration of the initiative. Because Wahluke had different coaches each year, I analyzed coach's data from year one with the no change group and the coach's data from year two in the increased scores group. All other schools with changes in scores had the same coach over the two year period. Any other school that had different coaches did not have different outcomes year one compared to year two. For example, Hazel Hill increased scores each year and across the two years, and the school had different coaches in year one and year two. The survey responses from these coaches were analyzed with the increased scores group.

Increased literacy benchmark scores compared to no change. The survey included four open-ended questions, so the answers from those questions were coded for general themes and ideas. The comments and codes were then grouped to compare the comments of coaches in schools with increased literacy scores to those of the schools without change in scores. Using this approach, I identified some patterns in the data.

Principal support. Each coach was asked to rate their principal on a scale from one to ten for the question: "How supportive do you think the principal was in helping you carry out your responsibilities?" After that question, coaches were asked to explain 


\section{SCHOOL REFORM AND COACHING}

the score they gave. All participants score the support of the principal, but two coaches did not use the open-ended question to explain the principal support score given.

The coaches at schools with increases in literacy benchmark scores felt supported by the principal. The Naches coach wrote, "The principal was supportive in so far as she spoke of the work and her confidence in my abilities." The year two Wahluke coach indicated, "I felt very supported. He gave me a few things that he wanted done with data." The Snipes Mountain coach reported, "The principal was very supportive in theory and we did discuss data and instruction.” The coach from Red Hill indicated, “... I was given flexibility to plan accordingly.” Finally, the year two coach from Hazel Hill described,

My principal at the time was supportive in terms of time, support and collaborative planning. The AP [assistant principal] was extremely supportive. Helping in the planning for meetings and prep for data analysis. Her experience as a [coach] made her an invaluable resource as we were able to discuss needs without having to review background information.

The year two Hazel Hill coach stated that the assistant principal understood the work because she had been a coach. Being able to "discuss needs without having to review background information" was something the Hazel Hill coach valued in her assistant principal. Other coaches reported wanting more from their administrators. After indicating the principal was very supportive, the Snipes Mountain coach reported, "However, in order to be truly helpful she would have needed to be present and involved 


\section{SCHOOL REFORM AND COACHING}

with teams and ... have a better relationship with staff." The coach from Naches also finished their explanation of principal support by writing, “ ... she was usually unaware of the work that was going on in data teams and planning for instruction based on the data." The year one Hazel Hill coach addressed the issue more pointedly, "The score would have been higher had their been directives for certain teachers to seek me out regularly for formal coaching." All of these written statements show that coaches at schools with increases in literacy benchmark scores felt supported, but would have been more supported if the principal understood the day-to-day work focused on the data informed decision-making initiative.

The coaches at schools with no change in scores had a variety of explanations about their perception of support from the principal. The coaches at Carlton and Applegate felt very supported. The Carlton coach wrote, "My principal has been very supportive of my role. She has advocated for the position and sees it as a positive method for teachers to engage in productive reflection and implementation of effective teaching strategies." The Applegate coach reported, "My principal reiterated the importance of data teams and consistently attended meetings .... Overall, I felt a high level of trust from my principal for carrying out my responsibilities." These two coaches were the exception in this group. Most other coaches did not feel as supported. The year one Wahluke coach indicated, "Was not around; often cited union/contract issues with data team meetings." The Meridian coach had multiple administrators during the two years of the initiative. The coach wrote, "One assistant principal did her best to make sure to create barriers between me and the work I had to do." Another administrator the coach worked 


\section{SCHOOL REFORM AND COACHING}

with, “...leaned on me heavily for what were basically administrative tasks-scheduling, observing teachers and students, figuring out computer system for testing, etc." The coach from Red Mountain reported, "The principal of my school at the time I was a [coach] was having major difficulty with staff morale and building climate. The RtI work was secondary to the general work of helping everyone get through this difficult period." Finally, the Chelan coach wrote, "The principal used the coach as more of an 'end all be all' to every task which needed assistance. So the [coach] became like an AP [assistant principal].” Though the specific issues are different, a common theme of lack of focus can be observed in each of these coaches' comments. Some, like Red Mountain, did not focus because of staff morale. Other schools, Chelan and Meridian, lacked focus because the coach was asked to do too many different tasks not directly related to the work of increasing data use to inform literacy instruction. Still others, Wahluke and Meridian, had administrators that refused to support the work of the coach. The idea of focusing on the work will be discussed more when I discuss the findings from the interviews of the coaches and the principals.

Principal understanding. Some of the lack of support from principals might be because the principals did not understand the work of the coaches. On the survey, coaches were asked, "How well do you think your principal understood the data informed decision-making process (DataWise and RtI) as a way to help teachers deliver more effective instruction?" The coach then rated their perception of the principal as: $1=$ not at all, $2=$ somewhat, $3=$ well, or $4=$ very well. The coach was asked to explain their answer. The same two coaches who did not explain their answer regarding principal 


\section{SCHOOL REFORM AND COACHING}

support did not explain their answer for principal understanding. Again, I compared the explanations of schools with increased literacy benchmark scores to those schools with no change, to identify patterns in the answers.

I found most coaches who had increased scores also perceived their principal had an understanding of the data informed decision-making work. The year two Wahluke coach wrote, "my principal understood the overall concepts of the data and the implications to inform teaching." The Naches coach indicated, "I think her overall understanding of DataWise was probably pretty good.” The year two Hazel Hill coach reiterated these ideas by reporting, "the principal understood the overarching process of both the RTI and data wise and was conversant with curriculum and assessment tools.” The Red Hill coach wrote, "The principal understood the importance of benchmarking a (sic) progress monitoring ...." All of these coaches perceived their principals had an understanding of the data informed decision-making process.

These same coaches stated even though principals understood the overall concept, they felt the principal did not understand how the data informed decision-making process was implemented in the classroom. The Red Hill coach's full written statement was "the principal understood the importance of benchmarking a (sic) progress monitoring but did not understand the procedures and timeline and how it affected teacher instruction." The year two Hazel Hill coach wrote, "However, her literacy with regard to K-2 instruction and assessment was less complete than her understanding of (sic) for the upper grades." The Wahluke coach wrote, "But as to individual grade levels, he wan (sic) not certain." The Naches coach tried to explain where s/he thought the lack of principal understanding 


\section{SCHOOL REFORM AND COACHING}

was coming from by reporting, "Her understanding of what we were working on doing in the building was not good. She seemed to have the attitude that the [coach] was taking care of that work, so she didn't have to think about it much.” Finally, the Snipes Mountain coach summed up the ideas stated above by writing, "Again, she was very well informed theoretically, however the staff and the school needed much more support in terms of structural change and resources in order to truly have an effective RTI process." The coaches all perceived the principal understood, theoretically, the data informed decision-making process, but most coaches also stated they perceived the principal did not understand the day-to-day practices and structures needed to implement the data informed decision-making initiative in the classrooms.

Coach success. The next question on the survey was "do you think your work as a coach was a success?" Coaches could answer: yes, no, or not sure. Again, coaches were asked to explain their answer using an open-ended format to answer the question "what do you think was instrumental to your success or failure?" Every coach, except one, provided an answer to this open-ended question. The answers were, again, divided between schools with increased literacy benchmark scores and schools with no change in benchmark scores. The coaches in the schools with increased scores, overall, felt their work was a success (seven answered yes, one said no, and one said unsure). The coaches in schools with no change were more varied (three said yes, two said no, and three said unsure). Again, the open-ended comments were coded to find patterns and themes.

Two coaches from the schools that saw increases in literacy benchmark scores did not feel their work as a coach was a success. One coach said no, and then simply wrote, 


\section{SCHOOL REFORM AND COACHING}

"Too many other responsibilities." The other coach felt s/he was not sure if his/her work was a success, and that person was the one coach that did not explain his/her answer. The remaining coaches at schools with increased literacy benchmark scores had some common themes in their answers: trust and focus.

Trust. Many coaches discussed part of their success was because teachers trusted them. The year two Wahluke coach reported, "I think the success I had grew out of the fact the staff trusted me, my opinions, and advice/guidance." The Naches coach also indicated, "Good, trusting, professional relationships with teachers." The Red Hill coach wrote, "Overall it was the relationships that were built between the teacher and myself that ended up having the largest impact on instruction and student achievement." These coaches all discussed how the relationships between the coach and the teacher were an important aspect of their sense of success as a coach. Another perception these coaches had when discussing their success was the focus of the school's professional development on the data informed-decision making work.

Focus. Many coaches discussed their ability to focus on the work and help teachers use data to change their instruction. The Red Hill coach stated,

Through the process of being a [coach] I was able to work directly with teachers so that they could feel the impact of data analysis and how it affected their overall instruction. As teachers understand the process better they themselves were able to take over the procedures to help them guide instruction and to impact student success in the classroom. 


\section{SCHOOL REFORM AND COACHING}

The year two Hazel Hill coach said she met with new teachers once a week to help them learn how to use data for planning and instruction. She said, “... I saw these teachers become more fluent in the use of their classroom level data in planning for instruction and sorting students into groups." Finally, the Owl Creek coach simply stated, "I had the time to focus on this work." All of these coaches described how focusing on the work led to their feelings of success as a coach.

The Snipes Mountain coach indicated how the first two years of the initiative laid some groundwork for the work that is happening now at Snipes Mountain School. The coach said,

We made a lot of change in the school. Many of the changes that were started those first two years are now making big changes in student achievement. There were many other factors during those first years that kept the school from making the change it needed to to be effective at that time. Many of these issues were staff based (teachers who were unwilling and the relationship between staff and administration) and they made the work I was doing less effective.

Though the coach perceived the work during the two years of the initiative to not be effective, they also explain how those first two years laid the groundwork for the changes that are occurring now. This focus is different from the focus the other coaches discussed. The focus at Snipes Mountain School was a focus on the work over multiple years. The coach and building leaders at Snipes Mountain were able to continue to move 


\section{SCHOOL REFORM AND COACHING}

the work forward after the district stopped supporting the data informed decision-making initiative.

The coaches at schools with no change in literacy benchmark scores had a variety of feelings of success and reasons for their perceived success or lack thereof. When looking at the answers as a group, I did not see any patterns in the data. For this reason, I decided to look at these responses based on the coach's feelings of success. Three coaches felt their work was a success. Two felt unsuccessful, and three were unsure of their success as a coach. When I looked at the data in these categories, I identified some patterns.

Coach's perception of success. Three coaches from schools with no change in literacy benchmark scores stated they felt their work as a coach was successful. These coaches all discussed their work to build relationships with the teachers in the building. The Carlton coach said, "Taking time to build relationships with teachers. Approaching our data meetings as a team for decision making and supporting the work that teachers are doing." The year one Ribbon Ridge coach stated, "Being able to spend time with teachers and figure things out with them built strong relationships and a sense of common successes." Finally, the year one Wahluke coach said, "The fact that I was a teacher in the building and had an existing relationship with staff before I became an instructional coach." This focus on relationships supports the other coaches' sense of success because most of the coaches who felt they were successful discussed relationships and/or trust as a component of the success. These coaches also discussed some limitations to their success. The year one Ribbon Ridge coach stated, 


\section{SCHOOL REFORM AND COACHING}

There is a general lack of understanding around reading instruction, data analysis, and purpose of assessment in teachers from grades K-8 at the schools in which I worked. Many teachers did not have background knowledge to make full use of [coach] services or implement effective school reform. Some were defensive, so I had to spend time building relationships and begin the slow work of bringing new ideas through conversation.

The lack of assessment literacy of teachers could be one reason why the literacy scores at Ribbon Ridge did not change in the two years of the initiative. The year one Wahluke coach stated, "I wore many hats though I led three or four different teams; PBIS, Equity, student activities etc, so teachers knew I was committed to the school..." Though this coach sees the commitment to the school as a positive, it could also be perceived as a lack of focus on the data informed decision-making work. The coach from Umpqua Valley (a school with increases in benchmark scores) did not perceive their work as a coach as successful because they had, "too many other responsibilities." Both of these coaches did not have the focus on the data informed decision-making work that other coaches at schools with increases in benchmark scores reported.

Coach's perception of no success. Two coaches at schools with no changes in literacy benchmark scores said they did not think their work as a coach was successful. Both of these coaches stated external issues for why they were not successful. The coach from Chelan School said, “Administration. Teachers weren’t held accountable. And the coach was given way too many non-coach related items." This coach perceived the 


\section{SCHOOL REFORM AND COACHING}

administration and a lack of focus as the reasons the data informed decision-making initiative was not successful. The other coach, one of the year one Wahluke coaches stated, "The term PLC [Professional Learning Community] is still not understood by a majority of [Columbia School District] leaders, let alone teachers/counselors." The lack of understanding of the term PLC may or may not be a reason the work was not successful. I wonder if the coach is really talking about the lack of understanding of the data informed decision-making process and/or the data team structure. If so, then this issue could also be categorized as a lack of assessment literacy, which was also discussed by the Ribbon Ridge coach as a limitation of the implementation of the initiative.

Overall, the two coaches that did not feel their work was successful felt external factors, administration and understanding of PLCs, were what were instrumental in their feeling of failure as a coach.

Coach's perception of not sure of success. Three coaches at schools with no change in literacy benchmark scores stated they were not sure if their work as a coach was successful. These three coaches had very different answers from those who felt successful or unsuccessful. These coaches discussed the strengths and weaknesses of their work, which is probably why they stated they were unsure of their success. The coaches discussed school climate, turnover, and coach ability as the reasons they did not feel their work was a success. The Red Mountain coach said,

Having at least somewhat reliable data, the time to share it in a structured, regular way with staff allowed us to begin to hold similar expectations for all students. Looking at the data persistently by race and gender allowed us 


\section{SCHOOL REFORM AND COACHING}

to see patterns that gave us information about our biases and where we were really missing. Following through with this without the turbulence of a really rotten school climate and for an extended time would have given me more confidence that we were on to something that works for kids.

This statement shows the coach is conflicted about his/her sense of success. The coach sees the importance of the data informed decision-making initiative work, but the school climate was so "rotten" the work was not focused on and/or prioritized.

The Applegate coach was also conflicted. The coach said, I am confident that my year as a [coach] was most successful in regard to creating a culture that valued and used data. As a school we developed greater data literacy and had more meaningful conversations about student achievement. We started to disaggregate data by race as well and learned to identify tiers of instruction that supporting ( sic) student growth. As a special education teacher and having supported Title I programming, I had a strong background in reading instruction, data analysis, and, specifically DIBELS and easyCBM from my Masters at the University of Oregon. I felt very comfortable discussing student performance and running effective meetings. I have since [the years of the initiative] worked in a general education classroom. That experience itself was invaluable. I think my work as a coach was a "failure" in the sense that I was limited by [my own] background. I now have more expertise in the core curriculum which would have been helpful in my role as a [coach]. 


\section{SCHOOL REFORM AND COACHING}

The Applegate coach discussed creating a culture of data use and their comfort in discussing student data and running meetings. However, the coach felt his/her lack of general education experience limited his/her ability to be a coach for general education teachers. I feel it is important to note this coach left after the first year of the initiative to become a general education teacher. The coach's feeling of failure was his/her lack of general education experience could be a reason s/he decided to go back to the classroom after the first year of the initiative.

Finally, the Meridian coach was also unsure whether or not his/her work as a coach was a success. The Meridian coach said,

There was a huge turnover in ... my school after I left. Memories are short in this district and new waves of thought take over, often without taking the time to think back. At the time I was there, I instituted procedures and fostered discussion over kids and literacy that were valuable. It made an impact on kids those years. True success to me means a LASTING impact ... I do not know if what I worked hard to develop continued on after I left. Perhaps it did. Perhaps it took on another shape but got the ball rolling on using data to inform decisions. I worry that discussions around Smarter Balanced Assessments might be getting more focus. At any rate, the kids who learned to read better those years will continue to be better readers for the rest of their lives. This is a big measure of success. 


\section{SCHOOL REFORM AND COACHING}

The Meridian coach explained the frustration felt by many coaches about the work not being continued after the two years of the initiative. The coach's statement, "True success to me means a LASTING impact," showed the coach's desire to see lasting change in student literacy benchmark scores whether or not the coaches were still in their positions. This coach had a focus on the students that other coaches did not discuss in their open-ended responses. This focus on students could have been a way to successfully implement the data informed decision-making initiative. However, the coach also discussed huge turnover at the school and the lack of focus the district had for this initiative means the school is most likely not continuing on with the data informed decision-making initiative. The coach at Meridian did not know if the work was continuing at the school (this information was from another question on the survey).

Anything to add? The last question on the survey was an open-ended question. The question was "is there anything you would like to add about your experience as a [coach]?" Knowing that the survey could not be a complete representation of the coaches' experiences and perceptions, I added this question to see what coaches might want to add. Surprisingly, participants responded to this question with a consistent theme. Of the thirteen coaches who answered this open-ended question, ten stated the lack of district focus was disappointing.

Lack of district focus. The coaches that discussed the lack of district focus were from both schools that had increases and no changes in literacy benchmarking scores. The Naches coach stated, 


\section{SCHOOL REFORM AND COACHING}

I do not feel that [Columbia School District] showed the level of commitment to this endeavor that was needed for it to be successful. We had one year, then were on the verge of being dismissed before a last minute reprieve. The focus of the work seemed totally different between the two years. I loved working with the teachers in the school and felt fortunate to have that opportunity. But, I was frustrated that the bigger picture work on systemic change was not well planned or supported.

More coaches reiterated this frustration that the school district did not continue to focus on the data informed decision-making work. The Owl Creek coach stated, "Creating a data driven culture takes time. We were beginning to create momentum when the [coach] position was eliminated by the district."

Some coaches felt they were victim to the district's quick decision to end the initiative. The Meridian coach said,

Little respect was given to the [coaches] that were unassigned at the end of the two year period. What was supposed to continue on for many years was abruptly cut short. Then, many were scrambling to get back into buildings and, because so many principals did not understand what they [coaches] did, many were shortchanged when it came to job offerings. In my opinion, teachers should not be the victims of shortsighted trends made by district decision makers. Their jobs and sacrifices should be respected and understood, not just pushed aside for the next big thing. It felt at the 


\section{SCHOOL REFORM AND COACHING}

end like "we're done with you. See ya' Don't let the door hit you on the way out."

This coach's quote addressed the frustration with the district not continuing to do the data informed decision-making work, and it also identifies a lack of trust from this particular coach toward the school district. This coach felt the district not only abandoned the initiative, but the district also abandoned the teachers who were hired to do the work.

The lack of focus from the district was most evident in schools that have had new administrators since the initiative was abandoned. The Applegate coach stated, I was disappointed that with a new principal (two years after I left the [coach] position), there did not seem to be much follow through from the district in regards to continuing the data work that had been started. The school continues to use benchmarking, but the school culture and instructional programming, while still based on data, has not had significant continuity. It feels that there is a lack of communication and expectation across the schools in the district.

The coach was aware the school where they were a coach still uses benchmarking, but it is not clear if the school continues to use data team meetings and/or if there is still a coach to continue the work started by the initiative. Another coach, who remained in the building where they served as a coach, discussed the change in administration. One of the year two Hazel Hill coaches said,

During the time our school had a [coach], our school had consistent, dedicated time for staff to carefully examine literacy benchmarking and 


\section{SCHOOL REFORM AND COACHING}

progress monitoring data. This was done in grade-level teams, but there was also time for staff to work with data across grade levels.... During the years following [the initiative], teachers are asked to examine data and write reading action plans largely on their own. This has led to large inconsistencies in whether or not teachers complete literacy action plans at all, and as far as I can tell, little accountability about how teachers use classroom data. Teachers who are personally inclined to use data to make decisions continue to do so; those who are not (due to less experience/buyin/etc) are free to make "gut" decisions on student learning. My current principal gives the idea of data-driven decision-making lip service, but provides limited opportunities to complete the actual process. The current lack of adequate, dedicated time to examine student data with colleagues creates an impression that making data-driven instructional decisions is a good practice, but optional, for teachers.

These coaches discussed the lack of focus of the district by illustrating the change in data informed decision-making practices when a new leader came into the building. Another coach also discussed the idea that teachers are creating their action plans on their own. The year two Wahluke coach, who is still a coach at Wahluke School, stated "We have modified the data team meetings. I now meet with individual teachers to review data, and to plan.” Though the Wahluke School teachers still have the opportunity to work with a coach, they are missing the opportunity to work with other teaching colleagues to create action plans and/or discuss literacy instructional practices. The Wahluke teachers' 


\section{SCHOOL REFORM AND COACHING}

ability to work with a coach is different than the Hazel Hill teachers who are expected to work on their own.

Snipes Mountain School still has the same coach working with teachers. The Snipes Mountain coach said,

This year I feel like we have achieved critical mass and teacher[s] are using data, both formal benchmarking and in-class formative data in order to guide grouping and instructional decisions. I am incredibly hopeful about the direction of the school and the staff. Much of this change, from my perspective, is due to staff change, both teachers, classified, and administration. However we continue to need more support in terms of FTE for classified positions to support a vibrant and workable RTI system. This coach identified a couple of issues with the district losing focus on this initiative. First, the coach stated this year-two years after the district stopped funding/supporting the RtI work and the coach position - they have "achieved critical mass" of teachers using data. The diffusion of an initiative in a school takes time (Rogers, 1962), and this coach identified the need for multiple years of focus on this initiative to "achieve critical mass." Also, the coach mentioned the lack of funding because the district is not supporting the initiative anymore. Some administrators decided to keep the coach position, but that funding now comes from the school budget, not the district budget. This means fewer teachers and/or support staff can be hired if a principal values the work of their coach. Other coaches reiterated this sentiment. The year one Wahluke coach 


\section{SCHOOL REFORM AND COACHING}

stated, "I think all Title I schools should be budgeted for a [coach]." The Ribbon Ridge coach said, "I would support having a [coach] again."

Two other coaches made statements regarding the district's focus on the data informed decision-making initiative. The Red Hill coach, now a school administrator in the district, said,

I think this role as a [coach] help[ed] me to become an administrator within the district. I think that the [coach] training is essential for all administrators entering [Columbia School District] and that the district should consider using this model as future administrative program for those within the district that are looking to promote into future administrative positions.

This coach felt the training was invaluable and prepared him/her for his/her current position. The last statement was from the year one Hazel Hill coach. She said, "It [the initiative] was the first and only time that I felt like our district was aligning instruction and moving forward." These two statements - coaching as preparation for administration and finally moving forward-reiterate what all the other coaches stated. Each coach saw the district not focusing on the data informed decision-making work as a negative change of direction for the district.

The coaches perceived the success and failure of the initiative implementations in their schools and across the district in many ways. To understand how the initiative was successfully implemented in the short amount of time coaches had to complete the work, an analysis of the schools with statistically significant changes in literacy benchmark 


\section{SCHOOL REFORM AND COACHING}

scores and the survey results from the coaches in those buildings will be completed to determine a purposive selection of the coaches and principals to be interviewed.

Surveys and statistically significant changes in literacy scores. Four schools had statistically significant changes from the fall benchmark to the spring-Elkton, Willakenzie, Hazel Hill, and Owl Creek. Of those, Hazel Hill and Owl Creek schools showed increases in the percentage of low risk students and decreases in the percentage of high risk students. Elkton and Willakenzie's statistical significant data did not show increases in low risk rating and decreases in high risk ratings of students. Looking at survey data of those coaches allowed me to try and find some patterns in the coaches that were showing statistically significant gains to those that showed statistically significant losses.

Elkton and Willakenzie. Descriptive statistics showed Elkton and Willakenzie schools' statistical significance was not an increase in low risk students from fall to spring. I was curious if the coach survey might reveal some commonalities between these two schools to determine if there were some patterns of those coaches that could be considered to explain the data observed in the literacy benchmarking assessment analysis (see Table 24). In rating from one to 10 their administrator's support of the data informed decision-making, one rated their principal a nine, and the other rated their principal a four. Both stated that their principals understood the data informed decisionmaking work (somewhat and well). One of the coaches felt successful as a coach and the other did not. The one aspect of the survey different from other respondents was the amount of district training these two coaches received (see Table 25). Fourteen of the 18 


\section{SCHOOL REFORM AND COACHING}

respondents stated they always or almost always attended the bi-monthly professional development offered to the coaches by the district. These two coaches stated they participated in the professional development no more than half the time. This lack of professional development might have led to literacy benchmarking procedures that were not in line with what other schools were doing. The decrease in the number of students being assessed from fall to springs indicates the possibility not all of the students were benchmarked each benchmarking period.

Table 24

Selected Responses of Survey Questions for Elkton and Willakenzie Schools

\begin{tabular}{|c|c|c|}
\hline Question & Elkton coach & $\begin{array}{l}\text { Willakenzie } \\
\text { coach }\end{array}$ \\
\hline How often did you meet with the principal - Formally? & $\begin{array}{l}\text { 2-plus times per } \\
\text { month }\end{array}$ & weekly \\
\hline How often did you meet with the principal - Informally? & weekly & daily \\
\hline $\begin{array}{l}\text { On a scale from } 1-10 \text {, how supportive do you think the principal was } \\
\text { in helping you carry out your responsibilities }(1=\text { not supportive; } 10= \\
\text { extremely supportive)? }\end{array}$ & 4 & 9 \\
\hline $\begin{array}{l}\text { How well do you think your principal understood the data informed } \\
\text { decision-making process as a way to help teachers deliver more } \\
\text { effective instruction? }\end{array}$ & somewhat & well \\
\hline Do you think your work as a coach was a success? & no & yes \\
\hline $\begin{array}{l}\text { How often did you attend the coach trainings provided by the district } \\
\text { TOSAs? }\end{array}$ & half & less than half \\
\hline $\begin{array}{l}\text { Before the } 2011-12 \text { school year, how many years had your principal } \\
\text { been in the building where you were a coach? }\end{array}$ & new principal & $1-3$ years \\
\hline
\end{tabular}

Hazel Hill and Owl Creek. Hazel Hill and Owl Creek had statistically significant differences between the observed and expected frequencies of students in the high, some, and low risk categories from fall to spring. Hazel Hill had statistically significant differences over the duration of the initiative (fall 2011 to spring 2013). Owl Creek had 


\section{SCHOOL REFORM AND COACHING}

statistically significant differences only in the second year of the initiative (fall 2012 to spring 2013). Hazel Hill had one coach for the first year and another coach for the second year. Owl Creek had one coach who stayed in the role for two years. All three coaches are now administrators in the district being studied. The questions from the survey that were examined for Elkton and Willakenzie were also examined for Hazel Hill and Owl Creek. All three coaches felt their work as a coach was a success. Each of them rated their administrator as seven or higher for how supportive they were of the data informed decision-making work. Interestingly, the Owl Creek coach stated his administrator was extremely supportive (a ten on a one to ten scale), but also stated the principal's understanding of the work was only 'somewhat' (see Table 26). Hazel Hill's coaches both rated the principal a seven on how supportive he was, and they both stated that the principal's understood the work 'very well' or 'well'.

Table 25

Frequency of Coach Participation in District Led Professional Development

\begin{tabular}{lccccc}
\hline & always & $\begin{array}{c}\text { almost } \\
\text { always }\end{array}$ & half & $\begin{array}{c}\text { less than } \\
\text { half }\end{array}$ & never \\
\hline $\begin{array}{l}\text { How often did you attend the coach trainings } \\
\text { provided by the district TOSAs? }\end{array}$ & 6 & 8 & 1 & 1 & 2 \\
\hline
\end{tabular}

Note: One of the "never" respondents was only a coach for two months at the beginning of the initiative and was moved into an administrator position before December of 2011.

Using the literacy benchmark data and the survey results, I determined the best schools to interview for a deeper understanding of the structures needed for a coach to successfully implement a data informed decision-making initiative in a school are Hazel Hill and Owl Creek. These schools both showed statistically significant growth in 


\section{SCHOOL REFORM AND COACHING}

literacy benchmark scores in grades four to eight, and the coaches in those buildings perceived the administrators were supportive, understood the data informed-decision making work, and the coaches participated in the professional development offered to them throughout the two year implementation of the initiative.

Table 26

Selected Responses of Survey Questions for Hazel Hill and Owl Creek Schools

\begin{tabular}{|c|c|c|c|}
\hline Question & $\begin{array}{c}\text { Hazel Hill } \\
\text { coach-1 }\end{array}$ & $\begin{array}{l}\text { Hazel Hill } \\
\text { coach-2 }\end{array}$ & $\begin{array}{l}\text { Owl Creek } \\
\text { coach }\end{array}$ \\
\hline $\begin{array}{l}\text { How often did you meet with the principal - } \\
\text { Formally? }\end{array}$ & weekly & $\begin{array}{l}\text { 2-plus times } \\
\text { per month }\end{array}$ & $\begin{array}{l}\text { 2-plus times } \\
\text { per week }\end{array}$ \\
\hline $\begin{array}{l}\text { How often did you meet with the principal - } \\
\text { Informally? }\end{array}$ & $\begin{array}{l}\text { 2-plus times } \\
\text { per week }\end{array}$ & $\begin{array}{l}\text { 2-plus times } \\
\text { per week }\end{array}$ & daily \\
\hline $\begin{array}{l}\text { On a scale from } 1-10 \text {, how supportive do you think } \\
\text { the principal was in helping you carry out your } \\
\text { responsibilities }(1=\text { not supportive; } 10=\text { extremely } \\
\text { supportive)? }\end{array}$ & 7 & 7 & 10 \\
\hline $\begin{array}{l}\text { How well do you think your principal understood the } \\
\text { data informed decision-making process as a way to } \\
\text { help teachers deliver more effective instruction? }\end{array}$ & very well & well & somewhat \\
\hline Do you think your work as a coach was a success? & yes & yes & yes \\
\hline $\begin{array}{l}\text { How often did you attend the coach trainings provided } \\
\text { by the district TOSAs? }\end{array}$ & always & $\begin{array}{l}\text { almost } \\
\text { always }\end{array}$ & always \\
\hline $\begin{array}{l}\text { Before the } 2011-12 \text { school year, how many years had } \\
\text { your principal been in the building where you were a } \\
\text { coach? }\end{array}$ & new principal & new principal & $1-3$ years \\
\hline
\end{tabular}

\section{Interviews}

Interviews were conducted with the Owl Creek and Hazel Hill coaches and principals. Both schools are K-8 schools in the Columbia School District. Hazel Hill has two programs - neighborhood and Spanish Immersion. Hazel Hill School had more than one coach during the two-year initiative. Therefore, two coaches were interviewed 


\section{SCHOOL REFORM AND COACHING}

for this research. The first coach left coaching to take an administrative position at a school in Columbia School District identified one of the schools participating in the data informed decision-making initiative. Owl Creek offers a neighborhood program and had one coach for the two years of the initiative. Both Hazel Hill and Owl Creek had administrators that had not been in the building for more than three years when the initiative started. The Owl Creek administrator is still the principal, and the Hazel Hill administrator has moved to another building within the same district. Two of the three coaches, the Owl Creek and the first Hazel Hill coach each had at least ten years of experience teaching middle grades. The second Hazel Hill coach had no experience teaching middle grades, but did have two administrators with middle level experience. The only person still working in the building where they were during the two years of the initiative is the Owl Creek Principal.

Owl Creek coach (Sam). I met the Owl Creek coach at his current school at about 6:00pm. Sam (all names are pseudonyms) was moving furniture and supplies out of a classroom with the help of a custodian. He finished loading his car, and we met in his office. Before we started the interview, we discussed the Owl Creek data because he was very interested in how the students did and what I was finding. We also talked about our kids because they are about the same age. When we finished the interview, I helped him load the last of the materials into his car. When I asked what was going on, he informed me it was "a long story." During the interview he was very attentive and willing to answer the questions. Yet, some of the time, he seemed a little uncomfortable and formal, but overall was very willing to talk about his experience. Sam spent a lot of 


\section{SCHOOL REFORM AND COACHING}

the interview talking about structures and supports that allowed him to do his job, but he also talked a lot about building politics and the lack of trust of the administration during the years leading up to the initiative being studied. It seemed to me that the coaching and RtI work helped to focus the professional development at Owl Creek, and Sam was a large part of building trust and respect with the teachers.

Hazel Hill coach one (Tiffany). Tiffany and I met at her house after her staff meeting on a Monday night. Before the interview started, we talked about some mutual friends and about what has been happening in our schools. She was willing to participate and wanted to answer thoroughly. She gave many specific examples of structures and how she worked to focus and align the RtI work and move it forward. I know that she is currently using data informed decision-making as the Assistant Principal in a different building, and I should have asked her to discuss how the coaching work influenced what she is doing today. Tiffany did not discuss supports she got from her administrators, but the other Hazel Hill coach, Sara, offered information about those supports.

Hazel Hill coach two (Sara). I met Sara at the elementary school where she is currently working. I took a Friday off from work to meet with Sara and also Joe, the Principal of Hazel Hill. Sara asked to meet me in the morning, right after students started their day. I got to her school at about 8:45. The staff in the office knew almost every student's name, and each student was welcomed to school with a warm greeting and was offered breakfast while their late slip was being filled out. I sat in the office for about twenty minutes (next to the two kids going home because they were sick) and watched the support staff welcome parents and students and create a safe and welcoming place. I 


\section{SCHOOL REFORM AND COACHING}

commented to Sara before we started the interview how warm and clean and productive the school's office was, and how I wish my own children's front office felt that way. Sara took me to her office, which appeared to be an old storage area. There were two doors and only some very small windows at the top of one of the walls. We talked before and after the interview about mutual acquaintances and some of the work being done in the district. Sara had a unique perspective because in the two years of the initiative, she was a teacher, a coach, and then soon after an administrator in a building that had a coach during the two-year initiative (not Hazel Hill). She talked freely about the work, and she shifted between those three roles throughout the interview.

Owl Creek administrator (Paula). The Owl Creek Principal and I emailed back and forth for almost a week to find a time that would work for us to talk. We finally agreed to meet during a two-hour late opening, and she agreed to talk with me before the two hours of professional development started. I entered Owl Creek school, and the secretary greeted me almost immediately. There was music playing, and there was a productive hum in the office. Paula was kind and welcoming, but it was made very clear that she was ready to do the interview and then get started with her day. Even though she was very focused on completing the task, she was animated and willing to talk about the work happening in her building. She ended the interview by saying,

I just love my job. I'm very grateful to have this job. I'm grateful to be in education, and I feel like people don't say that enough. It's not vogue, but it's great that I get to come and do this job everyday. I haven't always felt 


\section{SCHOOL REFORM AND COACHING}

that way, but definitely the past few years...I feel like we have great teachers and now it's awesome.

Hazel Hill administrator (Joe). After meeting with Sara, the Hazel Hill coach, I went to meet Joe, the administrator. I got to the school where he currently works, and he was not feeling well. He and I had worked together many years before, and he wanted to postpone the interview. When I got to the school, he was meeting with his Assistant Principal. The three of us know each other, and we talked about the school board meeting from the previous Monday. As we were talking their Student Management Specialist came into the office because she had just found a knife in a student's backpack. I left the room, so the three of them could call the student's aunt. As I was waiting, I chatted with the secretary and a couple of other staff members. I went back into Joe's office to figure out another time to meet, and he agreed to "just get this over with." He spent most of the interview with his feet on his desk, his hands in his school hoodie's pocket, and his head back. His answers were short and he did not seem open to talking about the work done at Hazel Hill. I am still unsure if this was because he was not feeling well, or there was some other reason. When we started discussing how the coach and RtI work could have been better, he opened up and talked more freely about what he thought.

Each of the interview participants welcomed the discussion about their experiences with the data informed decision-making work. Two structures and many factors surfaced in the coding of these interviews. Leadership structures and professional development structures were themes in all of the participants recounting of the 


\section{SCHOOL REFORM AND COACHING}

implementation of the data initiative in their building. The interview coding also revealed some factors that increased the successful implementation of the initiative: focus, right seats on the bus, and assessment literacy. The findings from the interviews will be described with a focus on the structures and factors indicated above.

Leadership structure. All of the participants spoke about the school leadership and how the structure of leadership in the building was a shared, or distributed, leadership model. Both the principals and coaches discussed the leadership model in depth throughout the interview in explaining how the work of increasing the use of data to inform instruction was implemented. Both Hazel Hill and Owl Creek had a leadership team that involved a number of different teacher leaders. Both of the structures will be discussed as well as the coach and administrators perceptions of how the leadership structure help the coach move the data informed decision-making initiative forward.

Distributed leadership - Hazel Hill. The principal and coach were both new to Hazel Hill the first year of the initiative. The former principal hired the coach, but the coach and incoming principal had worked together briefly in previous years. Sara stated, Yeah, so when Joe came in ... he really brought a distributive leadership process into the building. He immediately identified and really went out of his way to get staff input. He talked to people as they came through the building. [He asked] who do you think I should call about this leadership team?

Sara continued, "And I think ... having staff feel like there was a process for getting input, there are people on the team that I can go to, that I know, when I don't know the 


\section{SCHOOL REFORM AND COACHING}

principal, meant a lot." Getting teacher input about who should be on the leadership team created some trust between Joe and the staff for the first year of the initiative.

Tiffany elaborated on the structure of the distributive leadership team. The team was representative of grade levels, immersion, neighborhood, and networks of teachers. Tiffany stated,

We made sure that our leadership team was representative of grade levels, that it was representative of immersion and the neighborhood program. We also looked at ... as the work moved forward and as we got to know the building better, the leadership team people had their network of teachers, had teachers that they would go to and get information, and then they would bring that back. So they'd get teacher input from their own circle that they already had some social capital with and helped in that way. That process wasn't really formalized, but it just kind of became what we did as a school.

By inadvertently inviting teacher leaders from different social circles to the leadership team, the creation of the leadership team appears to have incorporated another level of teacher input. According to Tiffany, this unintended consequence led to an increase of trust and ability to move the school improvement work forward.

Sara discussed the decision-making power the leadership team had in the building. "I really appreciated the model of, that was a decision making body, not just an input body. Decisions were often made right there and then." Sara continued to explain that the team was given a lot of resources from Joe to make decisions, and she stated if 


\section{SCHOOL REFORM AND COACHING}

the team could not come to a final conclusion, then Joe would "... come in with a more substantial, like, okay this is what we are going to do." I got the sense from both Sara and Tiffany that teachers sharing the leadership created a sense of ownership of the professional development and the running of the building.

Shared leadership - Owl Creek. Owl Creek's leadership model focused more on the principal's vision and the "buckets of work" that needed to get done. The leadership team consisted of the Principal, the coaches [there were two in the building at the time], the Student Management Specialist, the counselor, the Assistant Principal, and the after school program coordinator. Paula explained, "That leadership team meets every Monday for an hour and a half. We do some leadership pieces, then we do long term planning, and then short term planning during that time." This team met each week, and once a month another group of teacher leaders were asked to join the meetings.

Sam: We [leadership team] would meet weekly for two hours to discuss issues, professional development. Then, the building advisory team [BAT] would meet monthly. That team consisted of teacher representatives from the primary to midlevel and middle school. We would meet monthly to discuss building wide issues.

KD: Was it teacher representatives with these other people?

Sam: yes, it was all of the admin leadership [team] plus the teacher representatives.

KD: Was there one teacher like K-2, one 3-5, one 6-8?

Sam: Mm-hmm [affirmative]. 


\section{SCHOOL REFORM AND COACHING}

KD: What did the BAT team do?

Sam: We would discuss the initiatives that were being undertaken by the staff, professional development plans, the school improvement plan, and just help provide feedback to the leadership team about the effectiveness of the different initiatives and things that we were trying ot teach in perspective on how things were going.

Paula also explained that the shared leadership was very transparent. In discussing how the data team meetings were run and whether or not Paula participated, she stated:

I make that really clear for all of our meetings, who's driving the meeting. The coach drives that [data team] meeting. I'm a participant of that meeting and if there's key decisions that have to be made, I make those decisions. If not, I'm just one of many in that conversation.

She continues to talk about the meeting structures, and she shares that all meetings have a clear agenda, a point person, and are held in an "adult space" in the building. She was very clear of the structure of the leadership model, the purpose of the teams, and the person who is responsible for reporting back regarding the tasks completed.

These leadership structures, distributed and shared, created shared ownership of the school reform work. The leadership structure created time and space for teachers, coaches, and administrators to collaborate and make decisions. Both schools leadership teams oversaw the professional development planning; both coaches discussed their role in the professional development structures at their school. Hazel Hill focused on using 


\section{SCHOOL REFORM AND COACHING}

data to create a school improvement plan, and Owl Creek focused the professional development on what Sam was seeing in the classrooms.

Professional development structure. The focus of the work at Owl Creek and Hazel Hill is best described by looking at the professional development structure at each of those schools. Professional development includes the weekly, two-hour staff meeting time, embedded time in the day for structured professional conversations and/or experiences, the data team meetings coaches were expected to complete after each benchmarking period, and the one-on-one coach to teacher conversations and experiences. Both Sam and Tiffany discussed having the ability to run the professional development during their time as coaches. Because they spent time in classrooms, they were able to create professional development experiences to help teachers with issues they struggled with focused on data informed decision-making. Sam explained the process of how the professional development was co-created by him and Paula:

Generally, what we would do, like I spent a lot of time crunching data, looking at data. I would come to her [Paula] and say, "Hey, I'm noticing this pattern," or I would come to her saying, "I'm noticing this in my [classroom] observations and I feel like we need to implement this strategy." She would either give me the go ahead or . . . ask me some clarifying questions and maybe help me rethink my position.

Because of Sam's focus on data and instruction, he was able to have conversations with Paula about next steps in professional development. This model of professional development is still working at Owl Creek. The weekly staff meeting is a PLC 


\section{SCHOOL REFORM AND COACHING}

(Professional Learning Community) meeting, and they continue to have hour and a half data team meetings after each benchmarking period. Owl Creek teachers also participate in a quarterly, whole school data team meeting. Again, the data informed decisionmaking model became the culture of Owl Creek School.

The professional development structure of Hazel Hill was different. Tiffany stated, "The biggest thing that gave me traction, I think, was having the PD calendar and being able to be in charge of all of the professional development." Tiffany explained her focus on the data informed decision-making work and how the data work created the school improvement plan. Tiffany created a structure for all teachers to have input in the school improvement plan, and all the professional development for the year focused on the data, including student work, to improve teaching and learning in the building.

Like Sam and Paula, Tiffany and Joe used the weekly staff meeting time for grade-level PLCs. Grade level teams also met during the data team meetings, and Tiffany and Joe structured the master schedule so that grade level teams had common planning time during the school day. Sara discussed her experience, as a teacher, with some of the professional development Tiffany and Joe implemented.

We had staff meeting time to meet as a grade level team and then we were coming together again for those data team times. We also had shared slots for specials, so we were planning around the same times which gave us more opportunity to have those discussions [around data and instruction] and then getting into each other's classroom, I saw a real competitive spirit in a kind of friendly, positive way. 


\section{SCHOOL REFORM AND COACHING}

Sara mentioned getting into each other's classroom a number of times in her interview. As a teacher, and then as a coach, this component of professional development seemed to be important to her when looking at moving the data informed decision-making work forward at Hazel Hill.

Both Sam and Paula discussed, in detail, the leadership structure and professional development at Owl Creek. Sam talked about "buckets" of work. He stated that literacy and attendance were his buckets. Paula explained the work as "channels." Paula stated that each leadership team has been assigned channels of work that are in-line with her vision and the district vision. "They do tasks under their channel of work under those priorities and they have to make report back to me about how they're doing for those priorities." This process seemed to be very clear and focused. Sam has not worked at Owl Creek for almost two years, and he discussed the leadership model in very clear detail. The work at Owl Creek and Hazel Hill appeared, from conversations with coaches and administrators to be very focused. These structures - leadership teams and professional development-focused the work at these schools for the teachers, coaches, and administrators.

Focus. The focus of the staff on the data informed decision-making initiative was discussed by all of the participants. It appeared that focus started, at both schools, in professional development plans that focused on the data work and the principal's clear expectation that data would be used to inform instruction. Tiffany stated:

So, I got to use the data from the individual data team meetings to think about what the next step for the whole staff and where was the whole 


\section{SCHOOL REFORM AND COACHING}

staff ready. I got to redesign...we were in a year where we needed to do the school improvement plan, so I created kind of a data driven process for the school improvement plan and presented that to him (the principal), and he let me run with it.

That focus allowed the coaches to spend their time on coaching responsibilities and not other duties. The data work was used to create a "data driven" school improvement plan at Hazel Hill. The focus on data was seen the following year by the other coach, Sara. She stated, "It was easier for me coming in because they [the teachers] have had that time with Tiffany the year before and knew like this data was not going anywhere." The principal, Joe, reiterated the notion that using data is "not going anywhere." He stated, "In year one it was just being clearer that we were going to do this [use data], that this was the direction of the school." Joe also stated data informed decision making “... really became the focus of the direction of the school, and looking at individual student needs and meeting those, so it really was so central to the school." Finally, Joe talked about his role as the leader of the building in relationship to the work of the coach. I tried to remove barriers for [both] of them, and their personalities were so different that the barriers were different.... there were times when you're in a job like a [coach] where you see the disparities in instruction, you see the need, and you want to push faster than the staff can go, so sometimes my job was putting on the brakes a little bit so that it wouldn't crash and burn. That's a hard balance to figure out. 


\section{SCHOOL REFORM AND COACHING}

Joe's statement showed his understanding of balancing the need to move the data initiative forward, but also the need to make sure teachers are able to successfully do the work being asked of them without getting overwhelmed. Joe focused on the initiative by making sure the coaches were going the right pace to show teachers growth was happening.

The Owl Creek coach, Sam, explained how Paula liked to focus the work at Owl Creek. "Her philosophy is, don't do a bunch of things. Do one or two things and do them well. Those couple of years, she really focused on the data teams and the [coach] work." This focus appears to be what is still happening at Owl Creek, and Paula explained how she organizes the work and focuses their school improvement to be in line with both her vision and the district vision. "I make what their (coaches and other teacher leaders) tasks are aligned with my vision and my vision aligned with the district vision." Just like Hazel Hill, using data became the way Owl Creek focused their school improvement process. Paula stated, "Basically, responding to an intervention of any kind, for us right now, our main focus, really we've been focusing on our behavior data." Paula also talked about how Sam was instrumental in creating the data informed decision-making culture that continues today at Owl Creek.

Paula: That [literacy benchmarking data team process] was one of the main focuses, but we were a school in significant upset...from new leaders coming in, from the resistance that was happening here. For the academics, yes that was one of our huge focuses. Sam did bring that lens to everyone. We need to assess our kids. We need to know where they are. We need to put 


\section{SCHOOL REFORM AND COACHING}

interventions in place then we need to go back and see if it's working or not. If it's not, we need to tweak. Seems so simple, but we didn't have that system in place.

KD: Sounds like that system now is...

Paula: It's rolling.

KD: How everything works.

Paula: How everything works like that. That's a very good point, yes. We went from we didn't have a system to Sam and Terry [another instructional coach] putting that system in, our coaches, that was a huge part of their job responsibility. Yes, now that's sustained, but I still keep those positions, but it's sustained and it happens in all of our grade levels now.

The shift in culture to a data informed-decision making system was directly because of the work Sam, the coach, implemented in the first few years of the initiative. This focus and culture has been sustained in the building even though Sam is no longer there. Paula discussed the work done in her building as "layers". She talks about focusing the work and adding a new layer each year. Because they are focusing on adding behavior supports, Paula stated, "The layer we've added the past year is the mindfulness lens." This focused method of school improvement appears to have created a sense of trust and transparency to the work being done at Owl Creek. Both Sam and Paula discussed the school politics during the first year of the data informed decision-making initiative that had continued from previous years. The focus on this work helped to mitigate some of the politics that occurred in the building. 


\section{SCHOOL REFORM AND COACHING}

Right seats on the bus. Another aspect of the work done at Owl Creek was what I called the "right seats on the bus." The right seats on the bus is defined as matching job functions with individual talents (Collins, 2001). Paula and Sam both discussed this concept in detail. Paula stated, "In my view of leadership is...I hire really good people in leadership roles and I assign them very clearly what their tasks are.” A little later, she expanded on this idea.

You hire really good people. You hire your best teachers. You're like, 'I need you to teach teachers.' You find your best person in behavior management, 'I need you to coach teachers,' and put those people and support those people. That's how it works for us and it seems to be working pretty well.

Paula's belief in hiring the very best people to do the work is also evident in her work to move teachers into different teaching positions. Sam discussed the movement of teachers to key teaching positions as one way the data informed decision-making initiative got more movement.

KD: What do you think gave you that traction in your work [as a coach]?

Same: I honestly think a big change, like this movement of some key staff members.

KD: Was that between year one and two?

Sam: Mm-hmm [affirmative]. 


\section{SCHOOL REFORM AND COACHING}

KD: What's interesting about your data, if you're curious, is that the first year you guys didn't get statistically significant changes, but the second year you did...

Sam: I do think, because the two people that we had in the middle school, really key positions, it was very difficult. Those were the two people that I had the most difficulty getting buy-in. The second year we also replaced the science teacher [at the mid-level], and the new science teacher that we got on board was totally into reinforcing literacy skills in the content area. She was trained with Common Core and it was a big, big difference...

Sam made it clear in this statement that getting teachers into key positions shifted the data informed decision-making work to be more effective in year two. The data, as I mentioned to Sam in the above quote, supported the idea that getting the right people in the right seats on the bus had a significant impact on student literacy benchmark scores in year two. Sam reiterated this idea a couple more times in the interview. When I asked about the trust in the building, Sam reported some of the staff were ...happy with the status quo, and wanted to continue doing what they had always been doing, they left the building for various reasons. We were able to make some new hires and make some team shifts in position. The staff started to see the results of their work and so then things changed. 


\section{SCHOOL REFORM AND COACHING}

The focus of the administrator and coach on the data informed decision-making process allowed them to get the right people in the right seats on the bus. This leads me to wonder who they thought the right people on the bus were. Both the Owl Creek and Hazel Hill coaches had clear ideas of what teachers needed in order to successfully implement the data informed decision-making initiative.

Assessment literacy. All coaches discussed the need for teachers to have an understanding of assessment and how to use data to change their instruction. Sam at Owl Creek discussed assessment literacy as a factor in how the work moved forward at his school. He stated there were students placed in tier three interventions even though the data did not support that placement. He stated,

They were naughty black boys and they go put in [tier three intervention] and so I spent a lot of time that first year battling teachers about what's the data that put this kid here because the [state-wide assessment] scores are showing this [the students are meeting]. The easyCBM scores are showing this [they are low or some risk] and then, of course, the [tier three intervention] screeners were low.

His connection to the need of assessment literacy to ensure students were placed based on data and not on perception illustrates the moral imperative to use data to inform decisions. He continued this statement by saying:

Sam: We spent a lot of time our first year talking about assessment literacy, talking about using multiple data points.

KD: And that your experience as a teacher is a data point. 


\section{SCHOOL REFORM AND COACHING}

Sam: Yes. It's a valuable data point, but there also needs to be . . . to quote my good friend Isabel [another coach working on the initiative], "your in-program assessments are data points."

Sam was using this quote from another coach to illustrate the need for teachers to understand what data they are looking at, and if more data is needed, then they should collect more data before making a decision. The coaches from Hazel Hill reiterated the idea that the coach is working to increase teacher assessment literacy.

Tiffany discussed how she saw her role as focusing on teaching the staff to use data. "I saw myself as the expert for the change. I didn't see myself as 'I am the expert in you using [district curriculum] or you using these strategies.' I'm not those. I was teaching the process and the reflective data-driven process." Tiffany focused on teaching people to use the data. Sara explained that she worked to continue the work Tiffany started.

Sara: And then also she, I think she did an excellent job in terms of promoting their own professional ... theories. Like I hear you as a teacher saying yes the data says this, but I want to look at this child's, this piece so having them go back and look for more information. Dig deeper into that individual child using their professional wisdom to kind of guide those decision-makings as well as the data, but we are kind of requiring that to be also data driven was huge. Because it's, I think a lot of times we go use your "professional wisdom" and then you go back and you are just 


\section{SCHOOL REFORM AND COACHING}

using anecdotal information or your own sense of that child and it doesn't .

.. It defeats the data process.

KD: Right. And that's a piece of it but it's not ...

Sara: Right.

KD: It can't be all you do.

Sara: Right. And well your own professional judgment can be what guides you to go back and collect more data, it can't be what guides you in placing a child or in honing a whole instructional plan if you are just basing it off of your professional ... I feel this way about the child and then you go. I did see that. I saw teams that went back and said I feel this way about this group. I feel like they are struggling with this and they would say, or we would determine, okay how are you going to collect data on that. And they would come back and like, 'yeah, so I collected the data and actually they do know that.'

Sara explained most of the time teachers underestimated what the students knew, but the process of collecting data on what they thought students struggled with allowed her, as the coach, to have those conversations with teams and individual teachers. She reported working with teams to figure out ways to collect data on aspects of student learning teachers thought students struggled with in their classes. She stated, "I wanted to make sure they were getting the information they truly needed to back up their research, their work, kind of treating it more like an action or an action research than anything else." Her focus as a coach was to help people figure out how to use the data to inform their 


\section{SCHOOL REFORM AND COACHING}

instruction. However, if the data they had in front of them did not give them the information they needed, Sara worked to help teachers and teacher teams create ways to collect that data.

Tiffany talked about how some teachers who were resistant to the data work had low assessment literacy. I asked her about the level of trust in the building, and she stated the level of trust was pretty high in the building, but she also discussed why she thought some people did not trust either her or Joe, the principal. "I do think there were some people who didn't trust ... some of the veteran teachers didn't necessarily ... because of their low assessment literacy, they didn't trust that this was really a formative process and formative assessment. They were concerned that this was going to be tied to their evaluations, that this was going to be somehow used against them." Tiffany's statement connected assessment literacy to trusting the process of using data to inform decision-making. Trust will be discussed later, but it is important to highlight the connection coaches and administrators made between different structures and the trust that was built in the building through the work of the coach.

Sara (and Tiffany) understood the data informed decision-making process, and they used it to help teachers see how data can be used to inform their instruction. They did not just use the data protocols given to coaches by the district trainers. Instead, they pushed teachers to really understand how data can be used in the classroom. In a followup conversation with Tiffany, she stated, "I feel like all I did that year I was a coach was put data in front of people. If someone wanted to make a decision, I put the data in front of them." Her focus on data, the administrators focus on making it clear everyone would 


\section{SCHOOL REFORM AND COACHING}

be using data, and increasing assessment literacy seemed to help move the data informed decision-making initiative at Hazel Hill School.

\section{Limitations of Research}

As with most educational research, my study has a number of limitations. Each data collection method has its limitations. Some of those limitations were obvious before the research was conducted, but other limitations arose as the data was being collected and analyzed. I discuss these limitations and acknowledge that there may be other limitations that I have not identified.

Literacy benchmark data. Some limitations related to using the literacy benchmark data for the two-year period of the initiative. Two important limitations are (a) the expectation that statistically significant increases would be seen in the first two years of the implementation of an initiative, and (b) fidelity to the data collection. The expectation that schools would see statistically significant increases in benchmark scores in the first two years is lofty, and many schools had increased scores, just not statistically significant increases. Further research would need to be done at schools where the initiative is still in place to determine if there have been statistically significant increases from the beginning of the initiative until now. Lack of fidelity to the data collection expectations could lead to discrepancies in the data that was analyzed and the actual results that teachers and administrators saw in their buildings during this initiative.

Initiative implementation. It is important to remember comprehensive school reform can take many years to create significant changes in teaching and/or learning (Desimone, 2002; Rogers, 1962; Sterbinsky, Ross, \& Redfield, 2006). Because this 


\section{SCHOOL REFORM AND COACHING}

initiative was only supported by the district for two years, some schools might have been moving in the right direction but those results will not be seen because the early years of the initiative is the only data analyzed. Unfortunately, Columbia School District abandoned the initiative before more meaningful analysis of effectiveness could be identified. If the initiative was still in place, data from the past four years could have been analyzed to determine if more schools were seeing statistically significant increases from the beginning of the initiative to today. A comparison between schools where scores increased quickly (Hazel Hill and Owl Creek) and where scores increased slowly over time could have been conducted to develop a clearer picture of the structures and supports coaches and administrators need for successful implementation of a new initiative.

Fidelity to data collection. When analyzing the data, I found that coaches did not always collect the data that was expected. The coaches were asked by the district trainers to work with all teachers to benchmark every student at each benchmarking period. That data was used for data team meetings, discussions of interventions, creation of action plans to address specific gaps, and to summarize the effectiveness of the RtI model being implemented in the building. Many schools had very different N's for fall, winter, and spring benchmarking periods. For example, Elkton had 680 data points in fall of 2011 and 315 data points in spring of 2013. The coach was the individual that ensured the data was being collected properly, so this limits my ability to adequately analyze the data. If a coach did not work to assess every student and/or if a teacher refused to complete benchmarking, then there is data missing. In looking at the data from Elkton and 


\section{SCHOOL REFORM AND COACHING}

Willakenzie - both schools with statistically significant decreases in literacy benchmarking scores - I wonder if those decreases were because the coach or teachers did not test every student at every benchmarking period.

When considering the fidelity of the data collection, another issue arose, and it was the absence of data from certain schools during specific benchmarking periods. Chelan School did not have any benchmarking data for winter 2013 or spring 2013. Elkton School did not have any benchmarking data for spring of 2013. It is unclear why this data is missing, and it raises questions about how those coaches and/or administrators implemented the data informed decision-making initiative in those buildings. A couple of explanations merit consideration - coach/teachers did not benchmark students, school decided to use a different benchmarking tool, and/or the benchmarking was completed outside of the benchmarking window. Without further conversation with those coaches, it will be hard to determine the reason for the missing data. Both of these issues, missing student data and missing school data, are reminders that the data informed decisionmaking initiative was implemented with varying degrees of success in each of the twenty buildings during the two-year period.

Surveys. The varying degree of success in the 20 school buildings was also seen in the survey data. The limitations of the survey were known before the data was collected. Specifically, the survey was perception data from one perspective at one point in time. The coach was the only participant in a school building who was asked to complete the survey. A more thorough understanding of the work occurring in the schools could have been obtained by surveying teachers, coaches, and administrators. I 


\section{SCHOOL REFORM AND COACHING}

chose to focus the survey on the coach because the survey was used to identify, with the literacy benchmarking data, coaches and principals that should be studied further. Each of the coaches filled out the survey focused on the time they served as a coach in the data informed decision-making initiative, so the information collected was the coach's perspective of what happened in a school more than two years prior. Because the information being collected was historic data, coaches might not remember the information correctly, so I acknowledged a limitation of the research is all the data collected from the survey was perception data from the coach at a specific point in time. A stronger data collection method would have involved collecting the survey data at the end of each of the years of the initiative, instead of two years after the last year of the initiative.

Interviews. As with the surveys, I conducted interviews to ask participants to remember what had happening in the building where they were during the 2011-2012 and 2012-2013 school years. Four of the five interview participants no long work in the school where they were either the coach or principal during the time of the initiative. Each participant worked to talk about the work done during the time of the initiative, but almost every participant related the work done in those years to the work they are doing now. I wanted to focus the interview discussion on the work during the initiative, which may have been a limitation. Specifically, participants did not necessarily talk about how the work of the initiative changed their current practice. This information might have been another way to measure the success of the initiative, but it was not the focus of my research. 


\section{SCHOOL REFORM AND COACHING}

Another limitation of the interviews was the people I chose to interview. I interviewed coaches and principals from schools with statistically significant increases in literacy benchmarking scores for the two years of the initiative. These coaches and principals identified structures and factors they perceived led to the successful implementation of the data informed decision-making initiative. I did not interview coaches or principals at schools without statistically significant increases, so I do not know if the structures they identified would have been seen in other schools.

\section{Summary}

Eight schools had increases in literacy benchmarking scores in the two years of the initiative: Amity, Hazel Hill, Naches, Owl Creek, Red Hill, Snipes Mountain, Umpqua Valley, and Wahluke. The data from these coaches' surveys were analyzed to determine any patters in factors that might have contributed to the increased literacy benchmark scores. Some factors that were identified were: trust and focus. Of these schools, two had statistically significant increases in literacy benchmarking scores: Hazel Hill and Owl Creek. The coaches and principals of these schools were interviewed to determine what structures were in place to support the data informed decision-making initiative. Some structures identified were leadership structure and professional development structure. Other factors identified were focus, assessment literacy, and getting the right people in the right seats. Seven schools had no changes in literacy benchmark scores over the two years of the initiative: Applegate, Carlton, Chelan, Goose Ridge, Meridian, Red Mountain, Ribbon Ridge, and Rogue. The survey of these coaches was also analyzed to determine what factors might have contributed to the lack of 


\section{SCHOOL REFORM AND COACHING}

improvement in literacy benchmarking scores. Assessment literacy of teachers, lack of focus, and a lack of understanding and/or support from the principal were all identified as possible factors. Finally, three schools had decreases in literacy benchmark scores: Elkton, Walla Walla, and Willakenzie. Two of these schools, Elkton and Willakenzie, had statistically significant decreases in scores. Comparing their survey information to the other participants, the factor that was identified that may have contributed to the statistically significant decreases was the lack of professional development the coaches received. Both coaches stated they participated in the district offered professional development no more than half of the time. Finally, the decision by the district to stop the data informed decision-making initiative after two years of implementation was discussed by almost every participant in the study. 


\section{SCHOOL REFORM AND COACHING}

\section{Chapter 5}

\section{Discussion}

The purpose of this study was to determine what organizational structures were needed for a coach to implement a data informed decision-making initiative successfully. Three data sets were used to determine what organizational structures are needed: literacy benchmarking data, survey of coaches, and interviews of coaches and principals. The literacy benchmarking data and the survey of coaches led to a purposive selection of the coaches and principals to be interviewed. The research questions were: (a) which urban schools showed increases in students' literacy benchmarking scores?; (b) what did the coach perceive as the significant structures that led to the implementation of the data informed decision-making model?; (c) what did the principal perceive as the significant structures that led to the implementation of the data informed decision-making model?; (d) what factors within the structure of the organization supported the coach in implementing the data informed decision-making model? This chapter has an overview of the findings from the data collection, discussed in the previous chapter, organized by research question. Making sense of the findings through the lens of organizational change, I will discuss implications and suggestions that could be useful in implementing a school reform effort using coaches as the professional development support. The chapter concludes with suggestions for future research.

\section{Synthesis of Findings}

Each of the research questions posed in this study was answered using different data sets (see Table 5). The question "Which urban schools showed increases in student 


\section{SCHOOL REFORM AND COACHING}

literacy benchmark scores?" was answered using the literacy benchmarking data set provided by the district being studied. The second and third questions, "What did the coach (question three)/principal (question four) perceive as the significant structures that led to the implementation of the data informed decision-making model?" were both answered using the interviews of the coach and principal, respectively. These two questions have been collapsed into one section because the findings are the same for coaches and principals when looking at the significant structures in place for the implementation of the data informed decision-making initiative. The fourth question, "What factors within the structure of the organization supported the coach in implementing a data informed decision-making model?" was answered using the coach surveys and the coach and administrator interviews.

\section{Which urban schools showed increases in student literacy benchmark}

scores? There were eight schools that showed increases in literacy benchmarking scores over the two years of the initiative using the decision-rules discussed in chapter three (see Table 2): Amity, Hazel Hill, Naches, Owl Creek, Red Hill, Snipes Mountain, Umpqua Valley, and Wahluke. Two of these schools, Hazel Hill and Owl Creek, had statistically significant increases. Hazel Hill had statistically significant increases over the two years of the initiative, and Owl Creek had statistically significant increases during year two of the initiative. Two other schools had statistically significant differences between expected and actual frequencies: Elkton and Willakenzie. Analysis of the descriptive statistics showed the statistical significance was not an increase in low risk and decrease in high risk scores. 


\section{SCHOOL REFORM AND COACHING}

What did the coach/principal perceive as the significant structures that led to the implementation of the data informed decision-making model? The coaches and principals all identified the same two structures that were in place to support the data informed decision-making initiative implementation: leadership structure and professional development. Both of these structures were discussed, in detail, in the interviews. These structures were perceived to create factors that contributed to the successful implementation of the data informed decision-making initiative.

Leadership structure. Hazel Hill and Owl Creek coaches and principals discussed the shared (Owl Creek) and distributed (Hazel Hill) leadership as a structure supporting the implementation of the data informed decision-making initiative. Both schools had leadership teams with multiple teacher representatives and regular meeting times. The leadership teams were a conduit between the administration and what was happening in the classrooms. The coach at each school was in integral part of these leadership teams, so the data informed decision-making process was modeled in those meetings and discussed as a part of the school improvement process.

Professional development. The term professional development (PD) encompasses all of the PD that occurred for teachers in the building. This includes weekly two-hour staff meetings, data team meetings, one-on-one and/or small group coaching. All of the interviewees discussed professional development as a structure that contributed to the implementation of the data informed decision-making initiative. Hazel Hill's coach in year one focused on creating a data informed process to create the school improvement plan, and she worked to create a culture of data use in all decision making 


\section{SCHOOL REFORM AND COACHING}

in the building. The year two coach focused more on helping individual teachers use data to plan instruction and working with the data teams to use data to create action researchtype projects to implement in their instruction. The Owl Creek coach used classroom observations and modeling to focus teachers on creating more inclusive lessons, mainly focused on sheltered instruction strategies. The specific structure of the professional development was different, depending on the coach, but all interview participants highlighted the need for ongoing and focused professional development for teachers on data use in the classroom that was connected to the larger professional development plan for the school. All three coaches discussed ways they focused teachers and administrators on the data informed decision-making work through professional development.

Another finding about professional development was the need for coaches to participate in regular and on-going professional development. The two schools with statistically significant decreases in literacy benchmark scores from fall to spring, Elkton and Willakenzie, had coaches who participated in the district coach professional development no more than half of the time. Almost every other coach participated "always" or "almost always." The need for coaches to come together, discuss issues, learn new skills, and receive ongoing professional development is evident by the literacy benchmark results of those two coaches compared to the other coaches in the study.

What factors within the structure of the organization supported the coach in implementing a data informed decision-making model? Some factors were seen throughout the data: focus, assessment literacy, trust, right people on the bus, and coach- 


\section{SCHOOL REFORM AND COACHING}

principal relationship. Both coaches and principals identified these factors. Coaches not interviewed identified some through their answers to open-ended questions on the survey. Focus, assessment literacy, trust, and right people on the bus were discussed at length in the previous chapter, so the findings for those factors will be discussed briefly. The last finding - coach-principal relationship - will be discussed in more depth here.

Focus. Focus was identified in both the coach survey and coach/principal interviews as a component of successful implementation of the data informed decisionmaking initiative. A lack of focus was also identified as an aspect leading to no changes in literacy benchmarking scores. Many coaches stated they had the time to focus on the work because it was the sole job for the coach. Other coaches who were not as successful discussed the lack of focus by describing the requirement they "wear many hats" in their buildings. Finally, almost every coach and administrator who was surveyed and/or interviewed discussed the lack of focus in the district as being a barrier to implementing the initiative.

Assessment literacy. Some of the surveyed coaches identified the need for assessment literacy; the interviewed coaches and principals also addressed the need to increase assessment literacy. On the survey, coaches were asked to use a one to four Likert scale to rate how often, in their opinion, teachers participated in specific professional practices (see Table 14). The change in the rating on the statement, "teachers using data to inform their instruction" increased significantly $(\mathrm{p}<0.05)$ between years one and two. Also, many coaches said teachers increased their ability to use benchmark, progress monitoring, and in-program assessments to change instruction 


\section{SCHOOL REFORM AND COACHING}

for students. Coaches also discussed the lack of assessment literacy as a barrier to carrying out the data informed decision-making work.

Some findings focused on principal's assessment literacy. The survey asked about the principal's understanding of the data informed decision-making initiative. Most coaches in schools with increases in benchmark scores felt their principal had strong general knowledge of the data informed decision-making initiative. However, coaches stated the knowledge decreased when considering the principal's understanding of classroom based assessments, curriculum, and/or interventions. A few coaches discussed the lack of understanding decreased the ability of the teachers and coaches to have an effective RtI process. Finally, the feeling of success as a coach in relation to the principal's understanding of the data informed decision-making initiative was not statistically significant (possibly because of the low $N$ ), but some patterns emerged. All of the coaches who felt they were successful stated their principal understood the data informed decision-making initiative. Of the four who did not feel successful, two stated their principal did not understand the initiative at all, and two stated the principal only understood the initiative somewhat (see Table 16).

Trust. Trust was discussed throughout the findings, but was only identified as a finding when looking at the survey results focused on the coach's feeling of success. The coaches at schools with increases in literacy who felt successful discussed either the trust or relationships built through the data informed decision-making initiative or how their existing relationships helped them implement the initiative. All of the individuals interviewed said trust was a factor that contributed to the success of the implementation. 


\section{SCHOOL REFORM AND COACHING}

Sara, the second Hazel Hill coach specifically identified ways the leadership and professional development structures, specifically the coach and the data team meetings, created trust. Sam, from Owl Creek, talked about the lack of trust in the building, and he also identified his willingness to model lesson and co-plan with teachers as a way to build trust between the coach and the resistant staff.

Right people on the bus. The Owl Creek coach and principal discussed getting the right people in the right seats on the bus (and getting the wrong people off the bus). The Hazel Hill coaches also discussed the need to have teachers in positions where they are successful. A few other coaches discussed how the focus of the work was helped or harmed by specific people on staff. The decision to get people in the right seats on the bus at Owl Creek was a collaborative effort between the coach and the principal.

Coach-principal relationship. The one factor not discussed specifically in chapter four was the relationship between the coach and the principal. One of the survey questions asked coaches how supported they felt by their administrator. Coaches who stated they felt successful as a coach had a higher average score on how supported they felt by their principal (see Table 15). Many coaches felt supported by the principal, and some coaches discussed their principal advocating for the coach position to stay in their school. However, the relationship between coach and principal is most evident in the interviews. Joe, the Hazel Hill principal, discussed the need to find the right balance between moving the work forward and slowing the work down. He based these decisions on the coach he was working with at the time. He stated, “... their personalities were so different that the barriers [to doing the work] were different." Joe knew both of his 


\section{SCHOOL REFORM AND COACHING}

coaches very well, even though he had only worked with them for a short amount of time. How Joe and Tiffany, and later Joe and Sara, worked together built trust between the coach and the principal. Sam and Paula from Owl Creek reiterated the importance of the coach and principal relationship. They both discussed how confident Paula was in Sam's skills. It was also clear Paula held the vision for the school and Sam worked to ensure that vision was being focused on each day through the data work.

\section{Larger Context}

The findings from my research can be situated in the larger context of the research literature discussed in chapter two. Each of the findings listed above will be discussed in relation to the body of research that I reviewed and situated in the theoretical framework of organizational change. Many of the findings from this research mirror the current understanding of organizational change and school reform. I will also discuss implications of the findings for the Columbia School District and other schools/districts considering using coaching as a way to increase the implementation of a data informed decision-making initiative. Finally, I will discuss any areas for further research that could be considered based on the findings from this study.

Increased literacy benchmark scores. Data informed decision-making can be a way for schools to increase student literacy benchmark scores (Feldman \& Tung, 2001; Kerr et al., 2006; Marsh et al., 2006; Marsh et al., 2009; Schmoker \& Wilson, 1995). The success of the initiative varied in each of the schools and this finding is supported by research showing the promise of data use has not been realized in many schools (Herman \& Griffons, 2001; Ingram et al., 2004; Jimerson \& McGhee, 2013). A number of 


\section{SCHOOL REFORM AND COACHING}

different reasons explain why data use has not been successful, and one reason is lack of professional development for teachers (Herman \& Gribbons, 2001; Murray, 2013; Park et al., 2012). Coaches were used to help teachers learn how to effectively use data to inform their instruction. In the two years of the initiative, nine schools saw increases in literacy benchmark scores. The schools with increases in scores had coaches who focused their work on the data informed decision-making initiative (Marsh et al., 2009). The focus on analyzing data and helping teachers change their instruction is supported in the research (Marsh et al., 2009). However, Marsh et al. (2009) also found coaches with three or more years of experience were significantly more likely to effectively use and analyze data than coaches with fewer years of coaching experience. Only three coaches of the 18 surveyed reported they had been a coach before the beginning of the initiative. Because the district abruptly stopped the initiative, there is not any data to determine if the findings of Marsh et al. would be supported.

Professional development structure. The three aspects of professional development identified in this study were: principal, coach, and teacher. Each group needed and received different professional development during the initiative. Principals were offered few (no more than four) opportunities for professional development, all in the first year of the initiative. Coaches received bi-monthly professional development from the district, and teachers received weekly, and sometimes daily, professional development in their buildings from administrators and coaches.

Principal professional development. My study showed coaches' perception of success decreased as the principal's understanding of the data informed decision-making 


\section{SCHOOL REFORM AND COACHING}

initiative decreased. The teachers' and coaches' capacity for data-driven inquiry is dependent on the school leader creating a culture of data use in the building (Wayman et al., 2007). Without the principal's strong understanding of the data informed decision making work, it was difficult for the coach and/or the teachers to implement the initiative. Principals had limited professional development (that was also poorly attended), and it was focused on the implementation of the initiative. I argue principals also need professional development focused on how change happens in schools. A meta-analysis of literature on effective school leadership suggested the ability of the principal to find balance between technical and adaptive leadership practices could improve student achievement (Waters et al., 2003). Like many school reform efforts, the initiative was created to solve adaptive challenges, but in many schools in this study it was implemented using technical fixes (Cuban, 1990; Elmore, 2004; Fullan, 2008b; Reeves, 2003; Supovitz, 2009). Professional development for principals focused on organizational change theory could ensure principals understood diffusion of innovation (Rogers, 1962), learning organizations (Senge, 1990), and continuous improvement (Deming, 1982). This would increase the principal's understanding of the data informed decision-making work (Deming, 1982), how to diffuse the initiative through the teachers in the building (Rogers, 1962), and how to create a trusting and productive work environment for teachers (Senge, 1990).

Coach professional development. One of the limitations coaches identified when discussing their ability to implement the initiative was lack of trust and/or resistant teachers. Coach professional development should include teaching coaches how to deal 


\section{SCHOOL REFORM AND COACHING}

with teacher resistance (Knight, 2006), not just how to help teachers use the data to inform instruction (Marsh et al., 2009). Ippolito (2010) argued coaches need training in how to address the complex interactions they have with teachers, so coaches can balance their responsive and directive interactions. Some coaches, in the interviews and surveys, referred to "coaching heavy" (Killion, 2008). I argue the need for coaches to be trained on how to coach heavy or light (Killion, 2008), or be responsive or directive, (Ippolito, 2010). Coaches received professional development from the Columbia School District twice a month. Coaches who participated in that professional development felt more successful and had greater increases in literacy benchmark scores than those who did not participate in the professional development. Marsh et al., (2009) also found coach professional development was an important factor in the success of the coach helping teachers implement a data driven decision-making program.

Assessment literacy. One finding from this study was the need for all school staff to have an understanding of assessments and data and how to use them effectively to change instruction to increase student achievement. Both researchers and practitioners of data use in the classroom support these findings. Research argued the need to separate data use in the classroom from high stakes accountability tests (Jimerson \& McGhee, 2013; Mason, 2002; Murray, 2013; Shen \& Cooley, 2008; Shen et al., 2012). In my research, not one coach mentioned the statewide reading test. One teacher mentioned the Smarter Balanced Test being implemented in 2015-16 year, but the test was mentioned as an example of the potential new focus at the school where they were serving as a coach. Research also indicated that teachers and administrators often lack the skills and/or 


\section{SCHOOL REFORM AND COACHING}

knowledge to use data to improve teaching and learning (Coburn \& Talbert, 2006;

Cosner, 2011). These findings were supported by the findings from this research.

Administrator understanding of data use and the data initiative affected a coach's sense of success in their work. Many coaches discussed the need to teach teachers how to use the literacy data to make decisions about instruction and student placement. The increases in assessment literacy led to teachers implementing the data informed decision-making practices more regularly. Practitioners also support the importance of assessment literacy. The Data Wise cycle of inquiry has eight steps. The second step is "assessment literacy" (Boudett et al., 2005) and includes the recommendations of teaching teachers and building leaders how to look at data, understand different assessments, and discuss data in a collaborative environment (Boudett et al., 2005; Boudett \& Steele, 2007). I believe the schools with increases in literacy benchmark scores created a collaborative environment where teachers could learn assessment literacy and the data informed decision-making process.

Teacher professional development. Teachers at schools with increases in literacy benchmark scores worked with coaches who reported focusing on the work of helping teachers to use data to change their instruction. Teachers need meaningful professional development to change their practice and coaching has been shown to increase the transfer of skills taught to teachers into their classroom practices (Cornett \& Knight, 2009; Joyce \& Showers, 2002). My study's findings support the research on coaching as an effective way to increase the transfer of new skills to teachers. Asking teachers to change their practice requires providing training and on-going support to ensure the new 


\section{SCHOOL REFORM AND COACHING}

practices are being used (Cornett \& Knight, 2009). Teachers in buildings with coaches who focused on this work had students with literacy benchmark scores that, on average, increased. More research would need to be done to find out how teachers used the coach and/or how the coach help to change teacher practices around data use.

Tiffany, the Hazel Hill coach, and Paula, the Owl Creek administrator, talked about the coaches as change agents - creating a culture of using data to make decisions in their buildings. Coaches can be a change agent while providing professional development to teachers (Fullan \& Knight, 2011). The coach as a change agent centered on providing meaningful and focused professional development on using data to make decisions. Because coaches are site-based, teachers got ongoing, daily professional development focused on the implementation of new practices (Borman \& Feger, 2006; Brown et al., 2005; Deussen et al., 2007; L'Allier et al., 2010; Toll, 2005; Veenman \& Denessen, 2001; Walpole \& Blamey, 2008). This focused and ongoing professional development led to at least two schools-Owl Creek and Snipes Mountain-continuing the work of creating a culture of data use to inform decisions in the classroom and, at Owl Creek, in the school. Both of these schools discussed the leadership structure as a way to work toward creating a culture of data use at their schools.

Leadership structure. The Owl Creek and Hazel Hill coaches and administrators discussed how the shared leadership structures in the building during the two years of the initiative increased the implementation of the data informed decisionmaking process. This finding is supported by literature in the fields of coaching research (Ippolito, 2010) and education leadership research (Spillane et al., 2001). Because the 


\section{SCHOOL REFORM AND COACHING}

coach at both schools was a participant in the shared leadership model, I believe the leadership structure discussed by the interview participants aligns with the research showing shared leadership can support the work of a coach (Burkins, 2007; Kral, 2007; Toll, 2009). The coaches, Sam and Tiffany, discussed how they were the initial data inquiry leaders, and they worked to build data use in all school personnel, including the principal. Wayman and Stringfield (2006) argued the principal could show strong leadership by modeling data inquiry. Even though this responsibility fell to the coach in both of these buildings, I believe the initiative was implemented successfully because of the shared leadership model. The shared leadership model allowed the coach to be the school leader who was knowledgeable and committed to data use (Feldman \& Tung, 2001; Herman \& Gribbons, 2001; Lachat \& Smith, 2009; Mason, 2002). Finally, the shared leadership model with strong data leaders was a way to address teacher resistance and/or lack of buy-in (Ingram et al., 2004). Sam, the Owl Creek coach, discussed his use of data as a way he built relationships with the teachers. Tiffany (Hazel Hill) also discussed her strategy of getting the data in front of people. Both of these coaches built teacher buy-in through modeling data use.

When reviewing the leadership structures of Hazel Hill and Owl Creek, I noticed their structures were similar to the components needed for systems thinking (Senge, 1990). The four disciplines, team learning, shared vision, personal mastery, and mental models, are surrounded by systems thinking to create a learning organization (see Figure 1). In both schools, the leadership team had a shared vision and had systems in place for the team to learn from each other. Each leadership team had individuals who were 


\section{SCHOOL REFORM AND COACHING}

experts on specific aspects of the work, and they used data to inform their decisions. These ideas are similar to the first four disciplines. Further research would need to be completed to compare the leadership structures of the two schools to Senge's (1990) learning organization.

A more complete analysis of leadership structures within the buildings where the initiative was being implemented would need to be completed to determine if Owl Creek and Hazel Hill's leadership structures were unique in the Columbia School District. If the structure is unique to these schools, it would be in the interest of Columbia School District to create principal professional development focused on school leadership structures to help building leaders create a shared leadership model in their own buildings. Again, understanding organizational change theory supports this idea. Heifetz and Laurie (1997) confirmed the importance of having different stakeholders who have different interpretations of the issues at hand on the leadership team when addressing adaptive challenges. School districts and universities should help train building administrators to identify technical and adaptive challenges and then find the balance between offering solutions for technical challenges and asking hard questions to address adaptive challenges (Heifetz \& Laurie, 1997). Finally, the meta-analysis completed by Waters et al. (2003) determined two primary variables in their research on effective school leadership: (a) the leader's understanding of the magnitude of change (adaptive versus technical), and (b) the focus of the change.

Focus. Focus was a factor discussed in the surveys and the interviews, and it is also discussed in the coaching and organizational change literature. Heifetz and Laurie 


\section{SCHOOL REFORM AND COACHING}

(1997) argued "Maintaining disciplined attention" was one of the six principles guiding successful adaptive leaders. Focus was discussed on two different levels: building and district. At the building level, focus, or lack of focus, was discussed by the coaches as a factor in their feeling of success, as well as a factor in coach's actual success at implementing the data informed decision-making initiative. Almost every participant commented on the lack of the district's focus in implementing this initiative.

Building level focus. Coaches who were not successful, there was no change in the literacy benchmark scores, and/or did not perceived themselves as successful, reported a lack of focus. The Umpqua Valley coach simply stated, "Too many other responsibilities" as their reason for not feeling successful as a coach. The Chelan coach said, "The principal used the coach as more of an 'end all be all' to every task which needed assistance.” Both coaches were pulled in too many directions to effectively implement the initiative. The job of a coach can be challenging because coaches can have many competing roles (Deussen et al., 2007; Killion, 2008; Toll, 2005; Veenman \& Denessen, 2001). When a coach's role is too expansive, as both coaches above eluded to in their statements, there is potential the coach's impact will be diluted (Killion, 2009; L'Allier et al., 2010; Marsh et al., 2009).

The lack of focus from the coach could be rooted in other factors. The principal might lack focus on the initiative. As mentioned above, the leaders in the building must build a strong vision for data use, and model data inquiry, in the school (Copland, 2003; Feldman \& Tung, 2001; Lachat \& Smith, 2009; Mason, 2002; Wayman \& Stringfield, 2006). Principal understanding of the data informed decision-making initiative was 


\section{SCHOOL REFORM AND COACHING}

connected to the coach's feeling of success in their work. Many coaches in schools with no change in literacy benchmark scores stated their principal understood the larger concepts of data informed decision-making, but lacked the depth of knowledge to move the work forward in the building. I wonder if the lack of knowledge was in data informed decision-making and/or in how to focus the work in order to bring about change within the organization (Fullan, 2008a, 2009; Schmoker, 2011; Senge, 1990). Further research, focused on the principals, would need to be done to determine where the root causes of the lack of focus within buildings with no changes in scores. Again, I argue principals need more professional development on how to create and sustain change in their buildings. Like teachers, this training needs to be on-going and help principals address the on-the-ground issues they are dealing with in order to bring about lasting change in instruction for our students. I believe this cannot be done until the district leaders decide what initiatives they want to focus on to create lasting school change.

District level lack of focus. Overwhelmingly, participants discussed the lack of focus on this initiative by the Columbia School District leaders. Focusing on one or two aspects of change at a time can lead to increases in student achievement (Schmoker, 2011; Schmoker \& Wilson, 1993, 1995). The lack of focus of the Columbia School District perpetuated the initiative fatigue that occurs in many school districts (Knight, 2009; Reeves, 2006; Schmoker, 2011). Rogers (1962) purported through his theory of diffusion of innovation that new initiatives take time to spread through an organization. The initiative studied was only in place for two years. Some coaches who participated in the initiative for both years discussed the focus of the work changing between years one 


\section{SCHOOL REFORM AND COACHING}

and two. This lack of focus could be one reason why literacy benchmark scores did not improve in some schools. Most of the coaches do not work in the same buildings, and even though many of the schools are still using literacy benchmarking, most do not have data team meetings to give teachers time to create action plans to help students.

Benchmarking students but not giving teachers' time and support to look at the data and make decisions perpetuates the problem of having too much data and not knowing what to do with it (Shen \& Cooley, 2008). The findings of this study indicate Columbia School District's lack of focus could be contributing to stagnant student literacy benchmark scores in the district. I argue it is difficult for administrators and coaches to focus their work without focus from the district level. I conclude that the lack of focus of the Columbia School District also affected the coach and principal's sense of trust in the district and its leadership.

Trust. The issue of trust was mentioned by many of the coaches in the survey as well as the coaches and principals who were interviewed. The issue of trust as an important prerequisite for organizational change is well documented. Daly and Chrispeels (2008) examined what conditions needed to be in place to ensure adaptive challenges can be addressed in schools, and they found a strong positive correlation between trust and adaptive leadership dimensions being successful. My findings supported this research. Many coaches mentioned trusting relationships as an indicator of their success as a coach. Sam and Tiffany discussed how the data initiative helped them build trust with colleagues. This trust was created because the data was used as a positive tool for change, and it was not linked to federal accountability measures like 


\section{SCHOOL REFORM AND COACHING}

NCLB (Jimerson \& McGhee, 2013; Mason, 2002; Murray, 2013; Shen \& Cooley, 2008;

Shen et al., 2012). Research literature focused on administrators support this finding. Strong, data focused administrators ensure data use is nonthreatening (Lachat, 2001; Wayman \& Stringfield, 2006). My findings support these ideas, though the change leader was the coach, not the principal. This research found coaches and principals identified trust as one of the most consistent factors contributing to the successful implementation of a data informed decision-making initiative. Further research needs to be conducted to determine if teachers perceive trust to be a contributing factor to their implementation of the data informed decision-making initiative.

Coach-principal relationship. Another aspect of trust was the relationship between the coach and the principal. Both the principals interviewed discussed the level of confidence and trust they had in the coaches they hired. The coaches and principals all discussed how their work, together, created the instructional leadership model in the building. Southworth (2002) argued the need to stop focusing on school leaders and instead focus on instructional leadership. This argument is supported in my research. Much of the literature about school leadership focuses on the principal. School leaders need to be both technical and adaptive leaders who can determine whether a problem is technical or adaptive and respond accordingly (Heifetz \& Laurie, 1997; Randall \& Coakley, 2007). By expanding what is considered a school leader, I argue the coach and principal at Owl Creek embodied the ability to be both a technical and adaptive leaders. The principal, Paula, focused her work on holding the vision for the school, and Sam focused his work on using data and coaching methods to change teacher practices around 


\section{SCHOOL REFORM AND COACHING}

data use in their classrooms and decision making. There is little research on coaches as change agents in education reform (York-Barr \& Duke, 2004). The results of this study indicate coaches can be change agents, and further research should be done to determine how the relationship between the coach and the principal created the factors allowing Sam and Tiffany to successfully create change in their buildings. A key aspect of Sam and Tiffany's ability to create change was the willingness of the principals to work on getting the right people on the bus.

Right seats on the bus. The Owl Creek coach and principal discussed the need to get the right people in the right seats on the bus in detail. On the survey, other coaches discussed how certain staff changes made big differences in the ability of the staff to implement the data informed decision-making initiative. The first step in the Data Wise cycle of inquiry is "organizing for collaborative work" (Boudett et al., 2005). That organization includes getting the right people on the data team (Boudett et al., 2005; Boudett \& Steele, 2007). Sam and Paula discussed getting the right people on the bus when discussing teaching staff. However, both principals discussed hiring the right coach to help them move the work forward. I argue getting the right people on the bus starts with getting the right principal on the bus and then allowing them to hire the right coach. Research supports my assertion of getting the right principal on the bus first. Wayman et al. (2007) stated, “...data use lives and dies in the principal's office (pg. 5). Without strong leadership that is trained in organizational change and data informed decision-making, I argue schools will continue to get mediocre improvements in student achievement. 


\section{SCHOOL REFORM AND COACHING}

\section{Implications}

Schools are complex organizations. To bring about the adaptive changes needed to increase student achievement, a number of factors and structures must be in place simultaneously for change to occur. The schools studied illustrated the complexity of implementing an initiative in a school culture that may or may not be ready to address adaptive challenges. The focus of this research was to determine what structures were needed for a coach to successfully implement a data informed decision-making initiative. The coaches were used as the professional development model to help teachers learn to look at data to inform and change their instruction with the goal of increasing student achievement. Before coaches can implement a new initiative with teachers, this research identified some structures and factors that could increase a coaches' ability to successfully help teachers learn about and use a new initiative in their teaching practices. Many coaches in this study had some of the factors and/or structures in place at the schools where they worked. For example, many coaches reported having trusting relationships with colleagues and administrators and functioning data team meetings, but these factors alone did not necessarily lead to increases in literacy benchmark scores. The findings have led me to some key implications and recommendations for the Columbia School District leaders, principals, and coaches.

Columbia School District. Many of the findings showed the principal and coach focus on the initiative had a significant impact on the ability of the teachers to implement the data informed decision-making model. Coaches in buildings with increases in benchmark scores discussed focus on the work as an important aspect for the successful 


\section{SCHOOL REFORM AND COACHING}

implementation. Coaches in schools with no change and/or coaches who did not perceive their work as successful cited the lack of focus in the building as a contributing factor. The most telling aspect of focus was the lack of focus on the initiative by the Columbia School District. I believe the lack of focus by the district created multiple unintended consequences, which also affected coach's abilities to implement the data initiative.

Initiative implementation. The implementation of the data informed decisionmaking initiative was only supported by the Columbia School District for two years. Rogers (1962) argued the diffusion of innovation can take longer than two years before leaders start to see results. Because the initiative was only a focus for two years, it is possible the teachers who are innovators and early adopters were the teachers coaches spent time with in their schools. Because of this, there was not as much discussion about resistance by the coaches because many coaches were working with the teachers who are willing to try new practices. If the district were to continue to focus on the initiative, there would need to be some supports and planning focused on how to help coaches and principals work with resistant teachers, specifically the laggards.

Initiative fatigue. An unintended consequence of the decision to abandon the data informed decision-making initiative was the coaches' feeling of initiative fatigue. Many coaches discussed their disappointment in the district's decision to not support the coaches and/or the data informed decision-making initiative. Most coaches reported their school was still completing literacy benchmarking each year (15 yes; 3 no). Unfortunately, only seven coaches stated the school still had data team meetings (4 no; 7 not sure). The purpose of the data informed decision-making initiative was to teach 


\section{SCHOOL REFORM AND COACHING}

teachers how to collect and analyze data through a collaborative process (Boudett et al., 2004). Without the collaboration, teachers are left to work on their own to create data informed decisions about their classrooms. One coach stated the frustration she had with this process.

During the years following [the initiative], teachers are asked to examine data and write reading action plans largely on their own. This has led to large inconsistencies in whether or not teachers complete literacy action plans at all, and as far as I can tell, little accountability about how teachers use classroom data. Teachers who are personally inclined to use data to make decisions continue to do so; those who are not (due to less experience/buy-in/etc) are free to make "gut" decisions on student learning.

This coach explained how teacher practices have gone back to how they were before the initiative. Because many schools are still collecting literacy benchmark scores, students are being asked to complete more assessments, teachers have more data they may or may not use, and changes to instruction may or may not be happening. As more initiatives are attempted, attacked, and then abandoned (Knight, 2009) in the Columbia School District, I wonder how many remnants of other initiatives have become part of what teachers and students are asked to do.

Trust. The lack of trust in the district was evident by a few coaches' responses on the survey. Again, I assert the lack of trust in the district was an unintended consequence of the lack of focus on this initiative. The Meridian coach discussed how s/he felt the 


\section{SCHOOL REFORM AND COACHING}

district gave up and kicked the coaches out of their jobs. I contend the lack of focus decreased the trust of the coaches and the principals in the district. The Columbia School District will have another initiative the leaders believe will bring about the adaptive changes needed to increase student achievement. However, without trust, those adaptive changes cannot happen (Daly \& Chrispeels, 2008). I recommend the Columbia School District spend some time building trust with the teachers and administrators before taking on another school reform initiative. One way to build trust could be bringing together a group of stakeholders who have different interpretations of the issues at hand and have them create the vision and/or plan for the new reform effort (Heifetz \& Laurie, 1997).

Leadership development. Even in the short amount of time the Columbia School District implemented the initiative, there were some positive outcomes for the district. Of the 18 coaches who responded to the survey, eight of those coaches are now administrators in the district. Most importantly, all three of the coaches who were interviewed are now administrators. One coach who became an administrator stated

I think this role as a [coach] help[ed] me to become an administrator within the district. I think that the [coach] training is essential for all administrators entering [Columbia School District] and that the district should consider using this model as future administrative program for those within the district that are looking to promote into future administrative positions.

If the leaders of the district chose to focus on the data informed decision-making initiative, the coaching work could become a professional development program for the 


\section{SCHOOL REFORM AND COACHING}

district's rising leaders. Of the eight administrators, seven were in schools with increases in literacy benchmark scores. These coaches understood aspects of the data informed decision-making initiative that helped them implement the initiative well. This training could be built upon as coaches become administrators and continue being instructional leaders in their building, and hopefully, the district. The Columbia School District should look at the coaches, mentors, and other teacher leaders, as potential building and district leaders. With a focus, the district could create a leadership channel allowing the district to deepen the work to address the adaptive challenges the schools face.

Recommendations. I recommend the Columbia School District consider some of the following recommendations before launching another initiative in the district. Any initiative being considered by the Columbia School District should have a five-year implementation plan-one that is detailed and district leaders follow. The plan needs to include ways to bring in all stakeholders to engage in an ongoing dialogue focused on planning the implementation and focus of the initiative. The plan also needs to identify support systems and structures for principals, coaches, and teachers to ensure the initiative is being implemented successfully. The support systems should include feedback loops to the district leaders to ensure the district leaders know what struggles and/or concerns teachers, coaches, and principals are having with the new initiative. District leaders and school principals also need to participate in walk-throughs of classrooms with the coaches and teachers from the building to increase the dialogue between the teachers and the decision makers. The district and building leaders could work with coaches and teachers to develop a continuous improvement cycle of inquiry 


\section{SCHOOL REFORM AND COACHING}

using protocols and other systems to build a trusting environment where all participants are learning.

With sustained focus by the Columbia School District, there could be ways to provide more meaningful and ongoing professional development. My research revealed that principals did not participate in the professional development offered. More research could be completed to try and determine the reasons principals did not participate. However, a sustained and ongoing focus on an initiative would require principals and other district leaders to participate in the training to support coaches and teachers in the initiative. Professional development for principals could happen a couple of different ways. First, the district could offer professional development at the leadership trainings the principals go to each month. This could be a cursory introduction to the new initiative and focus on technical aspects of the initiative and the research that supports the initiative's effectiveness in helping to increase student achievement. This training could also focus on introducing principals to organizational change theory and the learning organization model (Senge, 1990).

Second, the principal could be invited to training with the coaches. This model was used during the two years of this initiative, though it was not very successful. However, if the focus of this professional development was to give coaches and principals time to meet, plan, and determine next steps of the implementation of the initiative within their own building, principals might find value in the training. More importantly, an unintended consequence of the initiative studied was the use of the coach as the professional development mechanism to deliver training to the principal. This was 


\section{SCHOOL REFORM AND COACHING}

evident when talking to Paula, the Owl Creek Principal. She stated that Sam, the coach, taught her (and the others in the school) a lot about data use and how to determine if what teachers were doing in their classrooms was helping students to learn. Sam was providing professional development to the teachers, but he was also providing professional development to the principal. Formalizing this professional development option, and possibly creating a "principal coach" position could help administrators learn the skills needed to implement a new initiative, work with a coach, and focus on organizational change. Just like coaches and teachers, principals need meaningful professional development, so a coach could be one way to ensure principals and other instructional leaders in the building get the supports needed to help other adults implement a new initiative.

A third way the district could help increase meaningful professional development is hiring coaches to be administrators. The practice of hiring instructional coaches to be principals was evident in my research (eight of the 18 coaches surveyed are now administrators). Specifically, coaches would get ongoing professional development focused on the technical aspects of the initiative. Coaches could also receive professional development on how to work with adult learners, resistant teachers, and get a deeper understanding about organizational change. This leadership development would ensure that new administrators had a strong understanding of the initiative, the needs of adult learners, and the complex dynamics of organizational change.

Finally, the Columbia School District could work with local university teacher preparation programs to ensure that current initiatives in the district were being discussed 


\section{SCHOOL REFORM AND COACHING}

in preservice education classes. The preservice teachers would gain an understanding of the initiative, so they would be better prepared to enter as new teachers in the Columbia School District.

The Columbia School District's focus on an initiative could lead to the creation of a learning organization (Senge, 1990). The focus on an initiative with multiple layers of professional development and support could create a shared vision for the district with all stakeholders sharing their mental models. Such an approach could increase team learning and personal mastery because teachers, coaches, and principals would have time to focus on the initiative and continually work to improve instruction and ultimately increase student achievement. By adding the understanding of organizational change, specifically systems thinking, the district would have all of the components needed for a learning organization (Senge, 1990). This focus and development of a learning organization could build a district culture focused on the initiative being implemented. In turn, the district could experience a greater amount of trust and focus on the initiative across schools.

Principals. If other initiatives in the past have been implemented in the same way in the Columbia School District, then I argue that some of the principal's lack of understanding and buy-in could be due to the district's lack of focus. Principals only received opportunities for professional development in the first year of the initiative. Like teachers and coaches, I argue principals need ongoing professional development focused on the aspects of the data informed decision-making initiative they were responsible for implementing in their building. The implementation of the initiative was varied across the district, and some of this variation was the principal's understanding 


\section{SCHOOL REFORM AND COACHING}

and/or support of the initiative and/or the coach. This variation could be decreased if principals had a clear understanding of their role in the implementation of the initiative and received professional development and feedback focused on their individual needs. For example, the Red Mountain coach discussed the "turbulence of a really rotten school climate" as a major factor in their perception of why the data initiative was not implemented well. The district could offer professional development for the principal and coach focused on working with teachers to use the data to increase trust and eventually change school climate. If the district sustained focus, principals and coaches could receive ongoing professional development to become more adept at using data to change instruction and student outcomes.

Recommendations. Because the initiative success was dependent on the coach and the principal in each of the buildings, there are three recommendations I would make to the Columbia School District in relation to the needs of principals to implement an initiative with the support of a coach: training and support in working with coaches, creating a shared or distributed leadership model, and increasing understanding of data use. Coaches who felt supported by their principal also felt successful. The support of a coach to do their job is an important skill that should be developed in the principals who are given the funding to hire a coach. Without a clear understanding of the job responsibilities of the coach, an administrator can inadvertently create barriers to the coach implementing the initiative. Some of this can be mitigated through creating a shared leadership model within the school. With a shared leadership model, there is more transparency in decision-making. It is important to include the coach in the shared 


\section{SCHOOL REFORM AND COACHING}

leadership model to ensure the implementation of the initiative is a part of the decisionmaking of the leadership team. Finally, principals need support in using data to informed decisions. Principals and coaches have access to many different data sets, and they need help determining what data to use, and how to act on the data once it has been analyzed.

Principals also need to work to create a culture of respect and trust. Without trust, no initiative can be implemented successfully. Some of the ideas already mentioned have been shown to increase trust in a school setting: shared leadership, the use of protocols, and adaptive leadership. I also recommend the principal focus the number of initiatives being implemented in the building. With too many initiatives, teachers and coaches can lose focus and dilute the work of the coach and the effectiveness of the teachers which can lead to decreased trust within the staff.

Finally, district leaders should create some expectations about what needs to be in place before a principal receives funding for a coaching position. Some coaches stated they could not do the work asked of them because the school climate was too fragile or "rotten." District leaders need to spend time in buildings to get a sense of the school climate, the level of trust, the amount of focus, and other factors that could contribute to how effective an initiative would be implemented in a building by a principal. Just like teachers, principals were often left to manage their school without much direct oversight. Increasing transparency of practices in schools could be a high leverage practice in a district wanting to use coaching as a professional development model for the successful implementation of initiatives. One way to increase the effectiveness of the initiative implementation is for principals to use a shared leadership structure to build trusting 


\section{SCHOOL REFORM AND COACHING}

relationships through effective professional development and a focused school improvement plan.

Coaches. I believe coaches implemented the data informed decision-making initiative to the best of their ability. Some coaches discussed the lack of support and/or understanding from administration and/or lack of trust from the staff as barriers to successful implementation. If the data initiative was perceived as a technical challenge, then the initiative was implemented in a way consistent with current values and norms in the school (Waters et al., 2009). I contend many initiatives start out as technical fixes to adaptive challenges. However, with sustained focus and attention, the staff builds the skills needed to implement the initiative in a more meaningful and lasting way (Schmoker, 2011). All of the Hazel Hill interviewees discussed the change in culture in the building, making the data initiative an adaptive fix. Sara summed up their change in culture when she said, “the data isn't going anywhere." The principals and coaches at Hazel Hill and Owl Creek were early adopters of the new initiative (Rogers, 1962). With ongoing focus, I believe more schools would have seen statistically significant increases in literacy benchmark scores.

Recommendations. A number of factors and structures found in this research are important for the Columbia School District to consider before implementing another initiative. First, the district needs to continue to offer ongoing, consistent professional development for the coaches. As their skills in implementing the technical aspects of the initiative increase, the district can focus professional development on how to work with adult learners, aspects of organizational change theory, and create a professional learning 


\section{SCHOOL REFORM AND COACHING}

community for the coaches. This ongoing professional development should be required for all coaches because the two coaches with statistically significant decreases in literacy benchmarking scores both participated in professional development no more than half of the time. As the coaches continue to focus on the implementation of the initiative, the professional development could include walk-throughs of classrooms in different buildings to continue to make the teaching and learning in schools more transparent.

Second, the coach needs to have a strong working relationship with the principal in the building. Just as principals would need to show the structures already in place before a coach is placed in a building, the hiring of the coach needs to be a principal decision; the responsibilities should be mutually agreed upon by the coach and principal. Without a trusting relationship between the coach and principal, the ability of either person to help teachers effectively increase their use of instructional practices is hindered. Coaches and principals need to participate in some joint professional development sessions to help coach and principal teams build a trusting relationship. I recommend this professional development occur before the school year begins.

\section{Further Research}

A few places for further research have been mentioned already. However, two topics continued to be areas I wondered about as I completed this study. One, the relationship between the coach and the principal, was discussed in the findings. However, I believe more pointed research needs to be conducted. The other, efficacy, was a topic not directly related to the study, but it was discussed peripherally by many participants. 


\section{SCHOOL REFORM AND COACHING}

Efficacy. Throughout my research, I held assumptions about the people who were being studied. I assumed principals, coaches, and teachers had a strong sense of efficacy, a belief what they did could change the outcomes for students. Some coaches discussed teacher resistance and lack of trust in assessment as barriers to implementing the initiative. I argue those teachers could have a low sense of efficacy. As I analyzed the survey results, I started to wonder about the coaches' sense of efficacy. How many coaches felt they had the ability to help teachers use data to change their instruction? As I looked at responses from coaches who did not think their work as a coach was a success, I noticed many of their reasons were external to what they, as the coach, did to move the data informed decision-making work forward. This sense of efficacy was not a component of my research study. I believe more research on principal efficacy and coach efficacy would fill an important gap in the school leadership literature. Additionally, researching ways to increase teacher, coach, and principal efficacy would help coaches, principals, and district leaders create meaningful professional development focused on building practices which strengthen efficacy.

Coach-principal relationship. Further research is also needed to determine how the relationship between the coach and the principal affected the ability of the coach to implement the initiative. Some initial findings focused on trust and mutual respect in the schools where I interviewed coaches and principals. However, no research compared those relationships to the relationships between coaches and principals who did not trust each other and/or whose vision of the initiative implementation was not aligned. The idea of the coach and principal as the change agents in the school was also mentioned. 


\section{SCHOOL REFORM AND COACHING}

Much of the research on school leadership is separated between teacher leadership, coaching, and principal leadership literature (Neumerski, 2012). Coaches and principals are expected to work together to create change in schools, so studying their interaction and how they work together would be a meaningful addition to the school change literature. Such research could help districts and principals identify coaches and principals who would work well together to create the adaptive changes needed to increase student achievement.

\section{Summary}

In this chapter, I summarized the findings from the research organized by research question. The structures supporting the coach's ability to implement the data informed decision-making initiative were the leadership and professional development structures. Initial observations showed the leadership structures at the two schools mirrored the first four disciplines of a learning organization. Further research could need to be conducted to determine if this initial observation was correct. I asserted that principal and coach professional development is needed to ensure instructional leaders understand the initiative and also understand how to address adaptive challenges in schools. Many factors contributed to the implementation of the data initiative. Assessment literacy was identified as a factor for teachers, coaches, and principals. Ensuring the right people are on the bus, including the principal who is driving the bus, affected the data informed decision-making initiative implementation. I noted that the coach and principal relationship could be studied more fully to determine how those positions work together as change leaders in a school building. Many participants discussed trust and focus as 


\section{SCHOOL REFORM AND COACHING}

important factors in their feeling of success in implementing the data informed decisionmaking initiative. My recommendations for the Columbia School District centered on the need to focus the work of the district to increase trust, build capacity of leadership, increase principal and coach focus, and decrease initiative fatigue. Finally, I offered recommendations for research about teacher, coach, and principal efficacy in relation to initiative implementation as well as the need to research the coach-principal relationship as a system for lasting organizational change. 


\section{SCHOOL REFORM AND COACHING}

\section{References}

Alonzo, J., Park, B. J., \& Tindal, G. (2014a). An examination of the internal structures of the gr. K-5 easyCBM CCSS reading measures: A construct validity study (Technical Report \#1305). Eugene, OR: Behavioral Research and Teaching.

Alonzo, J., Park, B. J., \& Tindal, G. (2014b). An examination of the internal structures of the gr. 6-8 easyCBM CCSS reading measures: A construct validity study (Technical Report \#1304). Eugene, OR: Behavioral Research and Teaching.

Alonzo, J., Park, B. J., \& Tindal, G. (2014c). Examining the internal structures of the easyCBM reading measures, grades K-5 (Technical Report \#1302). Eugene, OR: Behavioral Research and Teaching.

Argyris, C., \& Schön, D. (1978). Organizational learning. Reading, MA: AddisonWesley.

Armor, D., Conroy-Osegueara, P., Cox, M., King, N., McDonnell, L., Pascal, A. \& Zellman, G. (1976). Analysis of the school preferred reading program in selected Los Angeles minory schools (Report No. R2007LAUSD). Santa Monica, CA: Rand.

Bean, R., Draper, J., Hall, V., Vandermolen, J., \& Zigmond, N. (2010). Coaches and coaching in reading first schools: A reality check. The Elementary School Journal, 111(1), 87-114.

Berman, P., Greenwood, P., McLaughlin, M., \& Pincus, J. (1975). Federal programs supporting educational change (R-1589/5-HEW). U.S. Department of Education, Department of Health, Education, and Welfare. Santa Monica, CA: Rand. 


\section{SCHOOL REFORM AND COACHING}

Bernhardt, V. L. (2004). Data analysis for continuous school improvement. Larchmont, NY: Eye on Education.

Borman, J., \& Feger, S. (2006). Instructional coaching: Key themes from the literature. Providence, RI: The Education Alliance at Brown University.

Boudett, K. P., City, E. A., \& Murnane, R. J. (2005). Data Wise: A step-by-step guide to using assessment results to improve teaching and learning. Cambridge, MA: Harvard Education Press.

Boudett, K., \& Steele, J. (2007). Data Wise in action: Stories of schools using data to improve teaching and learning. Cambridge, MA: Harvard Education Press.

Bradley, R., Danielson, L., \& Doolittle, J. (2005). Repsonse to Intervention. Journal of Learning Disabilities, 38(6), 485-486.

Brown, C. J., Stroh, H. R., Fouts, J. T., \& Baker, D. B. (2005). Learning to change: School coaching for systemic reform. Seattle, WA: Fouts \& Associates.

Burkins, J. M. (2007). Coaching for balance: How to meet the challenges of literacy coaching. Newark, DE: International Reading Association.

Cavaleri, S. A. (2008). Are learning organizations pragmatic? The Learning Organization, 15(6), 474-478.

Chappuis, J. (2009). Seven strategies of assessment for learning. Boston, MA: Allyn \& Bacon.

Coburn, C. E., \& Talbert, J. E. (2006). Conceptions of evidence use in school districts: Mapping the terrain. America Journal of Education, 112, 469-495. 


\section{SCHOOL REFORM AND COACHING}

Collins, J. C. (2001). Good to great: Why some companies make the leap... and others don't. New York, NY: Harper Collins.

Copland, M. (2003). Leadership of inquiry: Building and sustaining capacity for school improvement. Educational Evaluation and Policy Analysis, 25(4), 375-395.

Cornett, J., \& Knight, J. (2009). Research on coaching. In J. Knight (Ed.), Coaching: Approaches and perspectives (pp. 192-216). Thousand Oaks, CA: Corwin Press.

Cosner, S. (2011). Teacher learning, instructional considerations and principal communication: Lessons from a longitudinal study of collaborative data use by teachers. Educaiton Management Administration and Leadership, 39(5), 568-589.

Creswell, J. W. (2013). Research design: Qualitative, quantitative, and mixed methods approaches. Los Angeles, CA: Sage.

Cuban, L. (1988). The managerial imperative and the practice of leadership in schools. Albany, NY: State University of New York Press.

Cuban, L. (1990). Reforming again, again, and again. Educational Researcher, 19(1), 313.

Cuban, L. (2013). Why so many structural changes in schools and so little reform in teaching practice? Journal of Educational Administration, 51(2), 109-125.

Daly, A. J., \& Chrispeels, J. (2008). A question of trust: Predictive conditions for adaptive and technical leadership in educaitonal contexts. Leadership and Policy in Schools, 7(1), 30-63.

Darling-Hammond, L., \& Friedlaender, D. (2008). Creating excellent and equitable schools. Education Leadership, 65(8), 14-21. 


\section{SCHOOL REFORM AND COACHING}

Datnow, A., Park, V., \& Wohlstetter, P. (2007). Achieving with data: How highperforming school systems use data to improve instruction for elementary students. Los Angeles, CA: Center on Educational Governance, USC.

Davenport, T. H. (2005). Thinking for a living. Cambridge, MA: Harvard Business Review Press.

Deming, W. E. (1982). Out of the crisis. Cambridge, MA: MIT Press.

Deshler, D. (2007). A closer look: Closing the performance gap. Retrieved from Alliance for Excellent Education: http://www.all4ed.org/files/ACloserLook.pdf

Desimone, L. M., Porter, A. C., Garet, M. S., Yoon, K. S., \& Birman, B. F. (2002). Effects of professional development on teachers' instruction: Results from a three-year longitudinal study. Educational Evaluation and Policy Analysis, 24(2), $81-112$.

Deussen, T., Robinson, T. C., \& Autio, E. (2007). "Coach" can mean many things: Five categories of literacy coaching in Reading First. Washington, DC: U.S. Department of Education.

Dewey, J. (1910). How we think. Chicago, IL: D.C. Heath.

Dozier, C. (2006). Responsive literacy coaching: Tools for creating and sustaining purposeful change. Portland, ME: Stenhouse.

Driscoll, M. (2008). Embracing coaching as professional development. Principal Leadership, 9(2), 40-44.

Early, L., \& Fullan, M. (2003). Using data in leadership for learning. Cambridge Journal of Education, 33(3), 383-394. 


\section{SCHOOL REFORM AND COACHING}

Elmore, R. (2004). School reform from the inside out: Policy, practice and performance. Cambridge, MA: Harvard Education Press.

Elmore, R. (2009). Usable knowledge. Retrieved from Harvard Graduate School of Education web-site: http://www.uknow.gse.harvard.edu/leadership/leadership001a.html

Evans, L., Thornton, B., \& Usinger, J. (2010). Shared vision or collective assumptions? A study of educational leaders' perceptions of walkthroughs. Internaional Journal of Educational Leadership Preparation, 5(4), 1-12.

Evans, L., Thornton, B., \& Usinger, J. (2012). Theoretical frameworks to guide school improvement. National Association of Secondary School Principals Bulletin, 96(2), 154-171.

Farmer-Hinton, R. (2002). The Chicago context: Understanding the consequences of urban processes on school capacity. Journal of Negro Education, 71(4), 313-330.

Farstrup, A. E. (2008, October/November). A new school year: Challenges and opportunities. Reading Today, 26(2), 21-21.

Feldman, J., \& Tung, R. (2001 April). Whole school reform: How schools use the databased inquiry and decision-making process. ERIC Clearinghouse: ED454242.

Field, A. (2005). Discovering statistics using SPSS. Los Angeles, CA: Sage.

Fowler, F.J. (2014). Survey research methods. Los Angeles: Sage.

Frank, K. A., Zhao, Y., \& Borman, K. (2004). Social capital and the diffusion of innovations within organizations: The case of computer technology in schools. Sociology of Education, 7, 148-171. 


\section{SCHOOL REFORM AND COACHING}

Fuchs, D., \& Fuchs, L. S. (2006). Introduction to response to intervention: What, why, and how valid is it? Reading Research Quarterly, 41(1), 93-99.

Fullan, M. (2008a). Six secrets of change: What the best leaders do to help their organizations survive and thrive. San Fransisco, CA: Jossey-Bass.

Fullan, M. (2008b). What's worth fighting for in the principalship. New York, NY: Teachers College Press.

Fullan, M. (2009). The challenge of change: Start school improvement now! Thousand Oaks, CA: Corwin Press.

Fullan, M., \& Knight, J. (2011). Coaches as system leaders. Educational Leadership, $69(2), 50-53$.

Gersten, R., Morvant, M., \& Brengelman, S. (1995). Close to the classroom is close to the bone: Coaching as a means to translate research into classroom practice. Exceptional Children, 62(1), 52-66.

Guba, E. \& Lincoln, Y. (1994). Competing paradigms in qualitative research. Handbook of Qualitative Research. Thousand Oaks, CA: Sage.

Guerreiro, M., Alonzo, J., Tindal, G. (2014). Internal consistency of the easyCBM CCSS reading measures grades 3-8 (Technical Report \#1407). Eugene, OR: Behavioral Research and Teaching.

Hallinger, P. (2005). Instructional leadership and the school principal: A passing fancy that refuses to fade away. Leadership and Policy in Schools, 4(3), 221-239.

Hargreaves, A., \& Fullan, M. (2012). Professional capital: Transforming teaching in every school. New York, NY: Teachers College Press. 


\section{SCHOOL REFORM AND COACHING}

Harper, D. (2001). Online Etymology Dictionary. http://www.etymonline.com

Hasbrouck, J. E. (1997). Mediated peer coaching for training preservice teachers. The Journal of Special Education, 31(2), 251-271.

Heifetz, R. A., \& Laurie, D. L. (1997). The work of leadership. Harvard Business Review, 75, 124-134.

Heifetz, R. A., \& Linsky, M. (2002). Leadership on the line: Staying alive through the dangers of leading. Boston, MA: Harvard Business Press.

Heritage, M., \& Yeagley, R. (2005). Data use and school impveoment: Challenges and prospects. Yearbook of the National Society for the Study of Education, 104(2), 320-339.

Herman, J., \& Gribbons, B. (2001). Lessons learned in using data to support school inquiry and continuous improvement: Final report to the Stuart Foundation. Los Angeles, CA: The Regents of the University of California.

Ingram, D., Louis, K., \& Schroeder, R. (2004). Accountability policies and teacher decision-making: Barriers to the use of data to improve practice. Teachers College Record, 106(6), 1258-1287.

Ippolito, J. (2009). Principals as partners with literacy coaches: Striking a balance between neglect and interference. Literacy Coaching Clearinghouse. Retrieved from http://www.literacycoachingonline.org/briefs/Principals_as_Partners.pdf

Ippolito, J. (2010). Three ways that literacy coaches balance responsive and directive relationships with teachers. The Elementary School Journal, 111(1), 164-190. 


\section{SCHOOL REFORM AND COACHING}

Irvin, P. S., Alonzo, J., Lai, C., Park, B. J., \& Tindal, G. (2012). Analyzing the reliability of the easyCBM reading comprehension measures: Grade 7 (Technical Report \#1206). Eugene, OR: Behavioral Research and Teaching.

Jimerson, J. B., \& McGhee, M. W. (2013). Leading inquiry in schools: Examining mental models of data-informed practice. Current Issues in Education, 16(1), 1-18.

Jimerson, J. B., \& Wayman, J. C. (2012, April). Branding educational data use through professional learning: Findings from a study in three school districts. Paper presented at the annual meeting of the American Educational Research Association, Vancouver, BC.

Joyce, B. R., \& Showers, B. (1981). Transfer of training: The contribution of coaching. Journal of Education, 163(2), 163-72.

Joyce, B., \& Showers, B. (2002). Student achievement through staff development (3rd ed.). Alexandria, VA: Association for Supervision and Curriculum Development.

Kamil, M. L., Borman, G. D., Dole, J., Kral, C. C., Salinger, T., \& Torgesen, J. (2008). Improving adolescent literacy: Effective classroom and intervention practices (Report No. NCEE 2008-4027). Washington, DC: National Center for Education Evaluation and Regional Assistance, Institute of Education Sciences, U.S. Department of Education.

Kaufman, T. E. (2012). Data Wise: How to use data to tell your story. Portland Public Schools and Nike Portland Leadership Collaborative Quarterly Meeting. Portland, OR: Portland Public Schools. 


\section{SCHOOL REFORM AND COACHING}

Kerr, K. A., Marsh, J. A., Ikemoto, G. S., Darilek, H., \& Barney, H. (2006). Strategies to promote data use for instructional imporvement: Actions, outcomes, and lessons from three urban districts. American Journal of Education, 112, 496-520.

Kiedrowski, P. J. (2006). Quantitative assessment of a Senge learning organization intervention. The Learning Organization, 13(4), 369-383.

Killion, J. (2008). Are you coaching heavy or light. Teachers Teaching Teachers, 3(8), 14.

Killion, J. (2009). Coaches' roles, responsibilities, and reach. In J. Knight (Ed.), Coaching: Approaches and perspectives (pp. 7-28). Thousand Oaks, CA: Corwin Press.

Knapp, M. S., Copland, M. A., \& Swinnerton, J. A. (2007). Chapter 4 Understanding the Promise and Dynamics of Data-Informed Leadership. Yearbook of the National Society for the Study of Education, 106(1), 74-104.

Knapp, M. S., Swinnerton, J. A., Copland, M. A., \& Monpas-Huber, J. (2006). Datainformed leadership in education. Seattle, WA: University of Washington, Center for the Study of Teaching and Policy.

Knight, J. (2004). Progress through partnership. Journal of Staff Development, 25(2), 3237.

Knight, J. (2006). Instructional coaching: Eight factors for realizing better classroom teaching through support, feedback and intensive, indivualized professional learning. The School Administrator, 4(63), 36-40. 


\section{SCHOOL REFORM AND COACHING}

Knight, J. (2009). What can we do about teacher resistance. Phi Delta Kappan, 90(7), 508-513.

Kohler, F. W., Crilley, K. M., Shearer, D. D., \& Good, G. (1997). Effects of peer coaching on teacher and student outcomes. The Journal of Educational Research, 90(4), 240-250.

Kral, C. (2007). Principal support for literacy coaching. Literacy Coaching Clearinghouse. Retrieved from http://www.literacycoachingonline.org/briefs/PrincipalSupportFinal3-22-07.pdf

Krathwohl, D. R. (2009). Methods of educational and social science research: The logic of methods (3rd ed.). Ong Grove, IL: Waveland Press.

Kretlow, A. G., \& Bartholomew, C. C. (2010). Using coaching to improve the fidelity of evidence-based practices: A review of studies. Teacher Education and Special Education, 33(4), 279-299.

Kuhn, T. (1970). The structure of scientific revolutions. International Encyclopedia of Unified Science. Chicago, IL: University of Chicago.

Kvale, S. (2007). Doing interviews. Los Angeles, CA: Sage.

Lachat, M., \& Smith, S. (2009). Practices that support data use in urban high schools. Journal of Education for Students Placed at Risk, 10(3), 333-349.

L'Allier, S., Elish-Piper, L., \& Bean, R. (2010). What matters for literacy coaching? Guiding principles for instructional improvement and student achievement. The Reading Teacher, 63(7), 544-554. 


\section{SCHOOL REFORM AND COACHING}

Lipton, L., Wellman, B. M., \& Humbard, C. (2003). Mentoring matters: A practical guide to learning-focused relationships. Arlington, MA: MiraVia, LCC.

Marsh, J. A., McCombs, J. S., \& Martorell, F. (2009). How instructional coaches support data-driven decision-making: Policy implementation and effects on Florida middle schools. Educational Policy, 24(6), 872-907.

Marsh, J., Pane, J. F., \& Hamilton, L. S. (2006). Making sense of data-driven decisionmaking in education. Santa Monica, CA: Rand.

Mason, S. (2002, April). Turning data into knowledge: Lessons from six Milwaukie public schools. Paper presented at the annual meeting of the American Education Research Association, New Orleans, LA.

McLaughlin, M. (1974). Evaluation and reform: The Elementary and Secondary Education Act of 1965, Title I. Santa Monica, CA: Rand.

Moran, M. C. (2007). Differentiated literacy coaching: Scaffolding for student and teacher success. Alexandria, VA: Association for Supervision and Curriculum Development.

Morgan, D. (2007). Paradigms lost and pragmatism regained: Methodological implications of combining qualitative and quantitative methods. Journal of Mixed Methods Research, 1(1), 48-76.

Morgan, D. L. (2012). Integrating qualitative and quantitative methods: A pragmatic approach. Portland, OR: Portland State University.

Muhammad, A. (2009). Transforming school culture: How to overcome staff division. Bloomington, IN: Solution Tree. 


\section{SCHOOL REFORM AND COACHING}

Murray, J. (2013). Cricital issues facing school leaders concerning data-informed decision-making. School Leadership and Management: Formerly School Organisation, 33(2), 169-177.

Neufeld, B., \& Roper, D. (2003). Coaching: A strategy for developing instructional capacity: Promises \& practicalities. Washington, DC: Aspen Institute.

Neumerski, C.M. (2012). Rethinking instructional leadership, a review: What do we know about principal, teacher, and coach instructional leadership, and where should we go from here? Educational Administration Quarterly, 49(2), 310-347.

No Child Left Behind (NCLB) Act of 2001, Pub. L. No. 107-110, § 115, Stat. 1425. (2002).

Park, V., Daly, A. J., \& Guerra, A. W. (2012). Strategic framing: How leaders craft the meaning of data use for equity and learning. Educational Policy, 27(4), 645-675.

Porter, A. C. (2002). Measuring the content of instruction: Uses in research and practice. Educational Researcher, 31(7), 3-14.

Porter, A., Garet, M., Desimone, L., Yoon, K., \& Birman, B. (2000). Does professional development change teaching practice? Results from a three-year study. Washington, DC: U.S. Department of Education, Office of the Undersecretary.

Randall, L. M., \& Coakley, L. A. (2007). Applying adaptive leadership to successful change initiatives in academia. Leadership \& Organization Development Journal, 28(4), 325-335.

Ravitch, D. (2010). The death and life of the great American school system: How testing and choice are undermining education. New York, NY: Basic Books. 


\section{SCHOOL REFORM AND COACHING}

Reeves, D. B. (2003). High performance in hight poverty schools: 90/90/90 and beyond. Englewood, CO: Center for Performance Assessment.

Reeves, D. (2006). Pull the weeds before you plant the flowers. Education Leadership, $64(1), 89$.

Rogers, E. (1962). Diffusion of innovations. New York, NY: Free Press.

Saldaña, J. (2009). The coding manual for qualitative researchers. Los Angeles, CA: Sage.

Sanders, W., \& Rivers, J. (1996). Cumulative and residual effects of teachers on future student achievment. Knoxville, TN: University of Tennessee, Value Added Research and Assessment Center.

Schmoker, M. J. (2011). Focus: Elevating the essentials to radically improve student learning. Alexandria, VA: Association for Supervision and Curriculum Development.

Schmoker, M. J., \& Wilson, R. B. (1993). Total quality education: Profiles of schools that demonstrate the power of Deming's management principles. Bloomington, IN: Phi Delta Kappa Educational Foundation.

Senge, P. (1990). Schools that learn: A fifth discipline fieldbook for educators, parents, and everyone who cares about education. New York, NY: Crown Business.

Shen, J., \& Cooley, V. E. (2008). Critical issues in using data for decision-making. International Journal of Leadership in Education: Theory and Practice, 11(3), 319-329. 


\section{SCHOOL REFORM AND COACHING}

Shen, J., Cooley, V., Ma, X., Reeves, P., Burt, W., Rainey, M., \& Yuan, W. (2012). Datainformed decision-making on high-impact strategies: Developing and validating an instrument for principals. The Journal of Experimental Education, 80(1), 1-25.

Showers, B. (1982). Transfer of training: The contribution of coaching. Eugene, OR: Oregon University Center for Educational Policy.

Smith, M. K. (2001). Peter Senge and the learning organization. Retrieved from The Encyclopedia of Informal Education website: www.infed.org/thinkers/senge.htm.

Southworth, G. (2002). Instructional leadership in schools: Reflections and empirical evidence. School Leadership \& Management, 22(1), 73-91.

Spillane, J. P. (2010). Cognition and policy implementation: District policymakers and the reform of mathematics education. Cognition and Instruction, 18(2), 141-179.

Spillane, J. P., Halverson, R., \& Diamond, J. B. (2001). Investigating school leadership practice: A distributed perspective. Educational Researcher, 30(3), 23-28.

Sterbinsky, A., Ross, S. M., \& Redfield, D. (2006). Effects of comprehensive school reform on student achievement and school change: A longitudinal multi-site study. School Effectiveness and School Improvement, 17(3), 367-397.

Stiggins, R. (2005). From formative assessment to assessment for learning: A path to success in standards-based schools. Phi Delta Kappan, 87(4), 324-328.

Streeter, C. (1994). Education reform in America: The Texas governor's conference on total quality management and the national education goals. Social Work in Education, 16(3), 193-198. 


\section{SCHOOL REFORM AND COACHING}

Supovitz, J. (2009). Can high stakes testing leverage educational improvement? Prospects from the last decade of testing and accountability reform. Journal of Educational Change, 10, 211-227.

Supovitz, J. (2010). Knowledge-based organizational learning for instructional improvement. In A. Hargreaves, A. Liberman, M. Fullan, \& D. Hopkins (Eds.), Second international handbook of educational change (pp. 707-723). New York, NY: Springer.

Swan, G., \& Mazur, J. (2011). Examing data driven decion making via formative assessment: A confluence of technology, data interpretation heuristics and curricular policy. Contemporary Issues in Technology and Teacher Education, 11(2), 205-222.

Toll, C. A. (2005). The literacy coach's survival guide: Essential questions and practical answers. Newark, DE: International Reading Association.

Toll, C. (2009). Literacy coaching. In J. Knight (Ed.), Coaching: Approaches and perspectives (pp. 56-69). Thousand Oaks, CA: Corwin Press.

Tyack, D., \& Cuban, L. (1995). Tinkering toward utopia: A century of public school reform. Cambridge, MA: Harvard University Press.

United States Congress. (1994). An act to improve learning and teaching by providing a national framework for education reform; to promote the research, consensus building, and systemic changes need to ensure equitable education apportuities and high levels of educaiton achievement for all American students; to provide a freamwork for reauthrization of all Federal education programs; to promote the 


\section{SCHOOL REFORM AND COACHING}

development and adoption of a voluntary national system of skill standards and certifications; and for other pourposes. Washington, DC: 103rd Congress.

U.S. Department of Education (1974). Family educational rights and privacy act (FERPA). Retrieved from U.S. Department of Education: http://www2.ed.gov/policy/gen/guid/fpco/ferpa/index.html

U.S. Department of Education (2012). Elementary and secondary education: The federal role in education. Retrieved from U.S. Department of Education: http://www2.ed.gove/about/overview/fed/role.html

Veenman, S., \& Denessen, E. (2001). The coaching of teachers: Results of five training studies. Educational Research and Evaluation, 7(4), 385-417.

Walpole, S., \& Blamey, K. L. (2008). Elementary literacy coaches: The reality of dual roles. The Reading Teacher, 62(3), 222-231.

Waters, T., Marzano, R., \& McNulty, B. (2003). Balanced leadership: What 30 years of research tells us about the ffect of leadership on student achievement. Aurora, CO: Mid-continent Research for Education and Learning.

Wayman, J. C., \& Stringfield, S. (2006). Data use for school improvement: School practices and research perspectives. American Journal of Education, 112(4), 463468.

Wayman, J., Cho, V., \& Johnston, M. (2007). The data-informed district: A district-wide evaluation of data use in the Natrona County School District. Austin, TX: The University of Texas. 


\section{SCHOOL REFORM AND COACHING}

Webb, N. L. (1997). Determining alignement of expectiation and assessments in mathematics and science education. NISE Brief, 1(2), 1-7.

Wenglinksy, H. (2000). How teaching matters: Bringing the classroom back into discussions of teacher quality. Princeton, NJ: Policy Information Center.

Woodruff, S. (2009). Instructional coaching scale. Retrieved from Instructional Coaching Group:

http://www.instructionalcoach.org/images/downloads/tools/Instructional_Coachin g_Scale_Rev_8.0.pdf

Wray, K.A., Alonzo, J., Tindal, G. (2013). Internal consistency of the easyCBM vocabulary measures: Grades 2-8 (Technical Report \#1406). Eugene, OR: Behavioral Research and Teaching.

Yeo, R. K. (2005). Revisiting the roots of learning organization: A synthesis of the learning organization literature. The Learning Organization, 12(4), 368-382.

York-Barr, J., \& Duke, K. (2004). What do we know about teacher leadership? Findings from two decades of scholarship. Review of Educational Research, 74(3), 255316. 
SCHOOL REFORM AND COACHING

\section{Appendix A}

\section{Consent Forms}

\section{Coach Consent Form}

School Reform and Coaching: Identifying Structures for Successful Implementation of a Data Informed Decision-Making Program

\section{Consent Form}

You are being asked to take part in a research study of how schools with school improvement specialists (SISs) implemented the literacy-focused data informed decisionmaking initiative. We are asking you to take part because of your role as a SIS during all or part of the 2011-12 and/or 2012-13 school years. Please read this form carefully and ask any questions you may have before agreeing to take part in the study.

What the study is about: The purpose of this study is to learn how school leadership used the school improvement specialist (SIS) to help implement a data informed decision-making initiative.

What we will ask you to do: If you agree to be in this study, you will complete an electronic survey. The survey will include questions about your experience as a teacher/teacher leader, your role/responsibilities as a SIS, information about how the data informed decision-making program was implemented, and some questions about your perspective about the work you and the teachers in your building did during the 2011-12 and/or the 2012-13 school years. The survey should take about 30 to 45 minutes to complete. Some SISs and principals will be asked to participate in a follow-up interview. With your permission, the interviews will be recorded to aide in transcription. The interview should take no more than 45 minutes.

Risks and Benefits: There are no anticipated risks to your participation in this study other than those encountered in day-to-day life. There are no benefits to you. However, the researchers hope to learn more about how schools effectively utilize teacher leaders to help the district ensure future programs like this are implemented as effectively as possible.

Compensation: You will not receive any compensation for participating in this survey.

Your answers will be confidential. The records of this study will be kept private. In any sort of report made public, no information will be included that would make it possible to identify you. Research records will be kept in a locked file and/or on a password protected computer. Only the researchers will have access to the records. If the 


\section{SCHOOL REFORM AND COACHING}

interviews are tape-recorded, the recording will be deleted after it has been transcribed, no more than two months after its taping.

Taking part is voluntary: Taking part in this study is completely voluntary. You may skip any questions that you do not want to answer. If you decide not to take part or skip some of the questions, it will not affect your current or future relationship with Portland State University. If you decide to take part, you are free to withdraw at any time.

If you have questions: The researchers conducting this study are KD Parman and Prof. Micki Caskey. Please ask any questions you have now. If you have questions later, you may contact KD Parman at kdparman@pdx.edu or at (503)888-8286. You can reach Prof. Caskey at caskeym@pdx.edu. If you have any questions or concerns regarding your rights as a subject in this study, you many contact:

PSU Institutional Review Board

Office of Research Integrity

1600 SW $4^{\text {th }}$ Ave., Marketing Center Building, Ste. 620

Portland, OR 97201

(503) $725-2227$ or $1(877) 480-4400$

email hsrrc@pdx.edu.

You will be given a copy of this form to keep for your records.

Statement of Consent: I have read the above information, and have received answer to any questions I asked. I consent to take part in this study.

Your Signature:

Date:

If being interviewed: In addition to agreeing to participate, I also consent to having the interview tape-recorded.

Your Signature:

Date:

Person obtaining consent:

Signature:

Print:

Date:

This consent form will be kept by the researcher for at least three years beyond the end of the study. 


\section{SCHOOL REFORM AND COACHING}

\section{Principal Consent Form}

School Reform and Coaching: Identifying Structures for Successful Implementation of a Data Informed Decision-Making Program

\section{Consent Form}

You are being asked to take part in a research study of how schools with school improvement specialists (SISs) implemented the literacy-focused data informed decisionmaking initiative. We are asking you to take part because of your role as a principal during all or part of the 2011-12 and/or 2012-13 school years in a Zone School with a school improvement specialist (SIS). Please read this form carefully and ask any questions you may have before agreeing to take part in the study.

What the study is about: The purpose of this study is to learn how school leadership used the school improvement specialist (SIS) to help implement a data informed decision-making initiative.

What we will ask you to do: If you agree to be in this study, you will participate in a one-on-one interview. The interview will include questions about how the data informed decision-making program was implemented, how you use data as a school leader, and some questions about your perspective about the work you, the SIS, and the teachers in your building did during the 2011-12 and/or the 2012-13 school years. With your permission, the interviews will be recorded to aide in transcription. The interview should take no more than 45 minutes.

Risks and Benefits: There are no anticipated risks to your participation in this study other than those encountered in day-to-day life. There are no benefits to you. However, the researchers hope to learn more about how schools effectively utilize teacher leaders to help the district ensure future programs like this are implemented as effectively as possible.

Compensation: You will not receive any compensation for participating in this survey.

Your answers will be confidential. The records of this study will be kept private. In any sort of report made public, no information will be included that would make it possible to identify you. Research records will be kept in a locked file and/or on a password protected computer. Only the researchers will have access to the records. If the 


\section{SCHOOL REFORM AND COACHING}

interviews are tape-recorded, the recording will be deleted after it has been transcribed, no more than two months after its taping.

Taking part is voluntary: Taking part in this study is completely voluntary. You may skip any questions that you do not want to answer. If you decide not to take part or skip some of the questions, it will not affect your current or future relationship with Portland State University. If you decide to take part, you are free to withdraw at any time.

If you have questions: The researchers conducting this study are KD Parman and Prof. Micki Caskey. Please ask any questions you have now. If you have questions later, you may contact KD Parman at kdparman@pdx.edu or at (503)888-8286. You can reach Prof. Caskey at caskeym@pdx.edu. If you have any questions or concerns regarding your rights as a subject in this study, you many contact:

PSU Institutional Review Board

Office of Research Integrity

1600 SW $4^{\text {th }}$ Ave., Marketing Center Building, Ste. 620

Portland, OR 97201

(503) $725-2227$ or $1(877) 480-4400$

email hsrrc@pdx.edu.

You will be given a copy of this form to keep for your records.

Statement of Consent: I have read the above information, and have received answer to any questions I asked. I consent to take part in this study.

Your Signature:

Date:

If being interviewed: In addition to agreeing to participate, I also consent to having the interview tape-recorded.

Your Signature:

Date:

Person obtaining consent:

Signature:

Print:

Date:

This consent form will be kept by the researcher for at least three years beyond the end of the study. 


\section{SCHOOL REFORM AND COACHING}

\section{Appendix B}

\section{Coach Survey}

This survey is being used to research the structures that were in place at schools during the implementation of the coach and data informed decision-making reforms of the school district in which you are/were employed from 2011 to 2013. All participation is voluntary. There are four sections to this survey. Please answer questions to the best of your ability.

\section{SCHOOL CLIMATE}

For this section of the survey, consider how teachers and administrators supported your work and how willing teachers and administrators were to do the work of using data to improve instruction. When asked about teachers, use your best estimate of the general sense of teachers. It is best to not consider "the best" or "the worst," but the overall teaching staff. Use a $1-4$ scale to answer these questions. $1=$ not at all; $2=$ less than once a week; 3 = at least once a week; and $4=$ daily.

\begin{tabular}{l|l|l} 
& \multicolumn{2}{c}{ Rate $1-4$} \\
\hline $\begin{array}{l}\text { 1. In your experience as the coach, how often did teachers in } \\
\text { your building do the following? }\end{array}$ & $2011-12$ & $2012-13$ \\
\hline use best practices in reading instruction. & & \\
\hline share ideas and resources with each other. & & \\
\hline hold all students to high expectations. & & \\
\hline work collaboratively with colleagues. & & \\
\hline reflect on their teaching. & & \\
\hline support innovative ideas in instruction. & & \\
\hline use data to inform their instruction. & & \\
\hline engage in the data team meeting process. & & \\
\hline use you, as a coach, to help with instruction. & & \\
\hline use you, as a coach, to help with classroom management. & & \\
\hline use you, as a coach, to help with other problems or concerns. & &
\end{tabular}

SCALE: $1=$ not at all; $2=$ less than once a week; $3=$ at least once a week; and $4=$ daily. 


\section{SCHOOL REFORM AND COACHING}

\begin{tabular}{l|l|l} 
& \multicolumn{2}{|c}{ Rate 1-4 } \\
\hline $\begin{array}{l}\text { 2. In your experience as a coach, how often did administrators in } \\
\text { your building do the following: }\end{array}$ & $2011-12$ & $2012-13$ \\
\hline attend data team meetings. & & \\
\hline help literacy benchmarking of students. & & \\
\hline support, not direct help, literacy benchmarking of students. & & \\
\hline use staff meeting time for data team meetings. & & \\
\hline $\begin{array}{l}\text { use staff meeting time to discuss the importance of data team } \\
\text { meetings. }\end{array}$ & & \\
\hline
\end{tabular}

3. How often did you and the principal meet

formally (scheduled time to talk about coaching, data, and/or professional development)

informally (checking in not during a scheduled time to discuss coaching, professional development, and/or data)

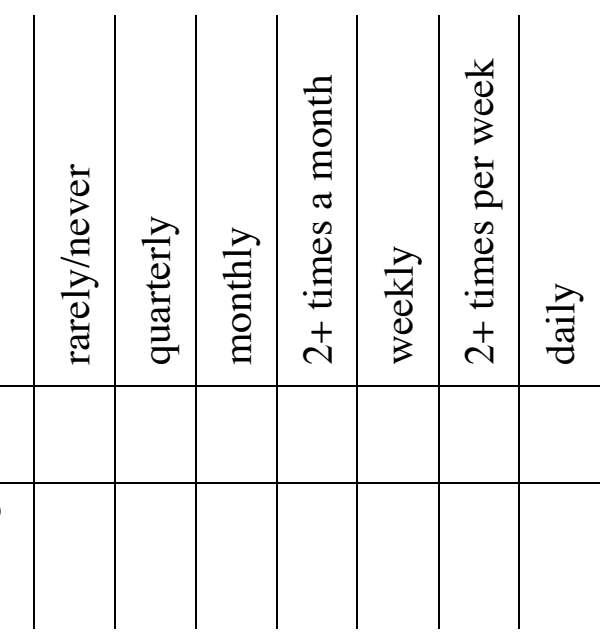

SCALE: $1=$ not at all; $2=$ less than once a week; $3=$ at least once a week; and $4=$ daily.

4. When meeting with the principal, what topics did you discuss at the meetings?

(check all that apply).

- data collection

- data analysis

- professional development

$\circ$ data team meetings

$\circ$ coaching of teachers

$\circ$ issues and concerns around instruction

$\circ$ planning of staff meetings or other meetings

o non-coaching topics

o other:

5. On a scale from $1-10$ ( 1 being not supportive and 10 being extremely supportive), how supportive do you think the principal was in helping you carry out your responsibilities? 


\section{SCHOOL REFORM AND COACHING}

6. How well do you think your principal understood the data informed decision-making process (DataWise and RtI as a way to help teachers deliver more effective instruction)?
Not at all
Somewhat
Well
Very Well

Please explain.

\section{STRUCTURES}

For this section of the survey, focus on the logistics and structures that were in place at the school where you worked as a coach. Please answer questions based on your time as the coach.

\begin{tabular}{l|l|l} 
& \multicolumn{2}{|c}{ Scale 1-4 } \\
\hline 7. How often were these structures were in place? & $2011-12$ & $2012-13$ \\
\hline allotted time for data team meetings & & \\
\hline requirement that teachers attend data team meetings & & \\
\hline time for literacy benchmarking & & \\
\hline $\begin{array}{l}\text { resources/Materials for literacy benchmarking (computers, stop- } \\
\text { watches, photocopies, etc.) }\end{array}$ & & \\
\hline $\begin{array}{l}\text { requirement that teachers complete benchmarking of their } \\
\text { students }\end{array}$ & &
\end{tabular}

SCALE: $1=$ not at all; $2=$ less than once a week; $3=$ at least once a week; and $4=$ daily.

\section{JOB RESPONSIBLITIES}

For this section of the survey, use your experience as a coach to answer these questions. Think about how you spent your time in a typical week.

8. How often did you perform each of the following duties work with teachers one-on-one focused on lesson and/or assessment planning work with teachers one-on-one focused on

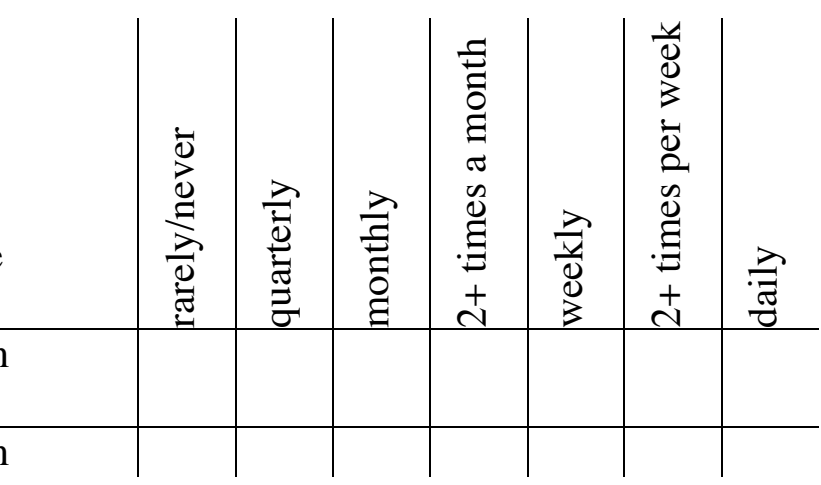




\section{SCHOOL REFORM AND COACHING}

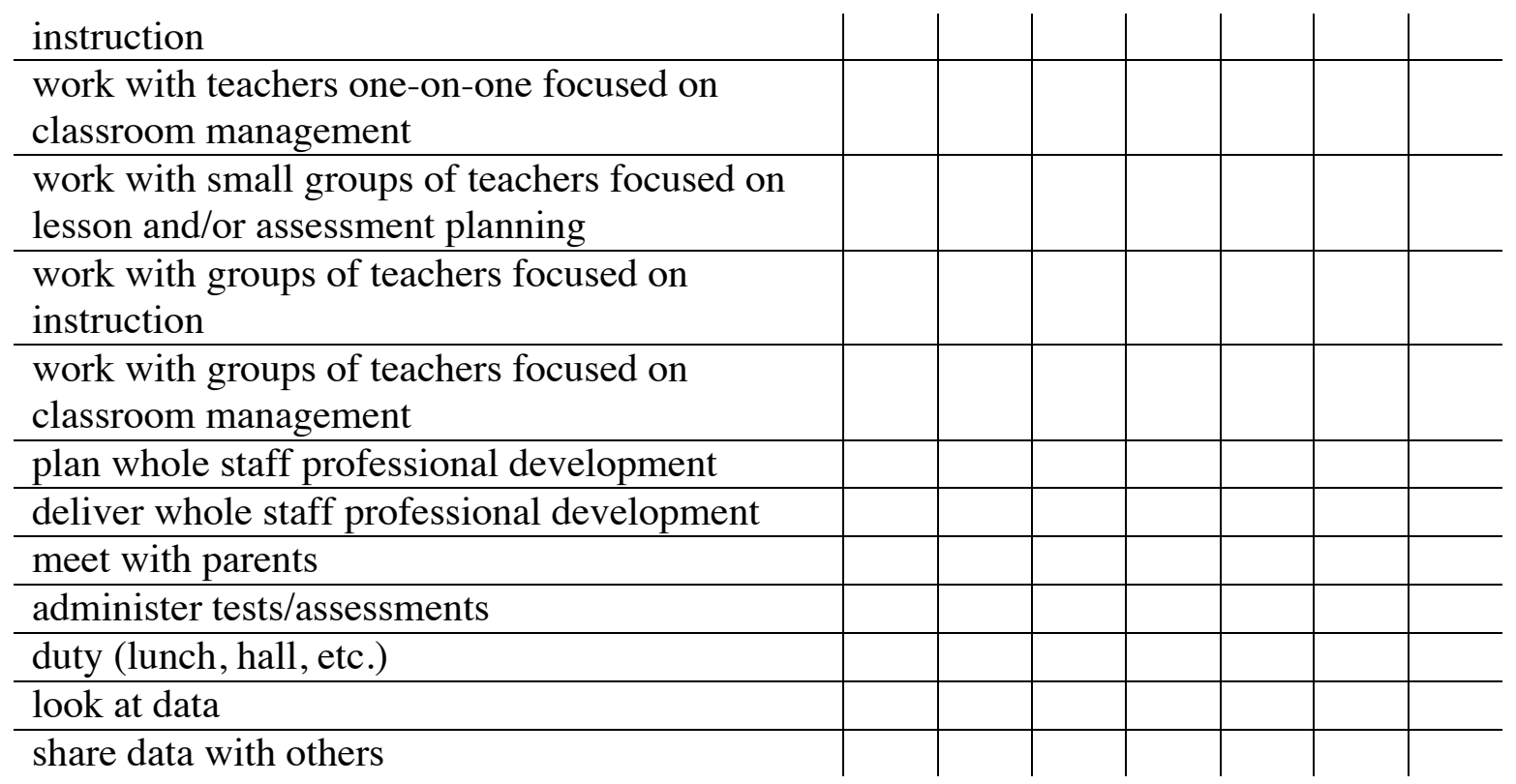




\section{SCHOOL REFORM AND COACHING}

Think about the easyCBM benchmarking assessment. The data wall is the color-coded student information based on the easyCBM benchmarking risk factor.

\begin{tabular}{|c|c|c|c|c|c|c|c|c|c|c|}
\hline \multirow[b]{2}{*}{$\begin{array}{l}\text { 9. How often did you do each } \\
\text { of the following: }\end{array}$} & \multicolumn{2}{|c|}{$\begin{array}{l}\text { Every } \\
\text { Fall, } \\
\text { Winter, } \\
\text { Spring }\end{array}$} & \multicolumn{2}{|c|}{$\begin{array}{c}\text { Most } \\
\text { Fall, } \\
\text { Winter, } \\
\text { Spring }\end{array}$} & \multicolumn{2}{|c|}{$\begin{array}{c}\text { Some } \\
\text { Fall } \\
\text { Winter, } \\
\text { Spring }\end{array}$} & \multicolumn{2}{|c|}{$\begin{array}{l}\text { Few Fall, } \\
\text { Winter, } \\
\text { Spring }\end{array}$} & \multicolumn{2}{|c|}{ Never } \\
\hline & 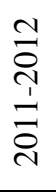 & 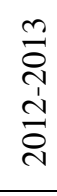 & 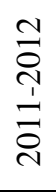 & 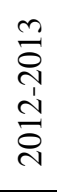 & 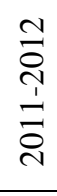 & 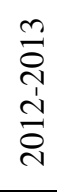 & 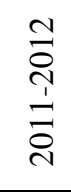 & 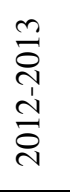 & 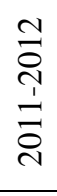 & 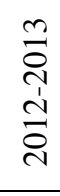 \\
\hline $\begin{array}{l}\text { administer literacy } \\
\text { benchmarking assessment }\end{array}$ & & & & & & & & & & \\
\hline $\begin{array}{l}\text { coordinate literacy } \\
\text { benchmarking assessments }\end{array}$ & & & & & & & & & & \\
\hline compile assessment data & & & & & & & & & & \\
\hline $\begin{array}{l}\text { update data wall (if } \\
\text { computerized, checked for } \\
\text { updates) }\end{array}$ & & & & & & & & & & \\
\hline lead data team meetings & & & & & & & & & & \\
\hline $\begin{array}{l}\text { share data team meeting } \\
\text { decisions with administrator }\end{array}$ & & & & & & & & & & \\
\hline $\begin{array}{l}\text { use data team meeting } \\
\text { outcomes for full staff } \\
\text { meetings }\end{array}$ & & & & & & & & & & \\
\hline
\end{tabular}

IV. DEMOGRAPHICS

Answer the following questions, based on your experience BEFORE becoming a coach.

\begin{tabular}{l|l|l|l|l|l|l} 
& \multicolumn{7}{c}{ Years of experience } & \\
\hline $\begin{array}{l}10 . \text { How many years of experience did you } \\
\text { have }\end{array}$ & 0 & $1-3$ & $4-5$ & $6-9$ & $10-19$ & $20+$ \\
\hline teaching & & & & & & \\
\hline teaching reading & & & & & & \\
\hline teaching fourth to eighth grade & & & & & &
\end{tabular}




\section{SCHOOL REFORM AND COACHING}

11. What are your areas of certification (choose all that apply):
O elementary
$\circ$ reading
○ language arts
○ social studies
o esl
O sped
O early childhood
- middle level
o other:

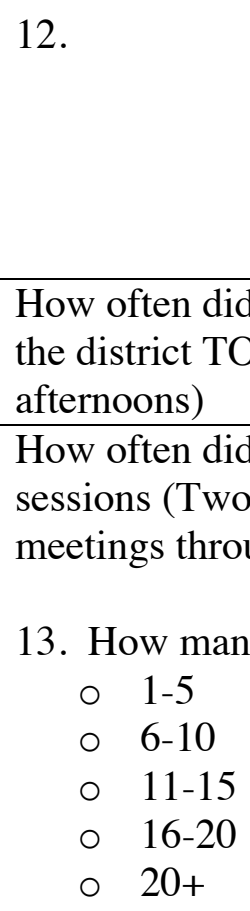

14. How many years had your building used the DataWise process for school improvement (the work done through the Nike PLC).
○ none
○ 1 year
○ 2 years
○ 3 years
○ 4 years
○ not sure

15. How many years had your principal been in the building? 


\section{SCHOOL REFORM AND COACHING}
○ new the first year
○ 1-3 years
○ 4-7 years
○ 8+ years

16. Were you a teacher in the building before you were assigned the coach position?
○ Yes
- No

If yes, what was your job before becoming the coach?
$\circ$ teacher
- specialist (sped/esl)
- reading coach
○ instructional coach
$\circ$ other

17. If you left the coach role before the end of the 2013 school year, why did you leave?
o became an administrator
o took another job within the same building
o took another job in a different building
o retired
- left the teaching profession
o other:

18. What is your current job(s)?
o teacher
○ coach
○ coach
○ administrator
- TOSA
O teacher-mentor (based in district offices)
o other teacher-leader position
o retired
o other:

Are you in the same building you were a coach?
o Yes
o No

19. Is the building that you were a coach still using literacy benchmarking data?
o yes
o no
○ don't know

20. Is the building that you were a coach still using data team meetings?
o yes 


\section{SCHOOL REFORM AND COACHING}

$\begin{array}{ll}\circ & \text { no } \\ \circ & \text { don't know }\end{array}$ 


\section{SCHOOL REFORM AND COACHING}

\section{Appendix C}

\section{Coach Interview Questions}

Reminder: The purpose of this interview is to engage in a purposeful conversation with the participants regarding their experiences of working with teachers to implement a data informed decision-making initiative.

Thank you for allowing me to interview you regarding your experiences with common planning time. You indicated in the Informed Consent Letter that you would allow me to tape this session in order to ensure an accurate account of what you are saying. I do want to remind you that everything you say is confidential and that your name will never appear on any of the documents or reports related to this research project. Additionally, the name of your school will not be used in any reports. In this interview, I am interested in understanding what you think about helping teachers implement a data informed decision-making initiative-what your experiences are.

1. Tell me about your fourth/fifth and/or your sixth to eight grade data team meeting.

2. How comfortable did you feel working with teachers and focusing on their literacy instruction?

3. Talk about the level of trust in the building - (teacher/teacher; teacher/coach; teacher/administrator)

4. Coaches are pulled between responding to teacher needs and improving instruction using the initiatives you have been trained to help implement. Talk about how you dealt with this balance.

5. How did you address teacher resistance?

6. What was the leadership model in the building?

7. Give examples of how you and the principal worked together as leaders.

8. How supportive was your administrator of the coach work? Of the RtI work?

9. What gave you traction as your work as a coach?

10. If you went back and started again, this year, as a coach, what would you do differently? 


\section{SCHOOL REFORM AND COACHING}

\section{Appendix D}

\section{Principal Interview Questions}

Reminder: The purpose of this interview is to engage in a purposeful conversation with the participants regarding their experiences of working with teachers to implement a data informed decision-making initiative.

Thank you for allowing me to interview you regarding your experiences with common planning time. You indicated in the Informed Consent Letter that you would allow me to tape this session in order to ensure an accurate account of what you are saying. I do want to remind you that everything you say is confidential and that your name will never appear on any of the documents or reports related to this research project. Additionally, the name of your school will not be used in any reports. In this interview, I am interested in understanding what you think about helping teachers implement a data informed decision-making initiative-what your experiences are.

1. What was the role of your coach?

2. How often did you and the coach meet?

3. Give an example of how you and the coach made decisions informed by the RtI data.

4. How involved were you in the data team meetings and RtI process?

5. Explain how you implemented (or are still implementing) RtI in your building?

6. How did the work of the coach fit in with other initiatives you were working on from 2011-13?

7. Give an example of how you use data to inform your decisions.

8. How did you support the work of the coach?

9. How could you have been more supportive of the coach and the RtI work?

10. If the district gave you the FTE to have a coach again, what would you do differently? 